\title{
Neugier auf Neues
}

mehr hören - mehr sehen - mehr wissen

10 Jahre Kinder-Uni der Georg-August-Universität Göttingen

Vorträge und Beiträge zur Festveranstaltung

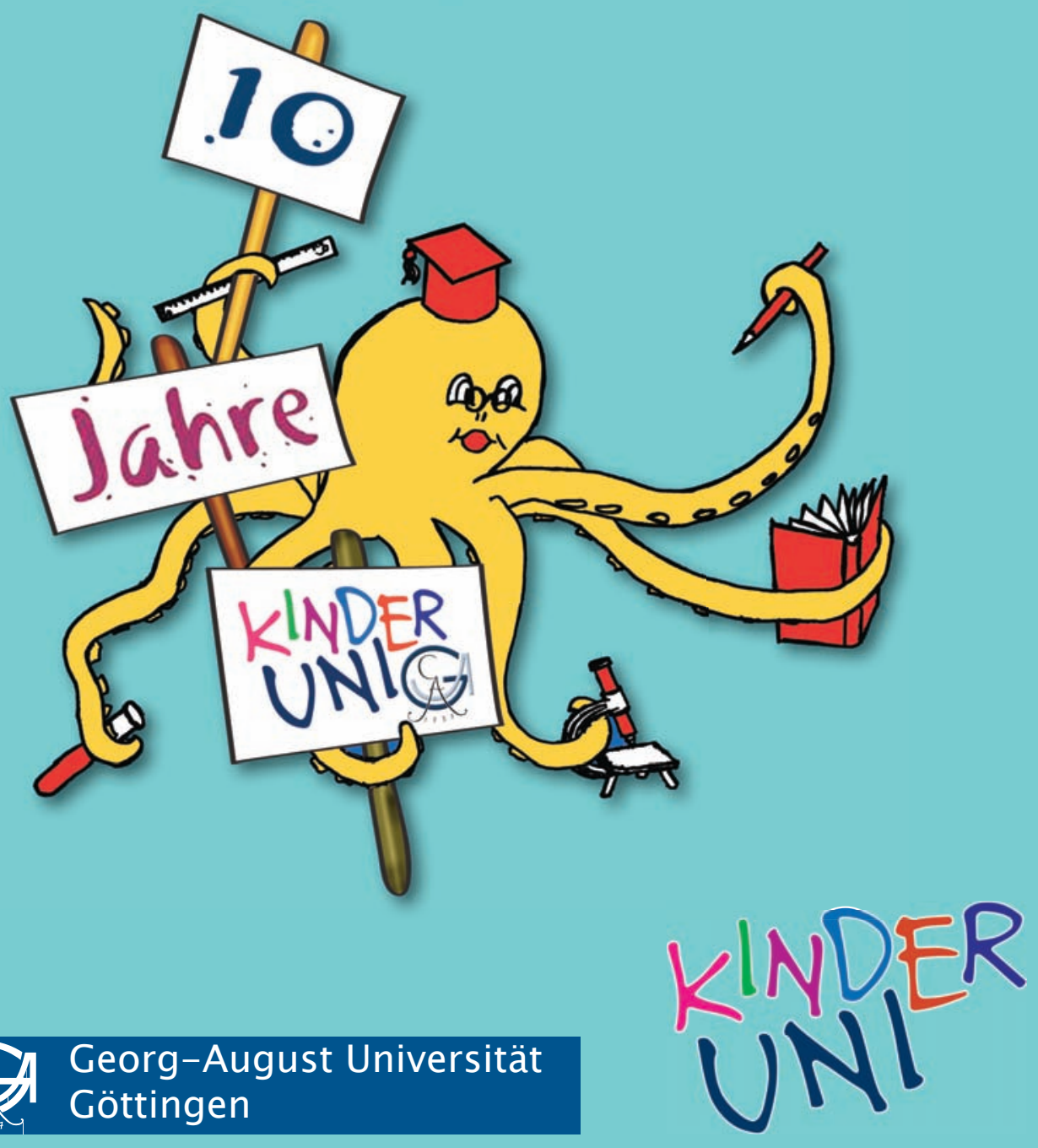



Kinder-Uni der Georg-August-Universität Göttingen

Neugier auf Neues

Dieses Werk ist lizenziert unter einer

Creative Commons

Namensnennung - Weitergabe unter gleichen Bedingungen

4.0 International Lizenz

(ㄷ) (1) (-) 

Kinder-Uni der

Georg-August-Universität

Göttingen

Neugier auf Neues

10 Jahre Kinder-Uni Göttingen

Vorträge und Beiträge

zur Festveranstaltung

am 14. Februar 2014

Herausgegeben von

Peter Brammer

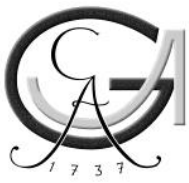

Universitätsverlag Göttingen

2014 
Bibliographische Information der Deutschen Nationalbibliothek

Die Deutsche Nationalbibliothek verzeichnet diese Publikation in der Deutschen Nationalbibliographie; detaillierte bibliographische Daten sind im Internet über $<$ http://dnb.ddb.de $>$ abrufbar.

Veranstalter

Georg-August-Universität Göttingen

Kinder-Uni

Wilhelmsplatz 1

37073 Göttingen

www.kinder-uni.uni-goettingen.de

Dieses Buch ist auch als freie Onlineversion über die Homepage des Verlags sowie über den Göttinger Universitätskatalog (GUK) (http://www.sub.uni-goettingen.de)

erreichbar. Es gelten die Lizenzbestimmungen der Onlineversion.

Satz und Layout: Jutta Pabst

Umschlaggestaltung: Jutta Pabst

(C) 2014 Universitätsverlag Göttingen

http://univerlag.uni-goettingen.de

ISBN: 978-3-86395-171-9 


\section{Inhaltsverzeichnis}

Begrüßung

Prof. Dr. Ulrike Beisiegel

Präsidentin der Georg-August-Universität Göttingen 3

Begrüßung

Peter Brammer

Projektleiter der Kinder-Uni Göttingen ....................................................................... 7

Grußworte

Frauke Heiligenstadt

Niedersächsische Kultusministerin

Grußworte

Wolfgang Meyer

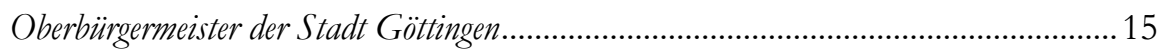

Grußworte

André Schüller

Sparkassenvorstand der Sparkasse Göttingen..............................................................19

Festvortrag

Einführung

Brigitte $A x$

Kinder-Uni Göttingen.

Festvortrag

Der „Sokrates-Club“ - mit Kindern das Denken entdecken

Prof. Dr. Julian Nida-Rümelin

Ludwig-Maximilians-Universität München 
Neugier auf Neues

mehr hören - mehr sehen - mehr wissen

10 Jahre Kinder-Uni der Georg-August-Universität Göttingen

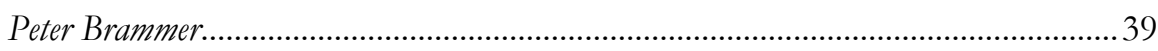

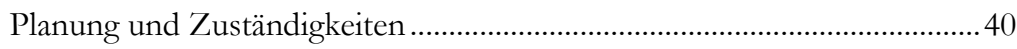

Angebote, Fakultäten und Kooperationspartner .......................................... 41

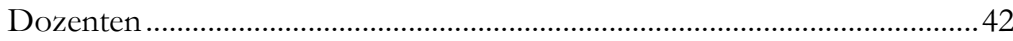

Einzugsbereich und Alter der Kinder.............................................................42

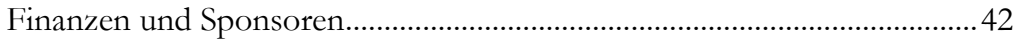

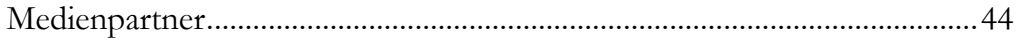

Programmstruktur und Akzeptanz ………………...................................... 44

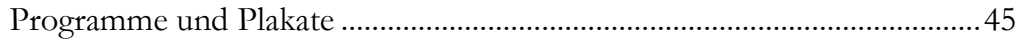

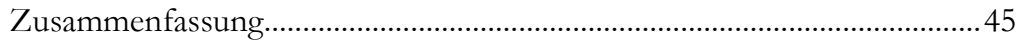

Weitere Informationen zur Kinder-Uni Göttingen .....................................46

Ehemalige und gegenwärtige Mitglieder des Kinder-Uni-Teams ................46

Professorinnen und Professoren, Dozentinnen und Dozenten für

Vorlesungen, Seminare und Workshops seit 2004 .....................................47

„Kinder informieren Kinder“

Ein Projekt der Kinder-Uni Göttingen

Nils-Christian Schwarz.

Leitfaden für Kinder-Uni Dozenten

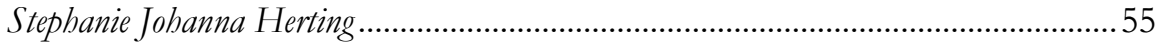

Sponsoren der Kinder-Uni Göttingen …………………………………………... 58

Medienpartner der Kinder-Uni Göttingen ............................................................ 58

Kinder-Uni Programmplakate der letzten 10 Jahre ..........................................61 


\section{Begrüßung}

Prof. Dr. Ulrike Beisiegel

Präsidentin der Georg-August-Universität Göttingen

Sehr geehrte Frau Ministerin Heiligenstadt, sehr geehrter Herr Oberbürgermeister Meyer, sehr geehrter Herr Schüller, sehr geehrter Herr Professor Nida-Rümelin und natürlich ein herzliches Willkommen Ihnen, sehr verehrte Gäste und vereinzelt auch Kinder!

Kinderstudierende kommen zur Kinder-Uni nicht nur zum Lernen, sondern auch, um als ,Lehrende zu arbeiten. Das ist sehr beeindruckend! Die heutige Festveranstaltung vermittelt einen guten Eindruck von der Kinder-Uni und ihrer Bedeutung für Göttingen. Auch der Film, den wir gerade gemeinsam gesehen haben, hat noch einmal sehr schön verdeutlicht, wie wichtig das Projekt Kinder-Uni für Göttingen ist. Sie alle, die die Kinder-Uni durchführen, vor allem aber Sie, lieber Herr 
Brammer, zeigen den Kindern mit Ihrem großen Engagement, wie viel Spaß das Lernen machen kann. Aus diesem Grund möchte ich Ihnen und allen, die mitmachen, an dieser Stelle meinen ganz herzlichen Dank aussprechen.

Mein Dank geht auch an die Sponsoren aus der regionalen Wirtschaft. Zum Start der Kinder-Uni vor zehn Jahren hat sich natürlich auch die Frage der Finanzierung gestellt und ich weiß, dass viele namhafte Unternehmen aus der Stadt und der Region die Kinder-Uni sehr unterstützt haben. Als Universitätspräsidentin möchte ich betonen, wie wichtig eine solche Unterstützung ist. Wir sind den Sponsoren aus der Region sehr dankbar dafür, dass sie Herrn Brammer kontinuierlich substanziell unterstützen. Es ist an dieser Stelle nicht möglich, alle Unterstützer zu nennen, dafür waren es in den vergangenen zehn Jahren tatsächlich zu viele, aber eines steht fest: ohne Sie wäre die Kinder-Uni nicht das geworden, was sie heute ist.

Ich freue mich auch, dass einige der direkten Partner der Universität sich auch in der Kinder-Uni engagieren. Ich denke, das ist ein gutes Beispiel dafür, wie sich Wirtschaft mit Bildung und Wissenschaft vernetzt und dass damit auch der Einsatz für die Nachwuchsförderung verbunden ist. Denn wenn wir über Nachwuchsförderung sprechen, dann fängt das für die Universitäten bei den Kindern an. Wer unser Modell aus der Exzellenz-Initiative kennt, weiß, dass zwar nicht die Kinder-Uni Teil des Antrags war, die Schülerlabore aber durchaus ein wichtiger Baustein des Konzepts waren. Denn eines steht fest: Frühe Nachwuchsförderung und Universität gehen ineinander über. Die Kinder-Uni und die Grüne Klasse sind dafür sehr gute Beispiele. Frau Weis, verantwortlich für die Grüne Klasse, ist heute ebenso hier wie Frau Professorin Neher, die verantwortlich das Schülerlabor XLAB aufgebaut hat und leitet. Gemeinsam mit der Kinder-Uni bereiten sie wunderbar auf das vor, was nach der Schule für viele junge Menschen wichtig wird, das Studium. Wir sind aktuell dabei, weitere Schülerlabore einzurichten, nämlich ein sogenanntes Y-Lab, das sich durch die Frage ,warum?‘ den Themen der kultur- und geisteswissenschaftlichen Fächer widmet. Dr. Gilbert Heß, der für das Y-Lab neu an der Universität Göttingen angefangen hat, ist heute Abend auch hier. Auch für seine Arbeit ist die gute Vernetzung mit der Kinder-Uni von besonderer Bedeutung. 
Meinen ausdrücklichen Dank für die finanzielle Unterstützung möchte ich an dieser Stelle auch dem Land Niedersachsen aussprechen. Es ist viel wert, junge Menschen, Schülerinnen und Schüler, zu begeistern und sie zu ermuntern, Fragen zu stellen. Darüber hinaus dienen diese Aktivitäten auch dazu, unsere jungen Lehramtsstudierenden in den Praxisunterricht einzuführen. Und wenn man sieht, wie früh die Lehrerinnen und Lehrer heute anfangen, Ihre ersten Unterrichtserfahrungen zu machen, dann bin ich überzeugt, dass dies eine sehr wichtige Vorbereitung für einen guten Start darstellt.

Abschließend möchte ich Ihnen, lieber Herr Brammer, ganz, ganz herzlich danken für zehn Jahre Kinder-Uni! Mein Glückwunsch zum Jubiläum und mein Dank an Sie. Als Gründer und ,Vater ${ }^{6}$ der Kinder-Uni haben Sie diese große Aufgabe ehrenamtlich übernommen und haben dabei einen unermüdlichen Einsatz gezeigt. Seit ich an der Universität Göttingen bin, hat es mich immer wieder beeindruckt, die Unterlagen und Erfolgsberichte über die Kinder-Uni zu sehen. Insofern gebührt die heutige Veranstaltung vor allem Ihnen und ich möchte Ihnen im Anschluss noch eine kleine Anerkennung übergeben. Es ist schön, mit so vielen Gästen das Jubiläum zu feiern: den 10jährigen Geburtstag der Kinder-Uni! 



\section{Begrüßung}

Peter Brammer

Projektleiter der Kinder-Uni Göttingen

Ich begrüße herzlich

Frau Präsidentin Beisiegel,

Frau Ministerin Heiligenstadt,

Herrn Oberbürgermeister Meyer,

Herrn Sparkassenvorstand Schüller,

Herrn Professor Nida-Rümelin als Festredner heute und

Sie alle als Freunde der Kinder-Uni.

Ich beginne mit einem Zitat aus dem Leitbild der Universität:

„Die Georg-August-Universität versteht sich als eine Quelle frucbtbarer Innovationen für alle Lebensbereiche, sie betrachtet es als ibre Aufgabe, ibr regionales Umfeld verantwortlich mitrugestalten". 
Die Grundhaltung, die in diesem Satz zum Ausdruck kommt, war und ist eine zentrale Voraussetzung dafür, dass wir heute auf 10 Jahre Kinder-Uni zurückblicken können. Offenheit für Neues, Offenheit für ein junges Publikum, Neugier auf Neues, seit dem ersten Semester vor 10 Jahren das gelebte Motto der KinderUni.

Der Beginn des Projektes 2003 war ganz unspektakulär. In einem meiner Seminare zur Schulentwicklung sollte sich eine Studentengruppe mit Projektmanagement beschäftigen. Meine Idee war, ein Konzept für eine Kinder-Uni in Göttingen zu entwickeln. Kerstin Richter und Nicole Walter gehörten zu den ersten Teammitgliedern, beide sind heute hier anwesend. Viele sind in den letzten Jahren dazugekommen und gleichfalls heute anwesend, darüber freue ich mich sehr. Einige kommen von weit her, aus Hamburg oder aus München.

\section{„Der Worte sind genug gewechselt, lasst mich auch endlich Taten sehen“.}

Wir entschieden uns 2003, unser theoretisches Konzept in einem Probesemester zu evaluieren. Die Akzeptanz bei Kindern und Eltern übertraf unsere Erwartungen um ein Vielfaches. Es wäre nicht zu verantworten gewesen, das Projekt nach diesem Probelauf einzustellen.

2004 schrieb Professor Horst Kern als damaliger Präsident an alle Fakultäten: „Ab dem Sommersemester wird die Kinder-Uni Göttingen eine Vorlesungsreihe für Kinder im Alter zwischen 8 und 12 Jahren anbieten. Professoren verschiedener Fakultäten und Fachrichtungen werden spannend und anschaulich aus ihrer Forschung vortragen und dabei Rätsel und Geheimnisse des täglichen Lebens klären. Durch die geplante Vorlesungsreihe können Kinder sich für Forschung begeistern und einen ersten Einblick in das Universitätsleben gewinnen. Als Präsident der Georg-August-Universität unterstütze ich das Konzept der Kinder-Uni ganz ausdrücklich“. Herr Professor von Figura hat als nachfolgender Präsident diese Offenheit und Unterstützung fortgeführt und Sie, Frau Präsidentin, haben für das Kinder-Uni Projekt und die dahinter stehende Intention, die Universität für ein jüngeres Publikum zu öffnen, immer ein offenes Ohr gehabt. Dafür danken das Kinder-Uni Team und viele Jungstudierende und deren Eltern herzlich.

„Die erste Kinder-Uni Vorlesung war für mich die bisher größte Herausforderung in meiner Karriere als Hochschullehrerin", so die Nobelpreisträgerin Christiane Nüsslein-Volhard aus Tübingen 2003. Mehr als 100 Professorinnen und Professoren und Dozentinnen und Dozenten unserer Universität haben bis heute diese Herausforderung angenommen. Ohne ihre Bereitschaft, Offenheit und ihren Mut gäbe es keine Kinder-Uni in dieser Stadt und in dieser Universität. An alle 100 geht unser, geht mein herzlicher Dank, denn außer einem kräftigen Applaus von 
den Jungstudierenden, einer Schachtel mit leckeren Pralinen von der Confiserie Cortes sowie immer einer sowohl freundlichen als auch sachlichen Presse durch unsern Medienpartner, das Göttinger Tageblatt, wird kein Honorar gezahlt. Der Beifall ist der Lohn des Künstlers.

Ich habe alle Zeitungsartikel, die im GT über die Vorlesungen und Seminare erschienen sind, sorgsam gesammelt und für diese Jubiläumsfeier zusammengestellt, einmalige Zeugnisse unseres Programms und eine wichtige Dokumentation, eine Quelle für weitere Studien zum Thema Wissenschaftspropädeutik und Öffentlichkeit. Wir sind dem GT für diese Medienpartnerschaft sehr dankbar, auch der HNA, die gleichfalls berichtet hat, herzlichen Dank dafür. Ich darf Ihnen, Frau Präsidentin, gleich anschließend ein Exemplar dieser Dokumentation überreichen, eine weitere Dokumentation erhält Herr Oberbürgermeister Meyer für die Stadt Göttingen.

Eine zusammenfassende Dokumentation „10 Jahre Kinder-Uni“ mit vielen Informationen haben wir für alle Gäste am Eingang der Aula ausgelegt, bitte bedienen Sie sich später, wenn wir hier fertig sind.

Ich möchte aus dieser Dokumentation nur einen Aspekt herausgreifen.

Die Kinder kommen freiwillig in die Vorlesungen und Seminare. Wären sie langweilig, methodisch und didaktisch nicht auf das junge Publikum abgestellt, würden sie, die Kinder, sehr schnell zu Hause bleiben. Dass dies auch nach 10 Jahren und bei mehr als 370 Vorlesungen und Seminaren nicht der Fall ist, spricht für Qualität.

Der Unterstützung durch unsere Sponsoren und Förderer ist es zu verdanken, dass wir das Konzept der Kinder-Uni erweitern und entwickeln konnten. Zusätzlich zu den Vorlesungen gibt es Seminare und Workshops für junge Forscherinnen und Forscher sowie eine Vorlesungsreihe „Kinder-Uni für Erwachsene“, eine Philosophiewerkstatt und die wundervollen KiK-Vorlesungen, Kinder informieren Kinder, an denen sich bisher nach intensiver Vorbereitung durch das Team, mehr als 100 Jungdozentinnen und Dozenten mit ihren Vorträgen beteiligt haben.

Einen kleinen Einblick konnten Sie durch unsern Einspieler zu Beginn bekommen.

Einige Akteure sind heute hier anwesend. Ich denke, sie sollten sich einmal zeigen und die Hände hochhalten, dann können wir sie mit einem kleinen Beifall belohnen. Ihre Leistungen, die Sicherheit, mit der sie ihr Thema präsentieren, sind wirklich beeindruckend. Dabei müssen Sie bedenken, dass jeder dieser Vorträge unge- 
fähr 10 Minuten bis 15 Minuten lang ist. Wir haben also heute hier nur einen kleinen Ausschnitt gesehen und gehört.

Insgesamt konnten wir fünf DVDs aufnehmen, das ist aber schon einige Jahre her, inzwischen sind die jungen Leute schon ein bisschen größer geworden. Die letzten beiden Vorträge vor zwei Wochen haben sich mit den Themen „Kakteen“ und „Schokolade“ beschäftigt. Minna Frieda hatte sich mit dem Thema Schokolade befasst und uns heute 200 Tafeln mitgebracht, die sie nachher auch verteilen wird.

Diese von mir aufgezeigte Entwicklung der Kinder-Uni war nicht selbstverständlich. Vor 10 Jahren gab es durchaus einige reservierte Vorbehalte. Frau Professor Lemmermöhle hat damals Hindernisse ausräumen können, den Weg geebnet und auch später als Vizepräsidentin die Kinder-Uni unterstützt, in der Nachfolge Herr Professor Lücke und jetzt Frau Professor Florack. In der Universität selbst hat die Kinder-Uni übrigens nie mehr als ein Postfach gehabt, wohl aber viele Unterstützer und viele hilfreiche Freunde.

Mein Dank geht schließlich an die Freunde und Förderer unseres Projektes, die nicht direkt zu einer dieser drei Gruppen, Dozenten, Sponsoren, Team gehören, den Sekretärinnen und Hausmeistern der Universität, den Schulen, den Schulleitern und Kollegen, den Eltern und den vielen Freunden. Ihre aufmunternde Unterstützung war und ist für uns sehr bedeutsam, auch und gerade wegen der uns immer wieder zum Ausdruck gebrachten Wertschätzung.

Ich komme zum Schluss, warum mache ich das? In Bildung von Kindern zu investieren war und ist mir ein persönliches Anliegen.

Ich danke Ihnen. 


\section{Grußworte}

\section{Franke Heiligenstadt}

Niedersächsische Kultusministerin

Sehr geehrte Frau Präsidentin Dr. Beisiegel, sehr geehrter Herr Oberbürgermeister Meyer, sehr geehrter Herr Brammer, sehr geehrter Herr Prof. Dr. Nida-Rümelin, sehr geehrte Damen und Herren, vor allen Dingen liebe Schülerinnen und Schüler,

ich freue mich sehr, die Grüße der Landesregierung zu dieser Veranstaltung zum heutigen 10. Geburtstag der Kinder-Uni in Göttingen übermitteln zu dürfen.

Ich möchte mich zunächst bei allen beteiligten Professorinnen und Professoren, Dozentinnen und Dozenten und Studierenden für ihren Einsatz bedanken, den sie seit 10 Jahren oder in Universitätseinheiten seit 20 Semestern für die Organisation und Durchführung dieser hervorragenden Veranstaltungsreihe erbringen.

Gleiches gilt für die Sponsoren und Spender, die die Kinder-Uni erst ermöglichen. Erfreulich ist auch das Engagement, Herr Brammer hat das schon erwähnt, 
der Schulen aus Göttingen und Umgebung, die sich sehr aktiv auch für die Kinder-Uni einsetzen und natürlich entsprechend auch werben. Die zahlreiche Teilnahme von Verantwortlichen aus den ganz verschiedenen Schulen an dieser Veranstaltung zeigt, dass sie hinter dieser Idee hier vor Ort auch stehen.

Ganz besonders aber möchte ich mich bei dem maßgeblichen Initiator dieser Veranstaltungsreihe, lieber Peter Brammer, bei Ihnen bedanken. Ihre Kinder-Uni ist eine beispielgebende Einrichtung, die nicht mehr wegzudenken ist. Auch über 10 Jahre, nachdem Sie sich eigentlich in den wohlverdienten Ruhestand begeben haben, setzen Sie sich mit höchstem Engagement, Ihr letzter Satz hat das, denke ich, deutlich gemacht, für die Bildung, insbesondere für die Kinder hier in der Region ein und damit für die Förderung auch des Nachwuchses. Ich wünsche Ihnen weiterhin ganz viel Engagement, ganz viel Energie, ganz viele, die Sie unterstützen bei Ihrer Arbeit, bei Ihrer Freude auch für diese Arbeit und bleiben Sie der Kinder-Uni in jedem Fall erhalten, aber vor allen Dingen behalten Sie die Energie, die Sie in den letzten 10 Jahren in dieses Projekt investiert haben.

Ganz, ganz herzlichen Dank Herr Brammer.

In den letzten 10 Jahren, so habe ich mir jedenfalls sagen lassen, haben rund 50.000 mal Kinder aus Göttingen und Umgebung an den Veranstaltungen der Kinder-Uni teilgenommen und Hauptanziehungspunkt waren die Vorlesungen, aber auch die Seminare, Workshops und die von Kindern, wie wir eben gerade auch gesehen haben, gestalteten Vorlesungen sind sehr gut besucht. Die angebotenen Themen machen unsere Kinder neugierig, aber eigentlich, ja, im Grunde sind die Kinder von sich aus neugierig und auch wissbegierig. Sie lassen sie aber auch in den Universitätsbereich hinein schnuppern und Neugier ist ja die Triebfeder allen Fortschritts, allen Wissens, allen Erlernens von Wissen und diese Neugier zu wecken bzw. auch zu erhalten, das ist, glaube ich, für uns alle lebenswichtig. Es gilt dem Nachwuchs dann kindgerecht erste Berührungspunkte mit Hochschule und Wissenschaft zu ermöglichen und es ist wichtig, auch Unkenntnis und Berührungsängste abzubauen gegenüber dem Wissenschaftsbetrieb, es gilt also, das Phänomen Universität auch Kindern verständlich zu machen. Und das funktioniert hier in Göttingen wirklich hervorragend.

Das, was wir an wichtigen Ressourcen in unserem Land haben, wenn man es aus ökonomischer Sicht betrachtet, das sind die Schätze in den Köpfen unserer Kinder. Wir haben ansonsten nicht viele Ressourcen. Aber es geht auch über die Hebung dieser wichtigen Ressource hinaus, es geht um eine gute und ausgewogene Bildung der Gesellschaft, sie ist auch der entscheidende Faktor für die Gestaltung unseres Staatswesens. Nicht zuletzt, weil sich die Landesregierung insbesondere auch für die Durchlässigkeit der Bildungssysteme und für eine verstärkte Bildungsteilhabe, nämlich auch von denen, die sonst vielleicht nicht in Richtung 
Universität blicken, einsetzt, ist dieses Projekt sehr unterstützenswert. Es lässt eine erhöhte Durchlässigkeit zu, weil Berührungsängste erst gar nicht entstehen können oder zumindest größtenteils abgebaut werden können, wenn Kinder schon sehr früh mit Universität, mit Wissenschaft und Hochschule zusammen gebracht werden können.

Die altersgerechten Angebote für Kinder haben sich an Niedersachsens Hochschulen fast flächendeckend entwickelt, ja es gibt sogar Städte in Niedersachsen, die Kinder-Unis anbieten, obwohl sie über gar keine Hochschule verfügen. Auch die Medien berichten immer wieder über die Kinder-Unis und Bilder von Hörsälen mit begeisterten Kindern, alle Reihen voll und die Augen und Münder offen, das sind natürlich positive Bilder, die wieder Mut geben und Begeisterung wecken, um weiterzumachen und diese Wege weiterhin zu beschreiten.

Allerdings bietet, glaube ich, auch die Kinder-Uni dem erwachsenen Lehrpersonal viel Spannendes. Aus erster Hand zu erleben, wie Kinder bestimmte Sachverhalte erklären ist, glaube ich, auch außerordentlich wichtig. Oder aber zu erkennen, wie sich die Lebenswelt der Kinder in den letzten 10, 15 Jahren durch diese digitale Revolution mit Internet, Smartphones und Apps massiv verändert hat, ist für viele Erwachsene sehr erhellend und interessant. Es gilt diese Entwicklungen aufzunehmen und insbesondere der Vortrag von Professor Dr. Nida-Rümelin zu dem Thema „Philosophie“ ist sicherlich ganz spannend. Ich habe sofort an die Gespräche mit meiner Tochter gedacht, die immer einen entsprechenden Rhythmus hatten, im Vorschul- aber auch im Grundschulalter: „Und warum ist das so?" Und dann kam die Antwort: „Und warum ist das dann so?“ Und dann kam wieder die Antwort: „Und warum“. Und irgendwann war man dann bei ganz Grundsätzlichem, bei den tatsächlich wichtigen Fragen des Lebens, dem Sinn des Lebens, angelangt, wenn diese Warumschleife beim 10. Mal endete. Herausfordernde Fragen, vor denen auch Eltern heute immer noch stehen. Ich denke, es ist ganz wichtig, dass wir diese Neugier, diesen Wissensdurst der Kinder weiterhin stillen können. Das Projekt Kinder-Uni in Göttingen wird dazu sicherlich in den nächsten Jahren beitragen.

Ich würde mir das jedenfalls sehr wünschen und bedanke mich bei allen, die sich so stark in den letzten 10 Jahren engagiert haben.

Herzlichen Glückwunsch zu diesem tollen Geburtstag. 



\section{Grußworte}

Wolfgang Meyer

Oberbürgermeister der Stadt Göttingen

Verehrte Frau Ministerin Heiligenstadt, verehrte Frau Präsidentin Dr. Beisiegel, verehrter Herr Schüller, lieber Peter Brammer, meine sehr geehrten Damen und Herren und natürlich liebe Kinder.

Die Kinder-Uni Göttingen hat die Mitte erreicht, nämlich genau das vermutete Durchschnittsalter der 8 bis 12jährigen Schülerinnen und Schüler aus den dritten bis sechsten Klassen, für die sie vor 10 Jahren ihre Türen erstmals geöffnet hat und deswegen feiern wir heute dieses Jubiläum mit allem drum und dran, natürlich auch mit einer Festveranstaltung und Grußworten, mit einem bunten Rahmenprogramm, mit Chor und Zirkus und mit vielen tollen Erinnerungen an die Höhepunkte eines Jahrzehnts Kinder-Uni, das schon jetzt unvergessen bleiben wird. Im Namen unserer Stadt gratuliere ich den Initiatoren, den Organisatoren und den Sponsoren der Kinder-Uni mit Freude zum 10jährigen ihres gemeinsamen Er- 
folgsprojektes und ich heiße Sie alle, Kinder und Erwachsene gleichermaßen zu dieser Festveranstaltung hier in der Aula herzlich willkommen. Ich sage mal das Juniorformat der Georgia Augusta feiert heute Geburtstag und nimmt zu Recht viele Glückwünsche entgegen. Interesse für Neues zu wecken, Motivation zu fördern, Schwellenängste abzubauen und die Hochschule in ihrer direkten Umgebung zu einer Universität zum Anfassen zu machen und das von Kindesbeinen an sozusagen, das alles hatte man sich 2004 vorgenommen.

20 Semester begleitende Programme mit Vorlesungen, Seminaren und Workshops, es besteht nicht der Hauch eines Zweifels, dass das absolut gelungen ist. Da darf man die ganz offizielle Bilanz gern zitieren: „Die Kinder-Uni hat durch ihr breites und umfangreiches Angebot die Universität für eine große Zahl von Kindern und Eltern konkret erfahrbar gemacht. Zudem wird durch die positive Resonanz und Akzeptanz der Kinder-Uni der Bekanntheitsgrad der Universität in ihrem sozialen und geographischen Umfeld erhöht, dabei erreicht die Kinder-Uni auch soziale Schichten, die bisher keinen Zugang zu universitären Einrichtungen und Angeboten hatten. Im Angebot der Kinder-Uni spiegelt sich das breite Spektrum der Studiermöglichkeiten der Georg-August-Universität wider.“ Das finde ich, ist ein vielversprechendes Resümee, das uns auch zeigt, wie perfekt sich die Kinder-Uni mit den Angeboten der Schullandschaft in unserer Stadt ergänzt. Und die, meine Damen und Herren, liebe Kinder, kennt nun wirklich vorzeigbare Qualitäten.

Ich möchte einige Zahlen nennen aus einer Göttinger Studie, die mit dem Titel: „Eine Schullandschaft in Bewegung“, sie wertet Daten zwischen 2009 und 2013 aus und sie ist von Peter Brammer angefertigt. Diese Studie kommt zu einem bemerkenswerten Ergebnis, immer bezogen auf unsere Stadt jetzt:

Annähernd 89\% der Schülerinnen und Schüler eines Jahrgangs besuchen ab Klasse 5 entweder eines der fünf Gymnasien oder eine der zwei Gesamtschulen. 89\%, das finde ich sensationell. Für diese Schülerinnen und Schüler ist der Zusammenhang zwischen sozialer Herkunft und früher Selektion durch das Schulsystem aufgehoben. Der Anteil der Schülerinnen und Schüler eines Jahrgangs, die nach der 12. bzw. 13. Klasse im Sommer 2013 die Schule mit dem Abitur verließen, liegt bei uns in Göttingen bei 69\% und die Qualität unserer Schulabschlüsse, messbar am Zentralabitur, ist exzellent. Jedes Jahr können wir Erfolgsmeldungen verzeichnen, die Ergebnisse liegen weit über dem Landesdurchschnitt. Alle Schulen des Sekundarbereichs I und II sind im Übrigen Ganztagsschulen oder aber Schulen mit einem Ganztagsangebot und Dank der Initiative der Landesregierung, die Ministerin ist hier, wird das Angebot und die Ausstattung des Ganztagsangebots in Zukunft noch besser sein. Ich bin fest davon überzeugt, dass überhaupt das Ganztagsangebot das einzig Wahre ist. Der Anteil der Schülerinnen und Schüler, die Göttinger Schulen ohne Schulabschluss verlassen, liegt kontinuierlich unter 
2\% eines Schülerjahrgangs, das ist ebenfalls ein super guter Wert. Für Schülerinnen und Schüler mit einem besonderen Förderbedarf gibt es gut ausgestattete Förderschulen mit kleinen Klassen oder Gruppen, drei Schulen im Sekundarbereich sind Inklusionsschulen. Ich könnte das fortsetzen, das Fazit der Studie wird so beschrieben:

Es gibt in Deutschland keine Schullandschaftsregion mit in der Summe vergleichbaren positiven Resultaten wie in Göttingen, heißt es dort. Das ist zum einen natürlich auch die Anerkennung für die Schul- und Bildungspolitik der Stadt, die auf Parteienstreit und Systemdebatten verzichtet hat und sich statt dessen auf die konstruktive Diskussion über den richtigen Weg zu möglichst vielen guten Schulen in der Stadt konzentriert hat und ich bin sicher, das wird auch in Zukunft so sein. Das soll für mich, für die Göttinger Kommunalpolitik und für unsere Stadtverwaltung aber kein Ruhekissen sein, dieses hohe Niveau, sondern eine herausfordernde Daueraufgabe im Interesse der Weiterentwicklung einer Schul- und Bildungslandschaft, die nach nunmehr 10 Jahren ohne Kinder-Uni nicht mehr vorstellbar ist.

Dafür gilt mein Dank der Universitätsleitung, den Fakultäten der Georgia Augusta, den Kooperationspartnern aus der Wissenschaft, den Sponsoren aus Stadt und Region, den über 100 Dozentinnen und Dozenten, den vielen Helferinnen und Helfern im Hintergrund, allen voran natürlich dem Projektleiter Peter Brammer. Peter, als Du in den Ruhestand gegangen bist, Du warst Leiter der IGS, hättest Du ja auch auf die Idee kommen können, Briefmarken zu sammeln oder ununterbrochen Weltreisen zu unternehmen. Ich bin ausgesprochen froh, dass Du damals beschlossen hast, weiter dort mitzuarbeiten und auf diese geniale Idee der KinderUni, mit andern zusammen, gekommen bist. Wie Du Dich da engagiert hast, das haben wir eben gehört, dafür bin ich Dir außerordentlich dankbar. Die ganze Stadt ist Dir dafür dankbar. Dein Engagement soll auch im zweiten Jahrzehnt der Kinder-Uni, den vielen Kindern aus Göttingen und Northeim oder Osterode, aus Kassel, Hannover oder Goslar, so breit ist der Einzugsbereich, zu Gute kommen. Die Kinder werden auch künftig Semester für Semester das Leitmotiv der KinderUni auf die Probe stellen, nämlich Neugier auf Neues, mehr hören, mehr sehen, mehr wissen, das wünsche ich mir und diesen Wunsch gebe ich der Kinder-Uni Göttingen gerne mit auf den Weg für die zweite Dekade.

Danke dass Sie zugehört haben, noch eine ganz kleine Anmerkung, im Moment tagt der Rat der Stadt Göttingen im Rathaus und das ist eine absolute Pflichtveranstaltung für einen Oberbürgermeister, deswegen haben Sie bitte Verständnis dafür, dass ich ganz schnell hier wieder weg muss. Vielen Dank. 



\section{Grußworte}

André Schüller

Sparkassenvorstand der Sparkasse Göttingen

Sehr geehrte

Frau Universitätspräsidentin Professor Beisiegel, sehr geehrte Frau Ministerin Heiligenstadt, sehr geehrter Herr Oberbürgermeister Meyer, sehr geehrter Herr Brammer, verehrte Damen und Herren.

Albert Einstein hat einmal gesagt: „Ich habe keine besondere Begabung, sondern bin nur leidenschaftlich neugierig." Diese Neugier ist jedem von uns schon von Geburt an in die Wiege gelegt worden, sie gehört zu uns wie das Denken und Fühlen. Und Kinder beginnen schon früh damit Fragen zu stellen, Frau Heiligenstadt hat es gerade berichtet und jeder, der von uns Kinder hat, weiß davon zu berichten und so manches Mal bekommen wir Löcher in den Bauch gefragt. Es ist noch gar nicht so ewig lange her, dass Kinder dann gebremst wurden mit der Aussage: Sei doch nicht so neugierig und somit wurde jede Neugier im Keime erstickt. 
Heute wissen wir, wie wichtig es ist, jede Frage ernst zu nehmen, eine gute Antwort auf sie zu finden und zu geben. Denn nur so ermuntern wir unsere Kinder auch weiterhin Fragen zu stellen aus deren Antworten sie lernen können. Diesen Denkansatz hat die Kinder-Uni vor 10 Jahren unter anderem aufgegriffen, weitergedacht und ein Garn aus den vorhandenen Ideen gesponnen. Und dabei herausgekommen ist ein bunter und abwechslungsreicher Leitfaden mit dem einladenden Motiv, wir haben es schon gehört, neugierig auf Neues, mehr hören, mehr sehen, mehr wissen.

Ziel dieses Projektes war es und ist es, die kindliche Neugier und den Forscherdrang mit immer neuen und spannenden Themen zu fördern. Aus einem anfänglichen Experiment ist so schnell eine feste und nicht mehr wegzudenkende Größe geworden. Die Kinder-Uni zeigt uns jedes Jahr aufs Neue, wie viel Freude Lernen bereiten kann und wer als Eltern mal das Glück hatte, an so einer Vorlesung teilzunehmen, weiß glaube ich, wovon ich rede.

Meine sehr verehrten Damen und Herren, weil auch die Sparkasse Göttingen weiß, was morgen zählt, das war übrigens das Motto unseres diesjährigen Neujahrsempfangs, liegt uns die Förderung von Wissen und Bildung besonders am Herzen. Sie ist ein wesentlicher Bestandteil unseres gesellschaftlichen Engagements und wir investieren in Bildung, weil wir wissen, dass eine gute Bildung eine solide und sichere Zukunft unserer Kinder ermöglichen kann. Und schon seit vielen Jahren unterstützt die Sparkasse Göttingen diverse wissenschaftliche Einrichtungen und Bildungsprojekte, wie auch das der Kinder-Uni. Als Bürger einer Stadt, die Wissen schafft, sind wir uns unserer Verantwortung bewusst und nehmen diese auch wahr.

In den vergangenen Jahren haben wir für Bildungsprojekte in der Region eine sechsstellige Summe bereitgestellt. Dieses Engagement macht uns zu einem der größten Bildungsförderer der Region und weil wir wissen, was morgen zählt, wollen wir auch in Zukunft dazu beitragen, unabhängig vom Einkommen und Vermögen der Eltern, dass diese Kinder die Möglichkeit haben, an dem wirtschaftlichen Wachstum unserer Gesellschaft teilzunehmen und hier spreche ich sicherlich auch stellvertretend für alle anderen Sponsoren. Unsere Kinder haben die Chance auf eine gute Bildung. Wir alle, die Politik, die Wirtschaft und das Elternhaus sind dafür verantwortlich, dass dies auch in Zukunft so bleibt.

Meine sehr verehrten Damen und Herren, weil wir wissen, was morgen zählt, unterhält die Sparkasse Göttingen seit 2012 auch zwei Schulkooperationen, zu denen das Felix-Klein-Gymnasium und die Berufsbildenden Schulen I gehören. Ziel dabei ist es, eine langfristige und regionale Bildungslandschaft mit einer sehr guten Berufs- und Praxisorientierung zu schaffen, denn wir wissen, dass die früh- 
zeitige Vorbereitung der Schüler auf die künftige Arbeitswelt in Ausbildung und Beruf überaus wichtig ist.

Es gilt, die Generation Y, die ihre Zeit gerne vor dem Computer verbringt und chattet, hostet und liked, frühzeitig auf die künftigen Aufgaben in Ausbildung und Beruf vorzubereiten. Dazu gehört auch die realistische Vermittlung von aktuellen Arbeitsplatzbedingungen durch verbindliche Absprachen und regelmäßige Gespräche. Im vergangenen Jahr hat die Sparkasse Göttingen die S-Spot-Filiale eröffnet, eine Filiale für junge Leute, ein neues Kapitel in der Zukunft des Banking. Unter dem Motto: „Mach doch, was Du willst“, eröffneten wir die bundesweit erste Ausbildungsfiliale, die sich genau an diese oben erwähnte Generation Y richtet. Hier steht der selbstbewusste, anspruchsvolle, wertkonservative und gebildete junge Mensch von 12 bis 25 Jahren im Mittelpunkt des Geschehens. Das Konzept S-Spot ist modern, offen, unkonventionell und geht in die Zukunft einer neuen Generation. Der Erfolg dieses Konzeptes liegt daran, dass wir die jungen Leute haben machen lassen. Die haben das alles entwickelt und wir haben irgendwie nur Ja sagen dürfen.

Meine Damen und Herren, wir sehen auch daran, lernen macht stark und eröffnet neue Perspektiven. Begonnen habe ich diese Rede mit den Worten Albert Einsteins und abschließen möchte ich sie aber mit dem leicht modifizierten Werbeslogan eines Pralinenherstellers, der ja übrigens heute zum Valentinstag besonders gut passt, denn „wen man liebt, dem schenkt man nur das Beste“, Bildung.

In diesem Sinne wünschen wir im Namen aller Sponsoren der Kinder-Uni weiterhin viel Erfolg und freuen uns auf noch viele weitere Semester und übrigens meine Damen und Herren, wissen Sie, wie Giraffen ihre Ohren reinigen, was bei der Apollo 13 Mission schief ging oder kennen Sie die Bedeutung von Hühnergöttern oder Donnerkeilen? Antworten liefern die Vorlesungen der Kinder-Uni.

Vielen Dank. 



\section{Festvortrag}

Brigitte $A x$

Kinder-Uni Göttingen

Zum Vortrag von Herrn Prof. Dr. Nida-Rümelin

Ihnen - auch von mir - einen guten Abend, die Sie heute der Einladung zur Festveranstaltung anlässlich des 10jährigen Bestehens unserer Kinder-Uni gefolgt sind.

Mein Name ist Brigitte Ax und ich zeichne verantwortlich für die Organisation der Philosophiewerkstatt, die wir seit 2011 jeweils 2mal im Semester in der Kinder-Uni anbieten.

Deshalb habe ich die Ehre und die große Freude, Ihnen kurz den Referenten unseres Festvortrages vorzustellen: Herrn Prof. Dr. Nida-Rümelin.

Herr Prof. Nida-Rümelin lehrt z. Zt. Philosophie und politische Theorie an der Ludwig-Maximilians-Universität in München. Auch in Göttingen ist er kein Unbekannter, denn er hatte von 1993-2003 einen Lehrstuhl an der Universität Göttingen inne (in der Nachfolge Günther Patzig). Manche von Ihnen mögen ihn 
aber auch aus den Medien kennen, z.B. aus diversen Talkshows, denn von 19982002 war er Kulturreferent der Stadt München und dann Mitglied des ersten Kabinetts Schröder als Kulturstaatsminister.

Für uns in der Kinde-Uni wurde er besonders wichtig und interessant durch sein Buch aus dem Jahr 2012, das er zusammen mit seiner Frau, Frau Dr. Nathalie Weidenfeld, verfasste. Es heißt: „Der Sokrates-Club“ und handelt von philosophischen Gesprächen mit Kindern.

Herr Nida-Rümelin und Frau Weidenfeld haben selbst drei aufgeweckte, neugierige Kinder, für die sie philosophische Gesprächsrunden organisierten, die dann offensichtlich ein so positives Echo fanden, dass sie auf Schulen und öffentliche Veranstaltungen übertragen werden konnten.

Das Buch gibt einige dieser Gespräche wieder und führt in die philosophischen Grundlagen für die jeweilige Thematik ein.

Herr Prof. Nida-Rümelin macht durch sein Buch deutlich, dass wir Kindern etwas zutrauen sollten. Wir fordern sie damit und - wenn wir es richtig machen - fördern wir gleichzeitig ihre Entwicklung zur Persönlichkeit.

Ich wünsche Ihnen nun neben Anregung und Information auch Vergnügen mit Herrn Prof. Nida-Rümelin und seinem Vortrag: „Der Sokrates-Club - mit Kindern das Denken entdecken.“ 


\section{Festvortrag \\ Der „Sokrates-Club“ - mit Kindern das Denken entdecken}

Prof. Dr. Julian Nida-Rümelin ${ }^{1}$

Ludwig-Maximilians-Universität München

Frau Präsidentin,

Frau Ministerin,

Herr Oberbürgermeister,

Herr Brammer,

Herr Schüller,

liebe Frau Ax,

verehrte Festversammlung,

Sie haben es in der Einführung ja kurz erwähnt: Mich verbindet etwas mit der Universität Göttingen, und ich bin schon deswegen gerne dieser ehrenvollen Einladung gefolgt, hierher zu kommen. Die Entscheidung gegen Tübingen und gegen Konstanz für Göttingen vor über zwanzig Jahren haben nicht alle gleich verstanden - aber wenn man weiß, wie das Wirken von Günther Patzig hier in einem Zeitraum von über 30 Jahren war, dann versteht man vielleicht eher, dass ich mich für Göttingen entschieden habe. Die Atmosphäre der Stadt hat auch eine Rolle gespielt, ich weiß noch, wie ich am Tag meines Vorstellungsvortrages durch die Stadt gegangen bin und gedacht habe, bei aller Wertschätzung Tübingen gegenüber (und eigene Vorfahren haben da gewirkt, das hat sich sogar in einem StraBennamen niedergeschlagen), aber Tübingen ist vergleichsweise eng, pietistisch.

\footnotetext{
${ }^{1}$ Dieser Text beruht auf der Abschrift des ohne Manuskript völlig frei gehaltenen Vortrages. Der mündliche Stil wurde weitgehend beibehalten (redaktionelle Überarbeitung von Susanne Kohl).
} 
Gut, Göttingen ist auch nicht ganz frei von Pietismus in seiner Geschichte, aber es ist eine offenere Stadt und ich habe mich hier eben gleich wohl gefühlt. Die Universität Göttingen, das darf ich in Anspielung an Ihren Vor-Vorgänger sagen, hat dann eine wichtige Rolle gespielt bei meiner Entscheidung, vorzeitig in die Wissenschaft zurückzukehren und nicht noch einmal vier Jahre länger in der Kulturpolitik als Kulturstaatsminister zu wirken: In einem sehr freundlichen Brief teilte mir Herr Kern mit, die Universität Göttingen könne mir diesen Lehrstuhl nicht länger freihalten und zudem sei der Aderlass unter Studierenden nicht länger zu verkraften - das war natürlich schmeichelhaft und hat es mir erleichtert, dann diese Entscheidung ganz für die Wissenschaft und gegen die Politik zu treffen. Unterdessen bin ich in München, wie Sie gemerkt haben. Es gab gute Gründe und der Hauptgrund war das familiäre Umfeld. Es sind unterdessen drei Kinder, eines noch nicht sprachfähig, da braucht man Großeltern und diese sind nun mal in München. Das sprach aus meiner privaten Perspektive für die Universität München und gegen die Universität Göttingen.

Ja, Kinderphilosophie: Wenn man in die Geschichte zurückblickt, ist der Eindruck ein wenig verstörend. Deutschland hat, insbesondere in den 1920er Jahren, eine Art Vorreiterrolle gespielt in der Kinderphilosophie. Ich gehe hier nicht auf die Details ein, aber wenn man die Texte liest, dann weiß man, wie sensibel dieser Bereich ist. Ich sage in meinem Büchlein nicht viel zu pädagogischen Fragestellungen, welche Rolle genau Kinderphilosophie oder Philosophieren mit Kindern (das ist eigentlich der bessere Ausdruck) spielen sollte, aber dies ist der Hintergrund, den ich hier wenigstens ansprechen möchte: In den 1920er Jahren gab es schon einmal einen Boom der Kinderphilosophie. Von Deutschland gingen die wichtigsten Impulse aus, ich will mal einen nennen, Herman Nohl, hier in Göttingen präsenter als anderswo: Ausgangspunkt war für ihn das philosophische Staunen von Kindern, das wurde heute schon mehrfach in den Vorträgen angesprochen und ist für alle, die mit Kindern zu tun haben, ein Faszinosum. Kinder fragen in die Tiefe. Nohl zieht daraus den Schluss, dass Kinder eine umfassende Antwort suchen. Er spricht sogar von einem gläubigen Einheitsgefühl, das Kinder hätten und dem man gerecht werden müsse. Grob gesagt ist die Antwort von Nohl auf diese Herausforderung durch kindliche Fragen Metaphysik. Aber Metaphysik eher in Form einer Weltanschauungslehre oder eines Beitrags zu einer mehr oder weniger schlüssigen Weltanschauung. Es gibt bei Nohl schon Anklänge, die einen im historischen Rückblick erschaudern lassen. Da geht es um das Heranführen an „sittliche Unerbittlichkeit“, die Missbrauchsanfälligkeit liegt auf der Hand. Nohl selbst hat sich später vom Nationalsozialismus viel erhofft, sich auch angebiedert und kam dennoch in berufliche Schwierigkeiten. Diese problematische Tendenz der deutschen Pädagogik wird dann offenkundig bei Arthur Lieberts „Philosophie in der Schule“, dort ist dann ganz unverhüllt - ich zitiere 
jetzt aus einer Schrift von 1927, also noch vor der Machtergreifung 1933 - von Philosophie als „Führungsdisziplin“ die Rede, wenigen Hochbegabten vorbehalten. Philosophie wird als „ordnungsstiftende Weltanschauungslehre“ charakterisiert.

Der mir weit sympathischere Antipode, mit dem mich mehr verbindet als nur das Thema „Philosophieren mit Kindern“, nämlich eine politische Grundhaltung, ist Leonard Nelson, ein Neukantianer, der Kinderphilosophie als sokratische Methode praktiziert („Sokrates-Club“, der Titel unseres Büchleins zum Philosophieren mit Kindern, ist bitte nicht miss zu verstehen, dass das nichts anderes sei als eine Fortsetzung dieses Projektes, aber die Anklänge sind durchaus gewollt, eben die sokratische Methode des methodisch geübten Selbstdenkens). Allerdings verbindet Nelson sein Projekt offenkundig mit einem maßlos überzogenen Rationalismus der Lebensform, der Lebensführung, des Denkens, der rigorosen Unterordnung unter Kriterien der rationalen Deduktion. Diese Schriften sind in einer beeindruckenden Form abgefasst, aber durchzogen von der Vorstellung, man könne das gesamte Philosophische in einer apriorischen, also von aller Empirie und Lebenserfahrung absehenden Form rekonstruieren. Die Kritik an rationalitätsorientiertem Denken darf man nicht überziehen. Manche werden sich vielleicht erinnern an die Kritik von Horkheimer und Adorno, die ja so weit geht, dass da die Vorstellung eines zweckgerichteten (Adorno spricht da auch von „männlichem“) Selbst zurückgewiesen wird, das sich desaströs in den zwei Weltkriegen und im Nationalsozialismus geäußert hat. Bei Adorno schlägt die fundamentalistische Rationalitätskritik um in eine anti-aufklärerische Geisteshaltung, die mich in vielem - ich will jetzt keinem Kollegen und keiner Kollegin aus den Geisteswissenschaften zu nahe treten - an die zumindest in den USA, teilweise auch in Deutschland unterdessen dominant gewordene postmoderne, poststrukturalistische Weltanschauung erinnert, wonach wir das Subjekt und mit ihm die großen Erzählungen von Gerechtigkeit und Freiheit, Rationalität und Vernunft verabschieden müssen. Was dann bleibt, ist nur noch ein Spiel.

Nicht untypisch für die gesamte intellektuelle Entwicklung in der Nachkriegszeit, allerdings sehr verspätet, reimportieren wir dann „Philosophieren mit Kindern“ aus den USA erst wieder in den 1980er Jahren. In der US-amerikanischen Philosophie gab hier Matthew Lipman mit „Growing up with Philosophy“, „Philosophy in the Classroom“ und vor allem mit „Harry Stottelmeiers Entdeckung“, das 1983 neun Jahre nach dem Erscheinen der englischen Fassung auch auf Deutsch erschien, entscheidende Impulse, ebenso wie Gareth Matthew mit „Dialogues with Children“, das auch in einer deutschen Fassung vorhanden ist. In Deutschland gibt es nun seit den 80er, vor allem 90er Jahren eine ganze Reihe von Philosophen und Pädagogen, die sich das zu ihrem Lebensthema gemacht haben: 
Ekkehard Martens, Detlef Horster und einige andere. Es gibt eine Gesellschaft für Kinderphilosophie. Da ist was in Gang gekommen und das finde ich insgesamt doch sehr erfreulich.

Was ich jetzt zunächst machen will, ist - vor diesem durchaus kritischen Hintergrund - ein bisschen was zur Rolle von Philosophie zu sagen, wohlwissend, dass das natürlich wieder eine Perspektive ist, die vielleicht aus der Distanz dann wiederum einseitig wirken wird. Aus meiner Sicht ist sie nicht einseitig, ich weiß, sie ist nicht Mainstream, sie ist nicht so, wie das die meisten Kollegen heute sehen würden, aber ich denke doch, dass manches sehr für diese Auffassung von Philosophie spricht. Und vor dem Hintergrund eines solchen Verständnisses von Philosophie ergibt sich dann die eine oder andere Schlussfolgerung für die Rolle der Philosophie in der Bildung, im Bildungswesen und speziell für die Rolle von Philosophie im Umgang mit Kindern. Wir haben es hier mit Acht- bis Zwölfjährigen zu tun, wenn ich recht informiert bin. Das ist auch genau der Adressatenkreis, den wir im Auge hatten, Acht- bis Zwölfjährige, gelegentlich auch mal Ältere oder Jüngere. Den Auftakt gab übrigens auch eine Einladung der analogen Initiative „KinderUni München“, die mich gebeten hat einen Vortrag zu halten und dann waren da 300 aufgeweckte, sehr lebhafte Kinder. Die beiden Pädagoginnen wurden zunächst dem Geschrei nicht so recht Herr, dann haben wir ein wunderschönes Gespräch gehabt und es hat mich sehr fasziniert, dass die Kinder dabei mucksmäuschenstill waren. Ich habe gedacht, na gut, dann versuchst du es auch und unterdessen, auch als Vater gestählt, hat sich das ganz schön entwickelt in den letzten zehn Jahren.

Nun also ein paar Bemerkungen zur Rolle der Philosophie, zum Verständnis von Philosophie. Wenn man sich nicht lediglich auf die aktuelle Situation der verschiedenen Disziplinen und Fächer in einer Universität wie z. B. Göttingen beschränkt, sondern den Blick etwas weiter, sagen wir auf die Zeit vor 200 Jahren richtet, dann muss man sagen, dass die Philosophie, bis auf drei charakteristische Ausnahmen, das war, was heute Wissenschaft überhaupt ist. Die drei Ausnahmen sind Medizin, Jurisprudenz und Theologie. Alles andere, was wir heute an wissenschaftlichen Disziplinen kennen, ist in den letzten zweihundert Jahren aus dem Schoß der Philosophie geboren worden und die Geburten verliefen sehr ähnlich. Es war ein Impuls, der mit dem Deutschen Idealismus und speziell mit der Bildungstheorie des Deutschen Idealismus zusammenhängt, insbesondere mit der von Wilhelm von Humboldt, der dann versucht hatte, das Realität werden zu lassen. Übrigens hat Göttingen dabei universitätsgeschichtlich eine wichtige Rolle gespielt. Demnach stehen im Zentrum der Universität nicht Berufsausbildung, sondern Wissenschaft und wissenschaftliche Erkenntnis. Das vergessen manche Bildungspolitiker heute, die denken, es sei modern, die Berufsausbildung ins Zentrum zu rücken, das war ja die Situation in der Zeit bis vor 200 Jahren. Das Zentrum, die Identität 
prägende Fokussierung der Universität sind, altmodisch formuliert, Wahrheitssuche und Forschung. Und die verrückte Idee - nicht nur von Humboldt, sondern von Schleiermacher, Fichte u.a. - war, dass die Konfrontation mit Forschung also nicht mit abgestandenem Lehrbuchwissen, das zum 25. Mal repetiert wird, sondern die unmittelbare Konfrontation mit Forschung - die Persönlichkeit in einer Weise bilden würde, die sich, entgegen dem Zerrbild, das gelegentlich in der bildungspolitischen Debatte von Wilhelm von Humboldt gezeichnet wird, außerhalb, primär außerhalb der akademia, außerhalb der Universität bewähren würde. Das war das Programm mit zum Teil sehr modernen Überlegungen, z. B. dass die Studierenden und die Lehrenden sich als Partner (vor 200 Jahren!) in diesem Projekt der Wahrheitssuche sehen sollten und es ganz unterschiedliche Formen dieser Partnerschaft gibt. Einsamkeit und Freiheit sind die üblichen Schlagworte, die da kommen, dabei ist das für Humboldt gar nicht charakteristisch, denn er spricht von Forschergruppen und von Kooperationen unterschiedlichster Art. Neuer Identitätskern der Universität und die Lösung der Krise - und die Universität war damals schon einmal in einer Krise, wie sie es die meiste Zeit in ihrer Geschichte war - war nun ihre Forschungsorientierung. Forschungsorientierung heißt weder primär noch gar ausschließlich, dass man sich mit den gerade aktuellen Experimenten und deren Resultaten auseinandersetzt. Sondern Forschungsorientierung wird sehr fundamental verstanden, nämlich als die Fähigkeit der Studierenden, sich ein eigenes Urteil zu bilden, und zwar auf einem so anspruchsvollen Niveau, dass das auch für diejenigen interessant ist, die Wissenschaft zum Beruf gemacht haben. Die Idee ist nicht, dass 90\% aller Studierenden nachher wieder die Universitätslaufbahn ergreifen. So schlecht war Humboldt nicht in Mathematik, um einen so verrückten Vorschlag zu machen. Der Identitätskern der Universität ist also die Forschung. Und daraus ergibt sich eine wesentliche Rolle für die Philosophie. Die Philosophie war damals, aus dem Trivium und dem Quadrivium noch des Mittelalters und der frühen Neuzeit hervorgegangen als eine Art Zusammenfassung all dessen, was nicht unmittelbar berufsbildend ist, in der unteren Fakultät, der sogenannten philosophischen Fakultät zusammengefasst. Und was passiert dann? Innerhalb von wenigen Jahrzehnten verlagert sich das Zentrum in diesen Bereich hinein. Dieser Bereich entwickelt eine immense Dynamik und - das gehört zu den Paradoxien der Bildungsentwicklung. Denn gerade die „Entzwecklichung" (um noch mal diesen Terminus von Wilhelm von Humboldt aufzugreifen) der universitären Lehre und Forschung führt zu einer wissenschaftlichen Dynamik, die mit einiger zeitlichen Verzögerung dieses, mit Verlaub, in politischer, technischer und ökonomischer Hinsicht rückständige Land Deutschland (soweit man am Anfang des 19. Jahrhunderts schon von einem Land reden kann, denn gerade ist das Heilige Römische Reich Deutscher Nation zugrunde gegangen, der deutsche Sprachraum ist zersplittert in viele Fürstentümer und erst 1871 kommt es mit der preußischen Hegemonie über andere Regionen zu einer Art Nationenwerdung) innerhalb weniger Jahrzehnte zur technologisch, ökonomisch und wis- 
senschaftlich führenden, ohne jeden Chauvinismus, Nation der Welt macht. Und das hängt mit diesem Paradigmenwechsel zusammen. Auf manchen Podiumsdiskussionen sage ich den Vertretern aus der Wirtschaft, ich verstehe sehr den Wunsch nach Praxisorientierung, Sie hatten es angesprochen, ganz in meinem Sinne. Ich glaube auch nicht, dass es gut ist, den dualen Bereich abzuwracken, aber Vorsicht, sägen wir nicht den Ast ab, auf dem auch der wirtschaftliche Erfolg beruht: Eine Forschung, die nicht unmittelbaren Zwecken dient und eine Lehre und eine Schule, die einen gewissen Abstand hält zur unmittelbaren Verwertbarkeit, die Persönlichkeit, Urteilskraft und Entscheidungsstärke bildet, selbstständige Persönlichkeiten reifen lässt. Das ist eigentlich das entscheidende Ziel.

Also in dem Sinn kann man sagen, ein wenig melancholisch vielleicht, Philosophie ist heute eine Art Residualwissenschaft, ihr ist das geblieben, was sich durch ein bestimmtes etabliertes Paradigma mit bestimmten akzeptierten Methoden, methodisch getragen von bestimmten Zielen und einem dynamischen Fortschritt, nicht so ohne weiteres klären lässt. Da sind allerdings viele Fragen dabei, die die gesamte Geschichte des philosophischen Denkens seit der Antike begleitet haben. Philosophie ist aber nicht nur Residualwissenschaft in diesem Sinne, sondern Philosophie ist auch eine Orientierungswissenschaft. Z. B. stellen sich in ihr ganz zentral normative Fragen, Kriterien des richtigen Handelns, Theorien der Gerechtigkeit, Theorien der Vernunft, der Rationalität, der praktischen Vernunft. Normative Fragen, wie sie nur in einer anderen Disziplin, nämlich der Jurisprudenz noch eine wichtige Rolle spielen und ansonsten im Wissenschaftsbetrieb weitgehend marginalisiert sind mit wenigen Ausnahmen. Also ist ein wesentlicher Teil, nämlich gerade der der Anleitung zu einer Praxis, in der Philosophie verblieben. Zum zweiten ist die Philosophie auch in der Hinsicht Orientierungswissenschaft, als sie als einzige Disziplin die Voraussetzungen einer „Mutterwissenschaft“ mitbringt oder ich muss vorsichtig sagen mitbrächte, wenn es das Ethos derjenigen prägen würde, die Philosophie zum Beruf gemacht haben, nämlich die verschiedenen einzelwissenschaftlichen Resultate zu beurteilen, nicht als Königsdisziplin, sondern sich mit ihnen auseinander zu setzen, sie ins Verhältnis zu bringen und möglicherweise auch einen Beitrag zu leisten zu so etwas, was man als wissenschaftliches Weltbild bezeichnen könnte: Ein wissenschaftlich, empirisch, rational begründetes Weltbild. Kritik an der Philosophie, wie sie sich heute aufstellt, übt fast niemand. Philosophie hat aber auch diese Aufgabe.

Jetzt ist die Frage, kann die Philosophie noch mehr? Und da ist Vorsicht angebracht und das ist besonders bedeutsam für die Praxis des Philosophierens mit Kindern. Die Philosophie ist jedenfalls nicht Ersatz für die da und dort verloren gegangene Religiosität. Sie kann den Priesterstand früherer Zeiten nicht ersetzen, sie soll auch gar nicht erst den Versuch unternehmen, das zu tun. Ich freue mich sehr darüber, dass in letzter Zeit die Esoterik-Regale in den Buchhandlungen wie- 
der schrumpfen, (ich habe sie nicht vermessen, aber ich glaube ganz falsch ist diese Einschätzung nicht) und die Philosophie-Regale wieder wachsen. Auch die ganze Beratungsliteratur, zum Teil zweifelhafter Seriosität, zeigt, dass es einen Orientierungsbedarf gibt, der von der Philosophie nicht gedeckt wird. Wenn die Philosophie in Anspruch nähme, das alles mit aufzunehmen, dann würde sie sich übernehmen und scheitern oder sie würde zur Weltanschauungslehre (Nohl, ich hatte darüber gesprochen) werden. Aber einen Beitrag zu leisten zur Klärung, Klärung der eigenen Überzeugung, Feststellung von Kohärenz, von Wertungen und Normen, die einzeln vertreten sind, das kann sie wohl. Ich will das gar nicht weiter begründen, aber ich glaube nicht, dass die Philosophie als Ethik allgemein verbindliche Regeln des Verhaltens philosophisch rechtfertigen kann. Sie kann zur Klärung beitragen, sie kann Widersprüche aufdecken, sie kann Kohärenz anstreben und dort, wo sie dann politisch relevant wird, muss sie sich einem öffentlichen Diskurs stellen. Am Ende ist sie nur ein Teil in diesem öffentlichen Diskurs und nicht die letzte Instanz, auf die man sich berufen kann.

Noch einmal, sie ist kein Ersatz für den Priesterstand vergangener Zeiten. Also Sie sehen schon, so wie ich jetzt hier Philosophie skizziert habe, ist sie einerseits sehr bescheiden, eine Residualwissenschaft, und andererseits unbescheiden. Sie ist ein Scharnier. Und damit bin ich bei der Frage, welche Rolle die Philosophie in den Schulen spielen sollte. Es gibt eine Merkwürdigkeit: Wir sind umgeben von Ländern, in denen die Philosophie in den Schulen eine zentrale Rolle spielt, Italien, Frankreich, Spanien, ein bisschen weiter weg Argentinien und Brasilien. Sie hören übrigens, welche Länder ich auslasse. Überall dort, interessanterweise in den eher katholischen Ländern des westlichen Kulturkreises, da zählt Südamerika im weitesten dazu, spielt die Philosophie eine ganz zentrale Rolle, auch im südlichen Nachbarland Italien, in einer sehr historischen Ausrichtung, aber sie ist dort genauso wichtig wie Italienisch als Fach, eine erste Fremdsprache oder Mathematik. Bei uns nicht. Niedersachsen ist in der Hinsicht weit besser aufgestellt als Bayern, das sage ich übrigens auch in Bayern, die Philosophie wird hier viel ernster genommen, das ist wirklich erfreulich, ich glaube sogar ganz vorne im Vergleich der Länder. Das habe ich auch damals schon gespürt, wie viele das ernsthaft betreiben. Bayern leistet sich die Besonderheit, dass dort Ethikunterricht an Gymnasien in der Oberstufe von Lehrern gelehrt wird, die noch nie ein Philosophiestudium, ein philosophisches Seminar oder eine Vorlesung in Philosophie gehört haben. Es gibt gelegentlich welche darunter, die das getan haben, aber das ist nicht vorgeschrieben, sondern ein Ergänzungsfach und man kann dieses Fach unterrichten, ohne eine Fachausbildung zu haben. Es gibt offenbar Bildungspolitiker, die meinen, das entspräche einem Wunsch der katholischen Kirche, das mag vor 30 Jahren der Fall gewesen sein. Unterdessen gibt es einen Beschluss der bayrischen Bischofskonferenz, die diesen Zustand beklagt. Also Philosophie in Schulen: Ich glaube, unabhängig davon wie man das genau konzipiert, dass die Philosophie - 
und ich weiß wohl um die Überladungen der Curricula - in den Fächern eine wichtige Rolle spielen muss und sollte. Es muss nicht ein eigenes Fach sein, das, finde ich, liegt auf der Hand, weil Philosophie eben nicht lediglich eine Geisteswissenschaft unter anderen ist. Man kann mit gutem Recht sagen, sie ist gar keine Geisteswissenschaft, das wird Sie jetzt verwundern. Wenn die DFG ihre Tagungen für geisteswissenschaftliche Forschungsprojekte veranstaltet, dann werden die unterteilt in zwei Gruppen, philologische und historische. Was ist die Philosophie? Philologie und Historie spielt eine Rolle, aber Philosophie ist weder ein philologisches noch ein historisches Fach. Metamathematik und Logik hat viel mit Philosophie zu tun. Die Wissenschaftstheorie ist eher an der Physik orientiert als an den Geisteswissenschaften. Die Parzellierung der Fächer in den Schulen, ein Erbe aus dem 19. Jahrhundert, die kleinteilige „Verschubladisierung“" des Wissens, welches in den Schulen vermittelt wird, ist ohnehin problematisch. Es gibt immer wieder Vorstöße, das wenigstens abzumildern, auch durch konkrete Praxis, wie z. B. Projekttage und ähnlichem. Das philosophische Denken kann hier eine wesentliche Rolle spielen, um die Einheit des Wissens wieder herzustellen und der Parzellierung entgegen zu wirken. Wenn man soweit geht, und manches spricht dafür, die Philosophie als Disziplin anzusehen, in der es um die Frage geht, was ein guter Grund ist, etwas zu meinen oder etwas zu tun oder eventuell auch bestimmte emotive Einstellungen zu haben, dann wird klar, dass das philosophische Denken eine Art Klammer in der gesamten Bildungsentwicklung einer Person darstellen kann. Was ist ein guter Grund etwas zu glauben? und Was ist ein guter Grund etwas zu tun? sind die beiden Grundfragen der theoretischen und praktischen Vernunft. Die einzelnen Fächer, ob das naturwissenschaftliche, sozialwissenschaftliche, geisteswissenschaftliche oder sprachliche Fächer sind, bieten Material, bieten Orientierung, bieten Wissen, welches integriert werden kann und dann einmünden in diese Frage: Was ist ein guter Grund etwas zu meinen oder etwas zu tun? Das sind normative Fragen der Praxis und Fragen der theoretischen Rationalität. Ich würde sogar vorschlagen, zum Zentrum, zum zentralen Bildungsziel die Forderung nach Urteilskraft zu machen. Alles ist darauf hingerichtet, die eigene Urteilskraft und die mit der Urteilskraft verbundene Orientierung in der Praxis zu ermöglichen. Es Kindern und Jugendlichen zu ermöglichen, sich ein eigenes Urteil zu bilden.

Es ist gar nicht so einfach zu sagen, worin Urteilskraft genau besteht. Ich will jetzt ex negativo ein paar Bemerkungen dazu machen: Urteilskraft ist nicht das gleiche wie Intelligenz. Es gibt hochintelligente Menschen, die haben ein geringes Maß an Urteilskraft. Ich will mal ein Beispiel nennen, das von Heidegger, zweifellos einer der intelligentesten Philosophen, der, fasziniert von der neuen Ideologie, überhaupt kein Problem hatte in seiner Antrittsrede als Rektor, sich diese Ideologie zu eigen zu machen und sie sehr unkritisch philosophisch zu überhöhen. Ich könnte zahllose Beispiele nennen, gerade aus meiner Generation. Ich sehe die lange Liste 
von intellektuellen Wegbegleitern, die, von ganz links außen kommend, irgendwann dann dort angekommen sind, wo der heutige Mainstream verortet ist und mir kam das immer als Ausdruck mangelnder Urteilskraft vor.

Urteilskraft ist auch nicht Wissen. Es kann Menschen geben, die, formal jedenfalls, ein geringes $\mathrm{Maß}$ an Bildung haben, die aber eine hochausgeprägte Urteilskraft haben. Davon lebt übrigens die Idee der Demokratie, sonst bräuchten wir ja eine Art Klassenwahlrecht, gebunden an den formalen Bildungsstand. Solche Vorschläge hat es gegeben. Da ist mein Held John Dewey. John Dewey erläutert in diesem wunderbaren Werk „Democracy and Education“, hier kaum rezipiert, jedenfalls früher nicht, das hat sich jetzt in letzter Zeit ein bisschen geändert, die Verwandtschaft zwischen Bildungs- und Demokratieidealen. Das Bildungsideal besagt, dass wir in der Lage sind, uns am Ende über wichtige Fragen zu verständigen, dass wir die Ressourcen haben, um zu klären, wie die Dinge sind. Dewey ist Optimist: Er sagt, wenn wir das klären, dann können wir auch zum Fortschritt und zu sozialen Reformen beitragen und die Welt verbessern, um es altmodisch auszudrücken. Die Demokratie lebt von der Vorstellung, dass es möglich ist, alle inklusiv mitnehmen, zu klären, was gut für uns ist. Deswegen diese merkwürdige Analogie bei Dewey, dass die Demokratie eigentlich eine Art Forschungsgemeinschaft ist, Gemeinschaft der Forscherinnen und Forscher. Man will herausbekommen, was gut ist für uns. Dafür braucht man Argumente, man braucht den öffentlichen Austausch von Gründen, man braucht eine bestimmte Persönlichkeit, die in der Lage ist, sich von den eigenen Interessen zu distanzieren und die die Zivilcourage hat, Dinge zu äußern, von denen sie zwar meint, dass gute Gründe für sie sprechen, von denen sie aber weiß, dass sie nicht gut ankommen.

Zivilcourage und Urteilskraft hängen eng miteinander zusammen. Weder die Demokratie noch die Wissenschaft können ohne diese Form von Zivilcourage leben. Wofür ich plädiere, ist die Praxis des Gründe-Gebens und Gründe-Nehmens (das ist jetzt kein gutes Deutsch, das ist das aus dem Englischen übertragene take and give reasons) in den Mittelpunkt zu stellen und die Philosophie dabei als eine Ressource zu nehmen, um diese Praxis des Gründe-Gebens und Gründe-Nehmens zu substantiieren. Da gibt es ein Kontinuum zwischen Gesprächen mit 6-jährigen Kindern, Gesprächen mit Erstsemestern und Gesprächen mit Kolleginnen und Kollegen aus der Philosophie. Die Unterschiede sind überraschenderweise manchmal oft gar nicht so groß. Ich war vor wenigen Tagen im Oskar-von-MillerGymnasium in München, ich werde dieses Beispiel nachher auch kurz inhaltlich heranziehen. Da ging es um die Frage was eigentlich Wissen ist. Ein Mädchen aus der 5. Klasse, bei der ich aufpassen musste, dass sie nicht die ganze Debatte dominiert, gab Antworten, die deutlich besser waren als das, was man normalerweise in den ersten Semestern im Philosophiestudium von den Studierenden hört. Das glauben vielleicht manche Pädagogen und Entwicklungspsychologen nicht, ich 
kann ja das nächste Mal ein Band mitlaufen lassen, um das zu belegen. Und Sie haben vermutlich in Ihrem Projekt der Kinder-Uni solche Erfahrungen auch gemacht. Es gibt ein breites Spektrum wie unter Erwachsenen auch, es gibt Erwachsene, die sich immens schwer tun von ihren persönlichen Erfahrungen zu abstrahieren, zu einem allgemeineren Argument vorzudringen. So gibt es auch Kinder, die gerne ihre Geschichten erzählen, Streit mit dem Geschwister oder Ärger um den Hund, um den sie sich nicht richtig kümmern usw. Das sind alles wichtige lebensweltliche Erfahrungen, die einfließen können in ein Urteil, aber manche lösen sich nur schwer davon und andere lösen sich ganz spielerisch. Das philosophische Gespräch ist also ein Kontinuum, die Unterschiede sind graduell, es gibt keine Sprünge. Eine Zeitlang hieß es von Seiten der Entwicklungspsychologie, Kinder könnten vor ihrem siebten Lebensjahr nicht logisch denken. Ja, wenn es sich so verhielte, dann könnten sie überhaupt keine Fähigkeit entwickeln, mit widerspenstigen Erfahrungen vernünftig umzugehen. Offenbar können sie sehr genau feststellen, dass sich einzelne Sachverhalte widersprechen, zugleich nicht gelten können, sie nehmen etwas als Widerlegung ihrer Überzeugungen, ich würde sogar sagen, sie sind hartnäckige Anhänger zweiwertiger Logik, um das so ein bisschen flapsig zu sagen, sie zwingen Erwachsene dazu, immer zu sagen, ist es jetzt so oder ist es nicht so. Und natürlich beherrschen sie, ohne dass sie das formalisieren können, die Grundregeln logischen Denkens, sonst würden sie sich ja gar nicht im Gespräch und in ihrer Lebenspraxis entwickeln können. Kinder sind selbstverständlich fähig zu einem gewissen $\mathrm{Maß}$ an Abstraktion und sie sind selbstverständlich in der Lage, zwischen Realität und Illusion zu unterscheiden. Auch da gab es bis vor kurzem Wissenschaftler, die behaupteten, das sei bei Kindern nicht möglich. Alles spricht dagegen. Kinder können unterscheiden zwischen Stofftieren und beseelten Tieren, die einen kann man in die Waschmaschine stecken, die andern nicht. Wenn das bei Kindern mal anders ist, dann ist der Kinderpsychiater oder Psychologe dringend erforderlich, und an der Stelle kann man sich eine boshafte Bemerkung nicht verkneifen, dass dies auch ein Problem von zahlreichen Tierethologen bis in die 1960er Jahre hinein war, die die Zuschreibung von mentalen Zuständen an Tiere für einen Anthropomorphismus gehalten haben und ebenfalls offenbar nicht in der Lage waren, eine solche Unterscheidung vorzunehmen, die schon vorsprachliche Kinder interessanterweise treffen können.

Ich will meine konkreten Erfahrungen nur in einigen Stichworten ansprechen, zögere auch ein bisschen, weil Sie ja die konkreten Erfahrungen selbst machen und warum soll ich hier Eulen nach Athen trage. Ich mache es jetzt mal trotzdem für meinen Bereich des Philosophierens mit Kindern. Was mir persönlich besonders wichtig erscheint aus diesen über zehn Jahren, in denen wir das bis jetzt praktiziert haben, ist erstens Respekt. Kinder sitzen nicht da und wollen in erster Linie von der Weisheit der lehrenden Person profitieren, sondern sie sind Gesprächspartner und sie fühlen genau, ob ihnen mit Respekt begegnet wird oder nicht. Es 
geht um ein Gespräch, um eine Klärung von Gründen, die für das eine oder gegen das andere sprechen, ein möglichst offenes Gespräch, das nicht vorab schon im Detail festgelegt werden darf.

Es gibt eine Praxis, die in den empirischen Sozialwissenschaften eine Rolle spielt, das halbstrukturierte Interview: Man nimmt sich vor, bestimmte Themen anzusprechen, aber wenn es nicht geht, lässt man eben einzelne Dinge fallen. Es sind nicht vorgefertigte Fragen, sondern man reagiert auf das Kind, wie es jeweils selbst Gedanken vorgebracht hat. Es sollte dann auch selbst merken, dass das eine Rolle spielt, was das Kind jeweils sagt - also ein offenes Gespräch.

Es ist eigentlich überflüssig zu sagen: Keine Anbiederung. Wir sind keine Kinder, also nicht von gleich zu gleich. Und wenn man versucht, sich selbst zu verkindlichen, führt das nur dazu, dass das Kind einen nicht mehr ernst nimmt. Es will ernst genommen werden, aber es will nicht, dass man sich als Kind camoufliert. Ernsthaftigkeit eines solchen Gesprächs und Humor schließen sich nicht aus.

Schließlich sollte man sich vor der deutschen Bildungsseuche hüten, die ich Mind Reading nenne: Ich habe einen Gedanken und will, dass das Kind meinen Gedanken liest, herausbekommt was ich gerade für einen Gedanken habe. Es wurde übrigens untersucht, dass das eine wichtige Rolle in den Schulen spielt, in Deutschland viel massiver als in vielen anderen Bildungstraditionen. Kein Mind Reading, sondern Argumente und Gründe. Das Kind kann sich mit diesen Gründen auseinander setzen, dann diskutieren wir darüber. Wir stehen nicht im Mittelpunkt des Geschehens, wir sind in der Hinsicht eben doch sokratisch, nur Hebammen, ja, Maieutike, die Mutter von Sokrates soll eine Hebamme gewesen sein, darauf bezog sich Sokrates. Wir sind ein Hilfsmittel zur Klärung der eigenen Gedanken, zur argumentativen Klarheit, ohne dass das umschlagen sollte in Logikschulen. Existentielle Fragen, die schon angesprochen wurden, spielen natürlich eine Rolle. Die Gefahr ist, dass die Philosophie sich dabei übernimmt und deswegen gehört es zu einem philosophischen Gespräch mit Kindern, die Grenzen der rationalen Klärbarkeit deutlich zu machen und nicht den Eindruck zu erwecken: Wenn du nur genug Philosophie kannst, dann lassen sich die Fragen nach dem Sinn des Lebens, Sie hatten es angesprochen, Frau Ministerin, beantworten - das kann die Philosophie nicht. Das ist jedenfalls meine feste Überzeugung.

Zum Schluss will ich noch ein Beispiel bringen, weil mir das gerade noch so frisch ist, es ist auch in einem Kapitel hier in dem Büchlein angesprochen, aber vielleicht nicht in dieser Zuspitzung, wie ich es jetzt bringen möchte. Ich hatte vor ein paar Tagen diese Schüler, fünfte Klasse, zwei Klassen im Oskar-von-MillerGymnasium mit zwei schwierigen Fragen konfrontiert und das hat sich dann als ein sehr lebhaftes und ich finde sehr fruchtbares philosophisches Gespräch entwi- 
ckelt. Ich bringe das deswegen, weil in der Auseinandersetzung um diese Frage Vorurteile eine Rolle spielen, die wir Erwachsene ganz überwiegend haben, bis hinein in die Rechtspraxis. Das ist jetzt kurz noch etwas zum Mitdenken am späten Abend und bevor wir zum gemütlichen Teil übergehen. Die erste Frage lautet: Kann man die Wahrheit sagen und dabei unwahrhaftig sein? Und die zweite Frage lautet: Kann man die Unwahrheit sagen und dabei wahrhaftig sein? Es gab vor kurzem eine Debatte, die lief durch die Feuilletons, dort hieß es: Erwachsene lügen $200 \mathrm{Mal}$ im Schnitt pro Tag, unglaublich, wie lügenhaft wir doch sind usw. Dann hat man versucht, die Quelle herauszufinden und man stieß auf einen Wissenschaftler, der zugab, dass er das nur geschätzt habe und dass er keine Untersuchung gemacht hatte. Ich glaube, die ganze These beruht auf einem Denkfehler, nämlich darauf, dass die Unwahrheit zu sagen schon als Lüge bezeichnet wird. In der Rechtspraxis wird Lüge definiert als wissentlich die Unwahrheit sagen. Das ist falsch. Und das muten wir jetzt Kindern zu. Also wenn Juristen behaupten, sie können Lüge definieren als ,wissentlich die Unwahrheit“ sagen, könnte man sagen, man kann doch nicht mit sechsjährigen Kindern dieses Problem diskutieren. Ich verspreche Ihnen: Es geht. Die sind erstaunlich schnell auf Beispiele gekommen, die zeigen, dass man die Wahrheit sagen kann und mit dieser Äußerung zugleich unwahrhaftig sein kann und umgedreht, dass man die Unwahrheit sagen kann und mit dieser Äußerung dennoch wahrhaftig sein kann, oder jedenfalls nicht unwahrhaftig sein, nicht lügen muss. Also diese beiden Thesen, kurz ein Beispiel, wir hatten 45 Minuten Zeit, die haben wir jetzt nicht mehr, deswegen bringe ich nur jeweils ein Beispiel, um das zu belegen. Wenn Sie gefragt werden von Ihrem Mann: Wo ist denn der Autoschlüssel? und Sie sagen: Der Autoschlüssel ist im Wohnzimmer oder auf dem Nachtkästchen, und Sie wussten, dass der Autoschlüssel auf dem Nachtkästchen ist, dann haben Sie die Wahrheit gesagt. Er ist ja im Wohnzimmer oder auf dem Nachtkästchen. Es ist wahr. Aber unwahrhaftig. Warum ist es unwahrhaftig? Es ist unwahrhaftig, weil Sie mit dieser Äußerung beim Adressaten dieser Äußerung den Eindruck erwecken, Sie wüssten, dass er da oder da ist, aber Sie wüssten nicht, ob er da ist oder da ist. Sie erwecken einen Eindruck mit einer wahren Äußerung, Gründe für eine Überzeugung, von der Sie aber wiederum wissen, dass sie falsch ist.

Und weil es so lange her ist und weil man ihn sonst ja in jeder Hinsicht nur schätzen kann, darf ich ein berühmtes politisches Beispiel bringen. Norbert Blüm hat mehrere Wahlkämpfe mehr oder weniger erfolgreich damit bestritten, zu sagen in diesem Dialekt, den ich leider nicht beherrsche: „Die Rente ist sicher“. Es war ja wahr, natürlich, die Rente war sicher, aber es war unwahrhaftig, denn man wusste seit den 70er Jahren, dass, wenn das so weiterläuft, irgendwann eben nur noch halb so viel, gemessen am Durchschnittseinkommen, zur Verfügung steht für die eigene Rente. Also es war wahr, aber es war unwahrhaftig, er hätte hinzufügen müssen: „wir haben auch ein großes Problem“. Stattdessen war die Botschaft: 
„Beruhigt Euch, es gibt kein Problem.“ Man kann mit der Wahrheit lügen. Man kann aber auch die Unwahrheit sagen und wahrhaftig sein. Das ist das, was komischerweise im Deutschen keinen rechten Ausdruck hat, die Amerikaner haben dafür einen, nämlich „,white lies“, weiße Lügen, und das sind keine Notlügen. Also wenn Sie in der Früh von Ihrem Büronachbarn gefragt werden: Wie geht es Ihnen? Und Sie sagen: Ach, ganz gut, dann ist das auch dann keine Lüge, wenn es Ihnen ziemlich schlecht geht. Warum? Weil der Fragende nicht erwartet, dass Sie wirklich eine wahre Antwort geben. Er wäre vielleicht sogar erschrocken, wenn Sie eine wahre Antwort geben, denn dann müsste er Ihnen Hilfsangebote unterbreiten und so nah sind Sie sich schließlich nicht. Kinder verstehen solche Zusammenhänge schnell, schließlich haben sie schon über Jahre gelernt, sich nicht nur im Denken, sondern auch im Leben zu orientieren. Viel Glück und Erfolg weiterhin mit der Kinder-Uni in Göttingen und speziell mit dem Philosophieren mit Kindern! 

Neugier auf Neues

mehr hören - mehr sehen - mehr wissen

10 Jahre Kinder-Uni

der Georg-August-Universität Göttingen

Peter Brammer

Mit dem Ende des Wintersemesters 2013/14 kann die Kinder-Uni Göttingen auf eine zehnjährige erfolgreiche Arbeit zurückblicken, seit ihrem Start 2004 also auf zwanzig semesterbegleitende Programme mit Vorlesungen, Seminaren und Workshops, an denen alle Fakultäten der Universität beteiligt waren. In Göttingen sowie in den umliegenden Landkreisen erfreut sich die Kinder-Uni einer anhaltend hohen Akzeptanz bei Kindern und Eltern.

Aus Anlass dieses 10-jährigen Jubiläums haben wir die wichtigsten Daten und Fakten zusammengetragen. 


\section{Das Leitmotiv der Kinder-Uni Göttingen lautet:} „Neugier auf Neues - mehr hören - mehr sehen - mehr wissen“.

In Stichworten:

- Interesse für Neues und bisher Unbekanntes wecken

- Motivation fördern und anregen

- Erste Erfahrungen mit der Institution Universität machen

- Schwellenängste abbauen

- Eigene Kräfte und Kompetenzen erkunden und testen $\mathrm{KiK}$ - Kinder informieren Kinder

- Experimentieren und „,forschen“ in Seminaren und Workshops

- Die Universität in ihrem sozialen und räumlichen Umfeld konkret und erfahrbar werden lassen

\section{Planung und Zuständigkeiten}

Die Kinder-Uni ist ein Projekt der Georg-August-Universität Göttingen. Die Kinder-Uni in Göttingen gibt es seit dem Sommersemester 2004.

Das Konzept wurde gemeinsam mit Studentinnen und Studenten des Intensivund Masterstudienganges im Rahmen des Seminars zur „Schulentwicklung und Schulorganisation" unter Leitung von Peter Brammer im Wintersemester 2003/2004 entwickelt. Während dieser Aufbauphase haben sich besonders Kerstin Richter, Irini Mataliotaki-Gehrke und Nicole Walter, Studentinnen des Intensiv- bzw. Masterstudienganges, engagiert.

Seit dem Sommersemester 2004 besteht ein Team aus Studentinnen und Studenten, das vor allem mit der Beratung der Kinder und deren Eltern sowie mit der Planung und Durchführung der KiK-Vorlesungen „Kinder informieren Kinder“ befasst ist.

Für die Verbindung zum Präsidium der Universität war bis 2009 die Vizepräsidentin Prof. Dr. Doris Lemmermöhle zuständig, danach Vizepräsident Prof. Dr. Wolfgang Lücke und seit diesem Wintersemester die Vizepräsidentin Prof. Dr. Ruth Florack. Der Kontakt-Dozent zum Institut für Erziehungswissenschaft ist seit 2008 Prof. Dr. Hermann Veith.

Die Organisation und Pflege der Internetseiten, die Anmeldungen zu allen Vorlesungen, Seminaren und Workshops u.a. hat Herr Simon Heider, GWDG und Doktorand, im Rahmen eines Werkvertrages übernommen. In der Abteilung für Presse und Öffentlichkeitsarbeit ist Frau Beate Hentschel für die Kinder-Uni zu- 
ständig und für das Rechnungswesen Frau Hannelore Heuer vom Institut für Erziehungswissenschaft.

Die KiK-Vorlesungen werden von Stephanie Kulgemeyer, Mareike Hemmeke, Rebecca Claude und Steffen Wübben (Studierende der Bildungswissenschaften) betreut, die Philosophiewerkstatt von Frau Brigitte Ax.

Für die Programmplanung, die inhaltliche Vorbereitung der Vorlesungen mit den Dozenten, für Verwaltung und Schriftverkehr, für die Koordination aller Aktivitäten, für Organisation, für Sponsoring und Pressearbeit, für Kontakte u.a. ist ehrenamtlich Peter Brammer als Projektleiter der Kinder-Uni zuständig. Die KinderUni hat in der Universität kein eigenes Büro.

\section{Angebote, Fakultäten und Kooperationspartner}

Die inhaltlichen Angebote der Kinder-Uni liegen bisher schwerpunktmäßig im naturwissenschaftlich-mathematischen Bereich. Darüber hinaus spiegelt das Angebot an Vorlesungen, Seminaren und Workshops aber auch die große Vielfalt und Breite der Studiermöglichkeiten an der Georg-August-Universität wider. Bisher haben sich Hochschullehrerinnen und -lehrer folgender Fakultäten engagiert

- Fakultät für Agrarwissenschaften

- Fakultät für Biologie und Psychologie

- Fakultät für Chemie

- Fakultät für Forstwissenschaften und Waldökologie

- Fakultät für Geowissenschaften und Geographie

- Fakultät für Mathematik und Informatik

- Fakultät für Physik

- Universitätsmedizin Göttingen

- Juristische Fakultät

- Sozialwissenschaftliche Fakultät

- Wirtschaftswissenschaftliche Fakultät

- Philosophische Fakultät

- Bernstein Center for Computational Neuroscience 
Kooperationspartner:

- Deutsches Primatenzentrum (DPZ)

- Deutsches Zentrum für Luft- und Raumfahrt - DLR-School-Lab

- Max-Planck-Institut für Sonnensystemforschung

- Technische Universität Clausthal

- Universität Kassel/Standort Witzenhausen

sowie Gastdozenten aus Universitäten in London (University College), Berlin, Hannover, Braunschweig, Erlangen-Nürnberg, Trier, WittenHerdecke und München.

\section{Dozenten}

Mehr als einhundert Professorinnen und Professoren sowie wissenschaftliche Mitarbeiterinnen und Mitarbeiter haben seit dem Sommersemester 2004 als Kinder-Uni-Dozenten Vorlesungen, Seminare und Workshops angeboten.

\section{Einzugsbereich und Alter der Kinder}

Die Kinder kommen zur Hälfte aus Göttingen und zur anderen Hälfte aus den Landkreisen Göttingen, Northeim und Osterode, in Einzelfällen aber auch aus einem weiteren Einzugsgebiet, z.B. aus Hannover, Kassel, Goslar, Witzenhausen u.a.

$\mathrm{Zu}$ allen Vorlesungen kommt regelmäßig ein Sonderbus aus Duderstadt mit 40 bis 50 Kindern.

Die Angebote der Kinder-Uni richten sich an Kinder der dritten bis sechsten Klasse, also an acht- bis zwölfjährige Schülerinnen und Schüler aller Schulformen.

\section{Finanzen und Sponsoren}

Kosten entstehen für den Druck und die Gestaltung der Programme und Plakate, für studentische Hilfskräfte, Materialien und Auslagen für Vorlesungen, Seminare und Workshops, Preise und Auszeichnungen, Reisekosten, vor allem für auswärti- 
ge Dozenten, Büromaterialien und Organisation, Internetadministration, Literatur u.a.

Finanziell getragen wird die Kinder-Uni vor allem durch Sponsoren und Spenden. Sponsoren bzw. Spendengeber sind oder waren bisher:

- $\quad$ Sparkasse Göttingen

- Sparkasse Duderstadt

- Kreis-Sparkasse Northeim

- Naturkost Elkershausen

- Städtische Wohnungsbau GmbH

- Universitätsbund Göttingen e.V.

- Fond der Chemischen Industrie

- Cateringhaus Göttingen-Böning - Schaumberg

- KWS Saat AG Einbeck

- Zeiss Göttingen

- Sartorius AG Göttingen

- Phywe

- dispo-Handelsgesellschaft

- Salvatore Espressamente

- HNO-Facharztpraxis Eilts, Osterode

- Conditorei Cafe Cortés

- Alfa Druck

- Buchhandlung Hugendubel (Deuerlich)

- Göttinger Sport und Freizeit GmbH

- Viani - Importe GmbH

- Feinbäckerei Ruch

- e.on - Mitte

- Stadtwerke Göttingen

- Hotel Freizeit In

- Sparkasse Hann-Münden

- Zentralverwaltung der Georg-August-Universität, Frau Dr. Anja Tobinsky

Die Stadtbibliothek Göttingen stellt für die Kinder-Uni-Studenten zu den einzelnen Themen der Vorlesungen geeignete Literatur zusammen. 


\section{Medienpartner}

Medienpartner der Kinder-Uni ist das Göttinger Tageblatt.

Über jede Vorlesung, aber auch über Seminare und Workshops sowie über die Vorlesungen für Erwachsene wurde seit Bestehen der Kinder-Uni ausführlich mit Bild, häufig auch mit Hinweis auf der Titelseite, berichtet. Alle Vorlesungen und Seminare wurden zudem angekündigt, insgesamt bisher 170 Artikel.

Das Eichsfelder Tageblatt übernimmt die Berichterstattung des Göttinger Tageblatts, so dass sie auch den ländlichen Raum erreicht.

Hinzu kommen Berichte in der HNA sowie in auf den südniedersächsischen Raum ausgerichteten Zeitschriften von Institutionen und Verbänden (z.B. Regjo, Charakter).

\section{Programmstruktur und Akzeptanz}

Das Programm der Kinder-Uni gliedert sich in fünf Bereiche:

1. Vorlesungen

2. Seminare für ,junge Forscherinnen und Forscher"

3. Workshops und Zusatzangebote

4. Kinder informieren Kinder $(\mathrm{KiK})$ - Vorlesung von Kindern für Kinder

5. Philosophiewerkstatt

6. Kinder-Uni für Erwachsene. Leitthema: Lernen im Kindesalter.

Zu 1: In den letzten zwanzig Semestern wurden insgesamt 117 Vorlesungen angeboten, an denen im Durchschnitt 350 Kinder teilnahmen:

40.950 Teilnahmen.

$\mathrm{Zu}$ 2: In den letzten neunzehn Semestern wurden insgesamt 155 Seminare angeboten, an denen im Durchschnitt 15 Kinder teilnahmen:

2.300 Teilnahmen.

$\mathrm{Zu}$ 3: In den letzten fünfzehn Semestern wurden insgesamt 75 zwei- bis viertägige Workshops angeboten, an denen im Durchschnitt 15 Kinder teilnahmen:

1.100 Teilnahmen. 
$\mathrm{Zu}$ 4: In den letzten siebzehn Semestern wurde jeweils eine Vorlesung angeboten, die Jungstudenten der Kinder-Uni selbst gestaltet haben (KiK). An diesen Vorlesungen nahmen im Durchschnitt jeweils 200 Kinder teil:

3.400 Teilnahmen.

Zu 5: In den letzten achtzehn Semestern wurde jeweils eine Vorlesung für Erwachsene angeboten: Kinder-Uni für Erwachsene. Diese Vorlesungen standen unter dem Leithema: Lernen im Kindesalter. Die Dozentinnen und Dozenten kamen aus Göttingen oder aus anderen Universitäten (Berlin, Hannover, Erlangen-Nürnberg, Witten-Herdecke und London).

An jeder Vorlesung nahmen im Durchschnitt 200 Personen teil: 3600 Teilnahmen.

Insgesamt sind also in den vergangenen zwanzig Semestern ca. 50.000 Teilnahmen zu verzeichnen.

\section{Programme und Plakate}

Für jedes Semester wurde ein Programmflyer (Auflage 10.000) sowie ein Plakat (Auflage 500) gedruckt. Siehe auch: www.kinder-uni.uni-goettingen.de oder www.uni-goettingen.de.

Die Programme werden über die Schulen an die Kinder ausgegeben. Jedes Kind der Klassen drei bis sechs in dem genannten Einzugsgebiet soll ein eigenes Programm erhalten. Darüber hinaus liegen die Programme an einigen zentralen Orten in Göttingen aus:

Altes Rathaus, Universitätsaula, Stadtbibliothek, Theater u.a.

\section{Zusammenfassung}

Die Kinder-Uni Göttingen hat durch ihr breites und umfangreiches Angebot die Universität für eine große Zahl von Kindern und Eltern konkret erfahrbar gemacht. Zudem wird durch die positive Resonanz und Akzeptanz der Kinder-Uni der Bekanntheitsgrad der Universität in ihrem sozialen und geographischen Umfeld erhöht.

Dabei erreicht die Kinder-Uni auch soziale Schichten, die bisher keinen Zugang zu universitären Einrichtungen und Angeboten hatten. 
Im Angebot der Kinder-Uni spiegelt sich das breite Spektrum der Studiermöglichkeiten der Georg-August-Universität wieder.

Annähernd 40 Prozent der fünfzehn bis zwanzig verschiedenen Angebote im Semester sind naturwissenschaftlich ausgerichtet, 60 Prozent verteilen sich auf alle anderen Fakultäten.

Ziel ist, Interesse und Neugier der Kinder zu wecken, zu erhalten und zu vertiefen.

\section{Weitere Informationen zur Kinder-Uni Göttingen siehe unter:}

www.kinder-uni.uni-goettingen.de.

Das aktuelle Semesterprogramm sowie auch die Programme seit der Gründung der Kinder-Uni mit Thema/Titel/Dozent u.a. können hier eingesehen werden.

Postadresse: Kinder-Uni Göttingen

Wilhelmsplatz 1 - Aula

37073 Göttingen

Telefon: 0551 - 793454 (priv.)

Email: brammer@kinder-uni.uni-goettingen.de

\section{Ehemalige und gegenwärtige Mitglieder des Kinder-Uni- Teams}

Benjamin Bolduan, Julia Boschmann, Rebecca Claude, Sarah Dahms, Anja Drebing, Franziska Dorn, Miriam Gregor, Mareike Hemmeke, Johanna Herting, Kathrin Horstmann, Jan Patrick Huber, Stefan Keitel, Anje Kliem, Benjamin Kuck, Stefani Kulgemeier, Astrid Kuttner-Siebeck, Irini Mataliotaki-Gehrke, Vera Pelkonen, Katharina Ratke, Kerstin Richter, Kevin Sheehan, Jörn Spichal, Anna Lena Schierzi, Nils- Christian Schwarz, Theres Stüber, Jennifer Struck, Christoph Többerwien, Nicole Walter, Agnes Wendroth, Nina Witt, Steffen Wübben. 


\section{Professorinnen und Professoren, Dozentinnen und Dozenten für Vorlesungen, Seminare und Workshops seit $2004^{1}$}

Sommersemester 2004: Wolfram Kollatschny, Jörg Magull, Ekkehard Wilichowski, Gerhard Wörner, Brigitte Groneberg, Karl-Heinz Willroth. Wintersemester 2004/05: Annette Broschinski, Robert Gillenkirch, Stephan Klasen, Rebecca Habermas, Wolfgang Send, Heike El-Hotabi-Sternberg, Harald Koegler, Claudius Jacobshagen.

Sommersemester 2005: Wolfgang Holtz, Gerhard Lauer, Rainer Ulrich, Ronald Stalder, Brigitta Hauser-Schäublin, Armin de Meijere, Ysette Weiss-Pidstrygach, Klaus Plaisir, Reinhold Wittig.

Wintersemester 2005/06: Julia Fischer, Michael Knauth, Georg Lemmer, Susanne Hermann, Karsten Bahr, Jörg Magull, Hartmut Bleumer, Paultheo von Zezschwitz, Gerald Hüther.

Sommersemester 2006: Hartmut Rothe, Herbert W. Roesky, Rudolf Kippenhahn, Barbara Veit, Ingo Helm, Elsbeth Stern.

Wintersemester 2006/07: Robert Gillenkirch, Stephan Klasen, Susanne Schneider, Stefan Treue, Gerald Hüther, Jörgh Magull, Georg Lemmer, Annette Scheunpflug.

Sommersemester 2007: Gerhard Wörner, Stephanie Grond, Florentin Wörgötter, Günter Schäfer, Herbert Hopf, Christian Pfeiffer, Isabel Pagalies, Gert Tröster, Axel Bauer, Alexandra Schulz, Mieke Westermann, Nadine Beetz. Wintersemester 2007/08: Ralf Heinrich, Regine Eckardt, Gert Webelhuth, Rainer G. Ulbrich, Jörg Magull, Cornelius Frömmel, Marcus Hasselhorn, Marina Hethke, Inis Fehrmann, Sven Frings, Jonas Loos, Gabriele G. Weis.

Sommersemester 2008: Martina Gerken, Michael Schultz, Julia Fischer, Sami K. Solanki, Gerald Hüther, Manfred Sailer, Imke Schlieter, Matthias Maume, Kornelius Kimmich, Alexander Riek, Dieter Schmitt, Janina Krause, Justus Lücke, Max von Oettinger, Maik Vahldiek.

Wintersemester 2008/09: Heinrich Detering, Rainer Willmann, Wolfgang Send, Dietrich Grönemeyer, Dietmar Stalke, Manfred Prenzel, Sascha Bargmann, Christoph Hesse.

\footnotetext{
${ }^{1}$ Mehrere Dozentinnen und Dozenten haben wiederholt in verschiedenen Semestern Seminare übernommen. In dieser Auflistung werden sie aber nur einmal in dem Semester genannt, in dem sie ihr erstes Seminar geleitet haben.

An vielen Vorlesungen und Seminaren haben auch Studentinnen und Studenten mitgewirkt.
} 
Sommersemester 2009: Thomas Mann, Wolfram Kollatschny, Volker Sommer, Birgit Großkopf, Klaus Grote, Arnulf Quadt, Karl Neumann, Janina Krause, Sonja Girod, Ernst Böhme, Daniel Schulze.

Wintersemester 2009/10: Annette Richter, Stephan Klasen, Claudia Keser, Julia Ostner, Oliver Schülke, Georg Lemmer, Dietmar Stalke, Franzis Preckel, Annette Steudel, Stefan Meyer, Daniel Schulze.

Sommersemester 2010: Gerhard Wörner, Peter Aufgebauer, Josephine Grant, Floretin Wörgötter, Stefan Treue, Arnulf Quadt, Gerald Hüther, Oliver Boguhn, Mike Reich, Tanja Stegmann, Artur Kremser.

Wintersemester 2010/11: Joachim Reitner, Nadia-Valerie Queric, Roman Loimeier, Hans-Jörg Uther, Uwe Groß, Daniel B. Werz, Donata Elschenbroich, Johannes Nickel, Daniel Keyhani.

Sommersemester 2011: Andre'Fiala, Janna Arp, Dorothea Drischel, Gerhard Lauer, Nicole Witte, Arnulf Quadt, Marcus Hasselhorn, Heribert Kremer.

Wintersemester 2011/12: Achim Dohrenbusch, Thomas Waitz, Johannes Bergemann, Christian Jooß, Ulrich Christensen, Gerald Hüther, Thomas Daniel, Felix Busse, Sam Donnerstag, Holmer Steinfath.

Sommersemester 2012: Torsten van der Lubbe, Georg Lemmer, Julia Ostner, Oliver Schülke, Gerhard Lauer, Mark Zurmühle, Joachim von Burchard, Arnulf Quadt, Karl Gebauer, Michaela Dölle, Manuel Punzet, Karin Gille-Linne, Mattis Karius, Heribert Kremer, Kristina Glöckner, Fabian Fröhlich, Philipp Schröder, Benjamin Bolduan, Eva Weber-Guskar, Aurelie Halsband.

Wintersemester 2012/13: Gerhard Wörner, Martin Potthoff, Volker Sommer, Axel Schneider, Thomas Waitz.

Sommersemester 2013: Thomas Moritz, Philipp Matschoß, Lars S. Maier, Gerhard Lauer, Joachim von Burchard, Thomas Ellrott, Arnulf Quadt, Jennifer Gräbeldinger, Stefan Goldmann, Jesus Rodriguez Colmenero, Alexandra Spinnhoff, Philipp Schröder.

Wintersemester 2013/14: Thorsten van der Lubbe, Stephan Klasen, Teja Tscharnke, Catrin Westphal, Gerhard Wörner, Thomas Waitz, Linda Kunde, Berit Gerhards, Lina Sophie Springer, Nina Wagenknecht, Mario Brandhorst, Julian Nida-Rümelin, sowie Studentinnen und Studenten vor allem aus der Physik und weiteren Fakultäten. 


\section{„Kinder informieren Kinder“" Ein Projekt der Kinder-Uni Göttingen}

Nils-Christian Schwarz

Man kann einen Menschen nichts lehren, man kann ibm nur helfen, es in sich selbst zu entdecken.

Galileo Galilei

Als zum Ende des Wintersemesters 2006/2007 hunderte Kinder-Uni Studenten in einem der größten Hörsäle der Georg-August-Universität Göttingen zusammenkamen, um etwas über geheimnisvolle bunte Sonnenuntergänge oder die Kreuzzüge zu lernen, war manches anders, als sie es sonst von der Kinder-Uni gewohnt waren. Weit und breit war kein anzugtragender Dozent oder Lehrer in Sicht, dafür herrschte rings um das Rednerpult ein geschäftiges Treiben von Studenten und Kindern, wurden noch kurz vor Vorlesungsbeginn Mikrofone getauscht und Folien ausprobiert. Tatsächlich erlebten die anwesenden Jungforscher die Geburtsstunde eines Projektes, welches hinter den Kulissen vom Team der Göttinger Kinder-Uni und freiwilligen Schülern über Monate hinweg durchdacht und vorbereitet worden war: Am 14. Februar 2007 hielten nach zahlreichen Übungsstunden und mehreren Generalproben erstmals fünf Teilnehmer der Kinder-Uni Göttingen Vorträge über ihre Lieblingsthemen und legten somit den Grundstein für eine inzwischen etablierte und nicht mehr wegzudenkende Säule der Göttinger KinderUniversität - „Kinder informieren Kinder“. 
Doch worum geht es bei diesem Projekt genau? Eine Kinder-Uni darf, dem Verständnis des Göttinger Projektteams nach, nicht nur Edutainment im Sinne von Bespaßung sein, sondern soll vielmehr Spaß am Lernen vermitteln. Indem Schüler an der Kinder-Universität Göttingen teilnehmen, lernen sie nicht nur etwas über die dort behandelten Themen oder entdecken die Universität als Bildungsinstitution, sondern erleben darüber hinaus was unterhaltsames und selbstbestimmtes Lernen bedeutet. Getreu des bildungshumanistischen Verständnisses von Lernen als Vorfreude auf sich selbst, hat eine Kinder-Uni also dann Erfolg, wenn sie die Kinder dazu anregt, sich selbst mit bestimmten Themen und Fragestellungen weiter auseinanderzusetzen. Eine gelungene Kinder-Uni macht neugierig auf Neues, so das Motto der Göttinger Kinder-Uni.

Um diesem Anspruch gerecht zu werden, wurden den Vorlesungen für Kinder zunächst zwei weitere Veranstaltungsarten zur Seite gestellt. Dabei handelte es sich zum einen um die „Kinder-Uni für Erwachsene“, welche je eine Vorlesung pro Semester umfasst. Durch sie soll die Kinder-Uni sowohl als Gesprächsthema Einzug in die Elternhäuser halten und so wiederum auf die Kinder rückwirken, als auch erziehungs- und bildungsrelevante Themen für die Eltern der Kinderstudenten aufbereiten. Als weiterer Veranstaltungstyp wurden zum anderen die „Seminare für junge Forscher" etabliert. Kinder, die sich für eines der Vorlesungsthemen besonders interessieren, können sich im jeweils folgenden Semester für solch eine mehrstündige Veranstaltung anmelden, um dann in einer Kleingruppe gemeinsam mit dem Dozenten, der schon die Vorlesung hielt, weiter „,nachzuforschen“. Besonderes Augenmerk wird bei den „Seminaren für junge Forscher" darauf gelegt, dass sie für die Kinder tatsächlich als kleine Forschungsseminare, bei denen es etwas zu entdecken gibt, konzipiert werden. Sie stehen damit im Gegensatz zum Vorlesungscharakter der klassischen Kinder-Uni und betonen die erwünschte selbstbestimmte und -motivierte Auseinandersetzung mit einzelnen Themen. Von besonderer Bedeutung ist hierbei, dass die Jungforscher die Universität als Institution aus einer nochmals anderen Perspektive wahrnehmen und mit Professoren und Doktoren echte Experten an die Seite gestellt bekommen. Das Lernen in den „Seminaren für junge Forscher" unterscheidet sich so in noch stärkerem Maße als schon die Kinder-Uni Vorlesungen vom alltäglichen und verregelten Lernort Schule.

„Kinder informieren Kinder“ ergänzte dann im WS 2006/2007 die Organisationsstruktur der Göttinger Kinder-Universität um einen vierten Bereich und setzte die kontinuierliche Entwicklung vorangegangener Semester fort. 


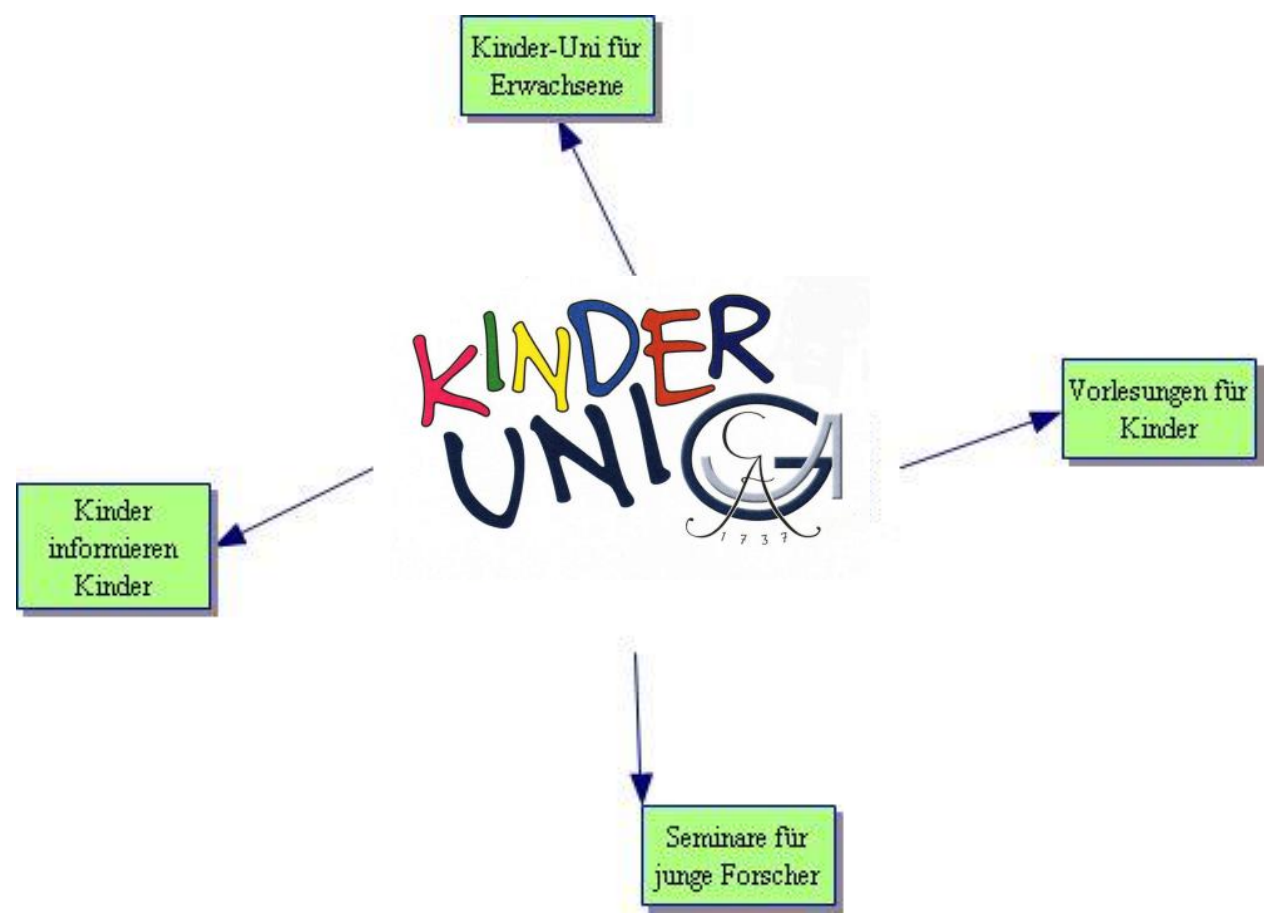

Nach einer kleineren Probeveranstaltung wurden im Spätsommer 2006 die Teilnehmer der Kinder-Uni erstmals offiziell aufgefordert, sich für ein Projekt zu melden, bei dem es darum ginge, anderen Kindern etwas über das eigene Lieblingsthema zu erzählen und beizubringen. Am Ende dieser Bewerbungsphase wurden dann alle potentiellen Kinderdozenten zu einem kleinen Workshop eingeladen, bei dem sie die anderen Bewerber und das Projektteam der Kinder-Uni kennen lernen sollten. Für die Studenten, die später die Kinder betreuen und bei ihrem Vortrag unterstützen sollten, diente das Treffen zudem dazu, sich über die verschiedenen Themen, die Motivation der Kinder und auch schon einen möglichen Arbeitsfortschritt zu informieren. Im Anschluss an den Workshop wurden dann nach intensiven Beratungen vier Themen ausgewählt, während den nicht berücksichtigten Bewerbern ein Vorrecht auf einen der vier Plätze im Folgesemester gewährt wurde. In den weiteren Monaten bis zur ersten „Kinder informieren Kinder"-Vorlesung arbeiteten die frisch gekürten Dozenten zum einen selbständig an den Inhalten ihrer Vorträge, zum anderen aber auch gemeinsam mit ,ihrem“ Studenten an freier Rede, Präsentation und verschiedenen Möglichkeiten der Veranschaulichung. Bei zwei Generalproben bot sich schließlich eine erste Gelegenheit, das Gelernte in einem Hörsaal umzusetzen, was sich für viele Kinder ob der 
besonderen Örtlichkeit als mit großer Aufregung verbundene Herausforderung herausstellte. Auf diese Weise leistete jedes Team aus Kind, Eltern und betreuendem Student Arbeit in großem Umfang und mit immer neuen Ideen, bis

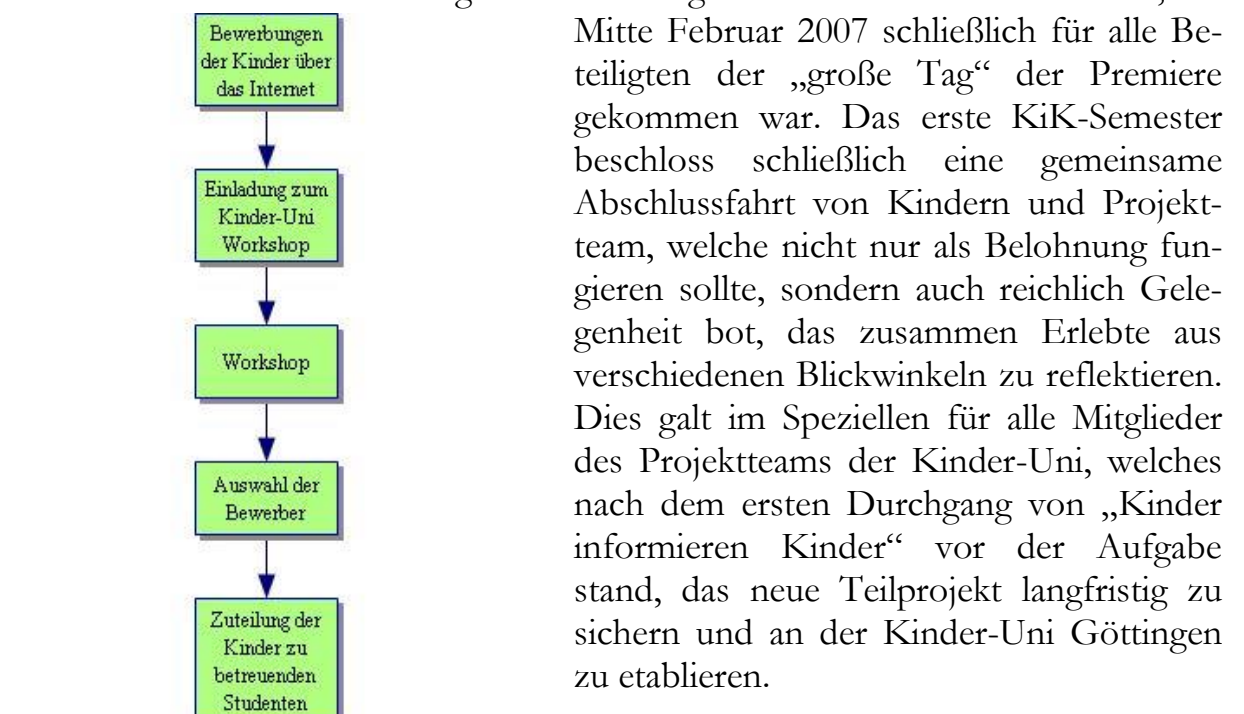

Seit diesen ersten Anfängen von „Kinder informieren Kinder" hat sich viel getan. Bis zum Wintersemester 2008/2009 hielten dreiundzwanzig Kinder verschiedener Schulformen sechzehn Vorträge zu völlig unterschiedlichen Themengebieten wie Geschichte, Physik, Sport etc. Die ursprünglich eingeführte Organisationsstruktur des Teilprojekts hat sich dabei bewährt, wurde jedoch im Detail weiter ausgestaltet. Die gewonnenen Erfahrungswerte früherer Semester helfen dabei, im ersten Workshop zueinander passende Themen auszuwählen und bei der Vorbereitung der Vorträge mit den Kindern gezielt auf solche Aspekte hinzuarbeiten, die sich für den Erfolg von Vorlesungen als wichtig herausgestellt haben. Trotz aller gesammelten Erfahrungen und der Tatsache, dass die ersten Nachwuchsdozenten der Kinder-Uni inzwischen schon entwachsen sind, bleibt eines jedoch noch immer gleich: Für die teilnehmenden Kinder ist „ihre“ Vorlesung immer ein 
einzigartiges Erlebnis, dem sie sich mit großem Engagement und kaum geringerem Lampenfieber stellen - und letzteres gilt insbesondere jedes mal aufs neue auch für das Projektteam „Kinder-Uni Göttingen“.

\section{Text: Nils-Christian Schwarz}

Projektteam: Katharina Rathke, Antje Kliem, Bejamin Kuck, Christoph Töpperwien, Miriam Töpperwien, Nils-Christian Schwarz

Projektleitung, Idee und Supervision: Peter Brammer 



\title{
Leitfaden für Kinder-Uni Dozenten ${ }^{1}$
}

\author{
Stephanie Johanna Herting
}

\section{Vortragsstil}

- Adressatengerechte Strukturierung: Kleine Zusammenfassungen nach Teilabschnitten sowie das Formulieren von Kernaussagen erleichtern den Kindern das Zuhören. Was haben wir gelernt?

- Adressatengerechter Redestil: Die Formulierung des Vortrags sollte kindgerecht sein, gleichzeitig wollen die Kinder jedoch ernst genommen werden, vermeiden Sie daher Verniedlichungen.

- Verwendung von Fremdwörtern: Kinder wollen neue Fachtermini lernen, diese müssen aber gut eingeführt werden. Benutzen Sie die Tafel.

- Bezüge und Anknüpfungspunkte zur Lebenswelt der Kinder schaffen: Inhaltlich sollten Sachverhalte anhand von Beispielen aus der Umwelt der Kinder spannend und anschaulich erläutert werden. Sinnvoll könnte auch eine Verdeutlichung anhand von Kuriositäten, Anekdoten oder Spektakulärem sein.

- Bezüge zu eigenen Erlebnissen, zu eigenen Erfahrungen und zur eigenen Forschung machen den Vortrag interessanter, authentischer und fördern die Aufmerksamkeit.

\footnotetext{
${ }^{1}$ Auszug aus der Arbeit zur Erlangung des Master of Arts in Education der Georg-AugustUniversität Göttingen, 2008., S. 76 ff.

Betreut durch Peter Brammer und Prof. Dr. Doris Lemmermöhle
} 


\section{Durchführung}

- Umgang mit Fragen und Redebeiträgen: Überlegen Sie sich, ob Sie Fragen bereits während des Vortrages zulassen wollen oder es Ihnen lieber wäre, am Ende der Vorlesung dafür Zeit einzuräumen, und kündigen Sie dies zu Beginn der Vorlesung als Hinweis an. In jedem Falle sollten Sie die Fragen begrenzen, da es sonst ins Uferlose führen kann.

- Seien Sie flexibel: Kinder stellen unvermittelt Fragen und möchten diese gerne beantwortet haben. Weisen Sie darauf hin, dass auch am Ende der Vorlesung die Möglichkeit besteht, Fragen zu stellen.

- Deutlichkeit von Redebeiträgen: Achten Sie bei Fragen oder Kommentaren darauf, dass diese laut und für alle verständlich sind, das bedeutet, dass sie ggf. noch einmal für das Plenum wiederholt werden müssen.

- Umgang mit Unruhe: Da es sich um eine Veranstaltung für Kinder handelt, ist Unruhe nicht auszuschließen. Versuchen Sie diese, soweit es Ihnen möglich ist, zu unterbinden. Sprechen Sie die Kinder ggf. direkt an. Die Kinder erhalten Verhaltensregeln mit ihrer Anmeldebestätigung.

- Schaffen Sie Auflockerungsphasen: Durch Abstimmungsverfahren oder Quizfragen u.a. werden die Kinder aktiv.

- Eine Vorlesung sollte nicht länger als 45 Minuten dauern. Achten Sie auch während der Vorlesung auf die Zeit.

\section{Medieneinsatz}

- Die Grundregel lautet: Die Inhalte bestimmen den Medieneinsatz.

- Abwechslung ist wichtig: ein Vortrag, der sich an Folien orientiert, mag inhaltlich interessant sein, ist für Kinder jedoch zu eintönig. Exponate, Anschauungsmaterial, Filmausschnitte und Experimente liefern zwischendurch eine willkommene Abwechslung.

- Dosierung des Medieneinsatzes: Achten Sie bei dem Einsatz von Medien, Experimenten oder anderem Anschauungsmaterial darauf, dass diese wohldosiert eingesetzt werden.

- Visualisierung: Folien und Filmausschnitte müssen gut lesbar bzw. sichtbar sein. Bei Folien ist zu berücksichtigen, dass diese nicht zu voll geschrieben sind, da viele Kinder dazu neigen, alles abzuschreiben, was zu Unruhe führt, wenn die Folien zu kurz auf dem Projektor liegen. 


\section{Zum Umgang mit den Kindern}

- Beteiligung der Kinder: Beziehen Sie einzelne Kinder oder kleine Gruppen als Assistenten oder Helfer in Ihren Vortrag mit ein. Stellen Sie diese Kinder vor und verabschieden Sie sie auch nach ihrem Auftritt.

- Kinder haben einen ausgeprägten Gerechtigkeitssinn: Achten Sie bitte darauf, dass gleich viele Jungen wie Mädchen Assistenten u.a. sein dürfen und dass alle Hörsaalbereiche berücksichtigt werden.

- Aufmerksamkeit aufrechterhalten: Wenn die Aufmerksamkeit der Kinder nachlässt, ist es hilfreich, etwas Neues, etwas Unerwartetes einzubauen.

- Autogramme und Fragen : Es wäre schön, wenn Sie nach Ihrem Vortrag noch Zeit für weitere Fragen der Kinder und für Autogramme einplanen.

Wir freuen uns auf Ihren Vortrag und danken Ihnen für Ihr Engagement! 


\section{Sponsoren der Kinder-Uni Göttingen}

Sparkasse Göttingen

Sparkasse Duderstadt

Kreissparkasse Northeim

HNO-Facharztpraxis Eilts, Osterode

Universitätsbund Göttingen e.V.

Zeiss, Göttingen

Städt. Wohnungsbau

Dispo-Natursteine

Phywe, Göttingen

Cateringhaus Göttingen - Böning-Schaumberg

Naturkost Elkershausen

Salvatore Trattoria

Confiserie Cortés

Sartorius AG, Göttingen

KWS - Saat, Einbeck

Viani alimentari

Hugendubel

Feinbäckerei Ruch

Göttinger Sport u. Freizeit GmbH

Alfa-Druck

Fonds der Chemischen Industrie - FCI, Frankfurt

\section{Medienpartner der Kinder-Uni Göttingen}

Göttinger Tageblatt 
Sparkasse

Sparkasse Göttingen

Duderstadt

SEIT 1801

:": Cateringhaus Göttingen

\section{dispo}

UNIVERSITÄTSBUND

GÖTTINGEN E.V.

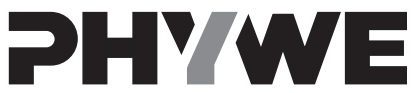

excellence in science

Elkershaulsen

Städtische Wohnungsbaü Göttingen
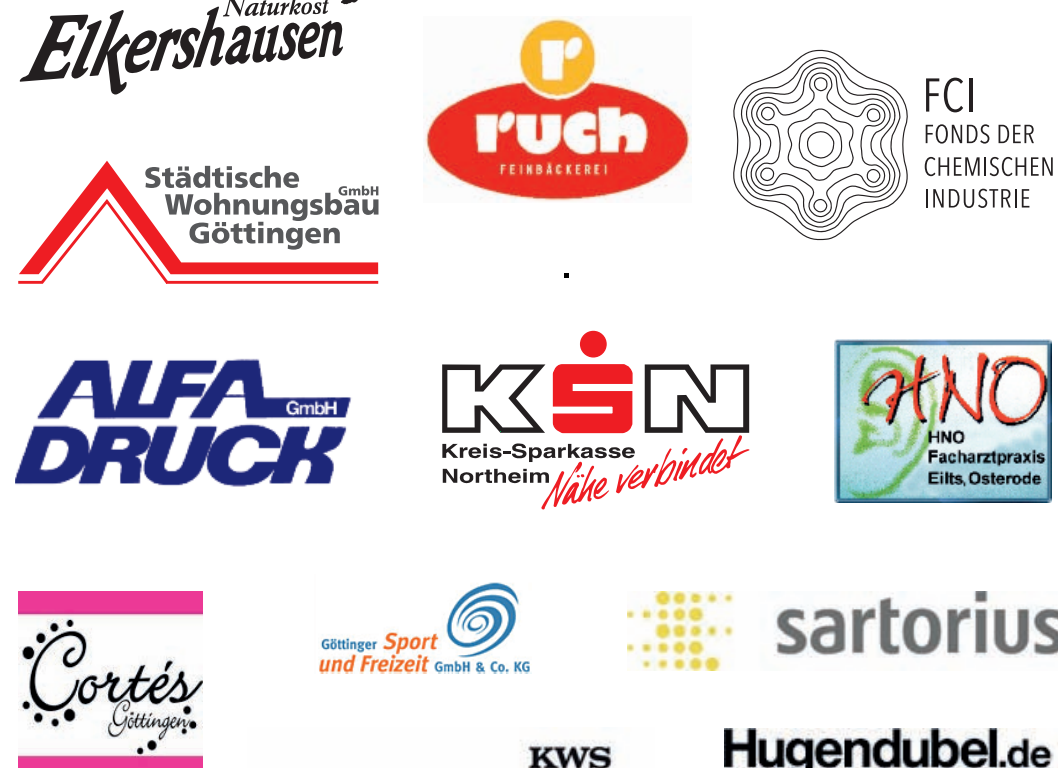

und freizeit so s co, $\mathrm{kg}$
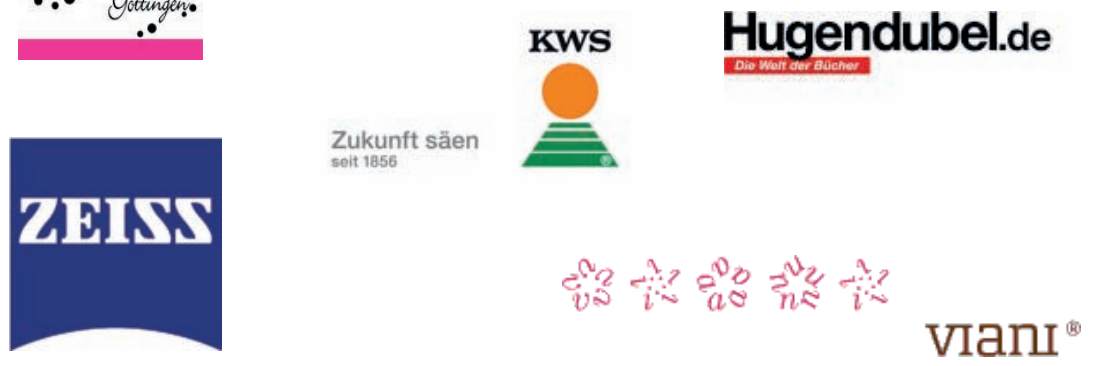

Kinder-Uni Programmplakate der letzten 10 Jahre 


\section{Neugier auf Neues}

mehr hören • mehr sehen • mehr wissen

\section{Kinder-Uni}

für Schülerinnen und Schüler der dritten bis sechsten Klasse

\section{Pädagogisches Seminar}

Eine Reise durch das Universum: Planeten - Sterne - Galaxien Mittwoch, 28. April 2004, 16.30 Uh

Prof. Dr. Wolfram Kollatschny (Fakultät für Physik/Universitäts-Sternwarte) Zentrales Hörsaalgebäude (ZHG), Platz der Göttinger Sieben 5, Hörsaal 010

Was ist leicht, geruchlos und unsichtbar, aber jedes Kind braucht es? Experimente mit Luft und seinen Bestandteilen

Mittwoch, 12. Mai 2004, 16.30 Uhr Prof. Dr. Jörg Magull (Fakultät für Chemie/Institut für Anorganische Chemie) Institut für Anorganische Chemie, Tammannstr. 4, Hörsaal I (MN 27)

Höher, weiter, schneller - Die Geheimnisse der Bewegung Mittwoch, 26. Mai 2004, 16.30 Uh Prof. Dr. Ekkehard Wilichowski (Bereich Humanmedizin/Abteilung Pädiatrie II) Zentrales Hörsaalgebäude (ZHG), Platz der Göttinger Sieben 5, Hörsaal 010

Warum funktioniert unsere Erde und was haben Vulkane damit zu tun? Mittwoch, 2. Juni 2004, 16.30 Uhr Prof. Dr. Gerhard Wörner (Geowissenschaftliches Zentrum/Abteilung Geochemie) Geographisches Institut, Goldschmidtstr. 5, Hörsaal MN 08

Geheimnisvolle Zeichen - Von den Anfängen der Schrift Mittwoch, 16. Juni 2004, 16.30 Uh Prof. Dr. Brigitte Groneberg (Philosophische Fakultät/Seminar für Keilschriftforschung) Zentrales Hörsaalgebäude (ZHG), Platz der Göttinger Sieben 5, Hörsaal 010

Die Wikinger: Seefahrer - Kaufleute - Krieger Mittwoch, 30. Juni 2004, 16.30 Uh Prof. Dr. Karl-Heinz Willroth

(Philosophische Fakultät/Seminar für Ur- und Frühgeschichte)
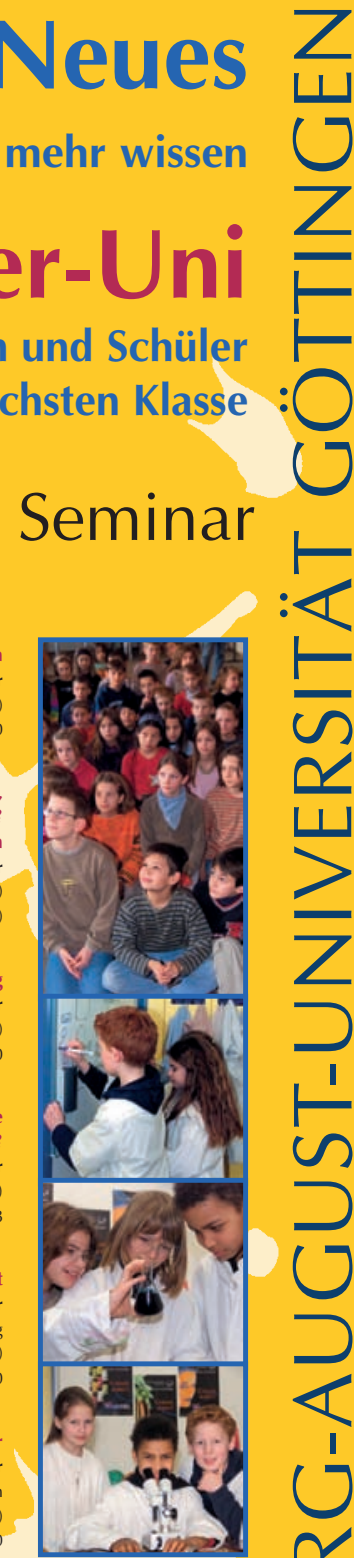

$(7$
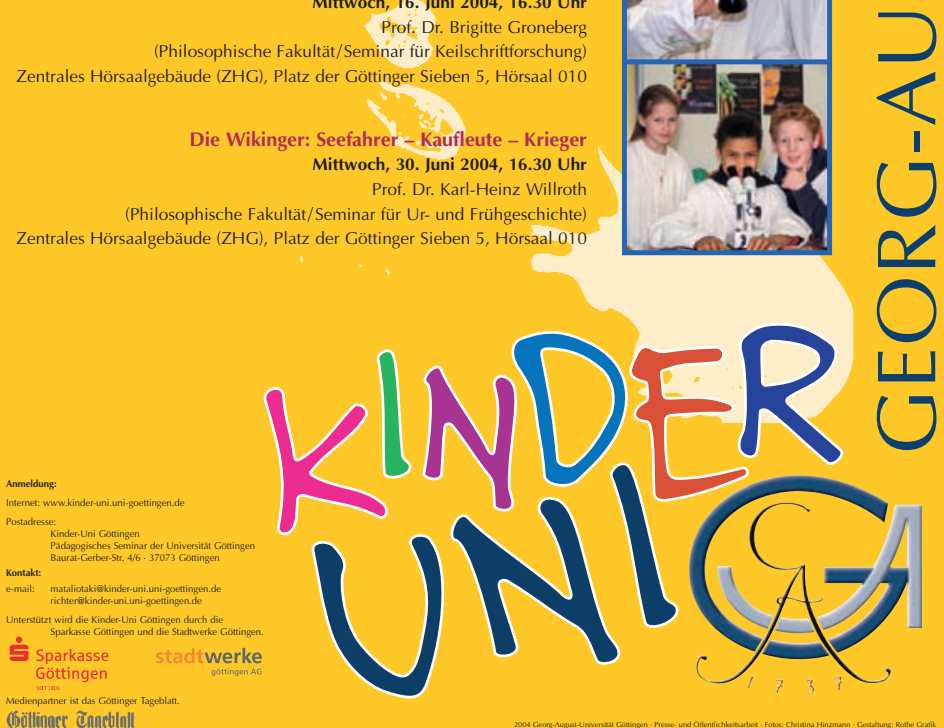


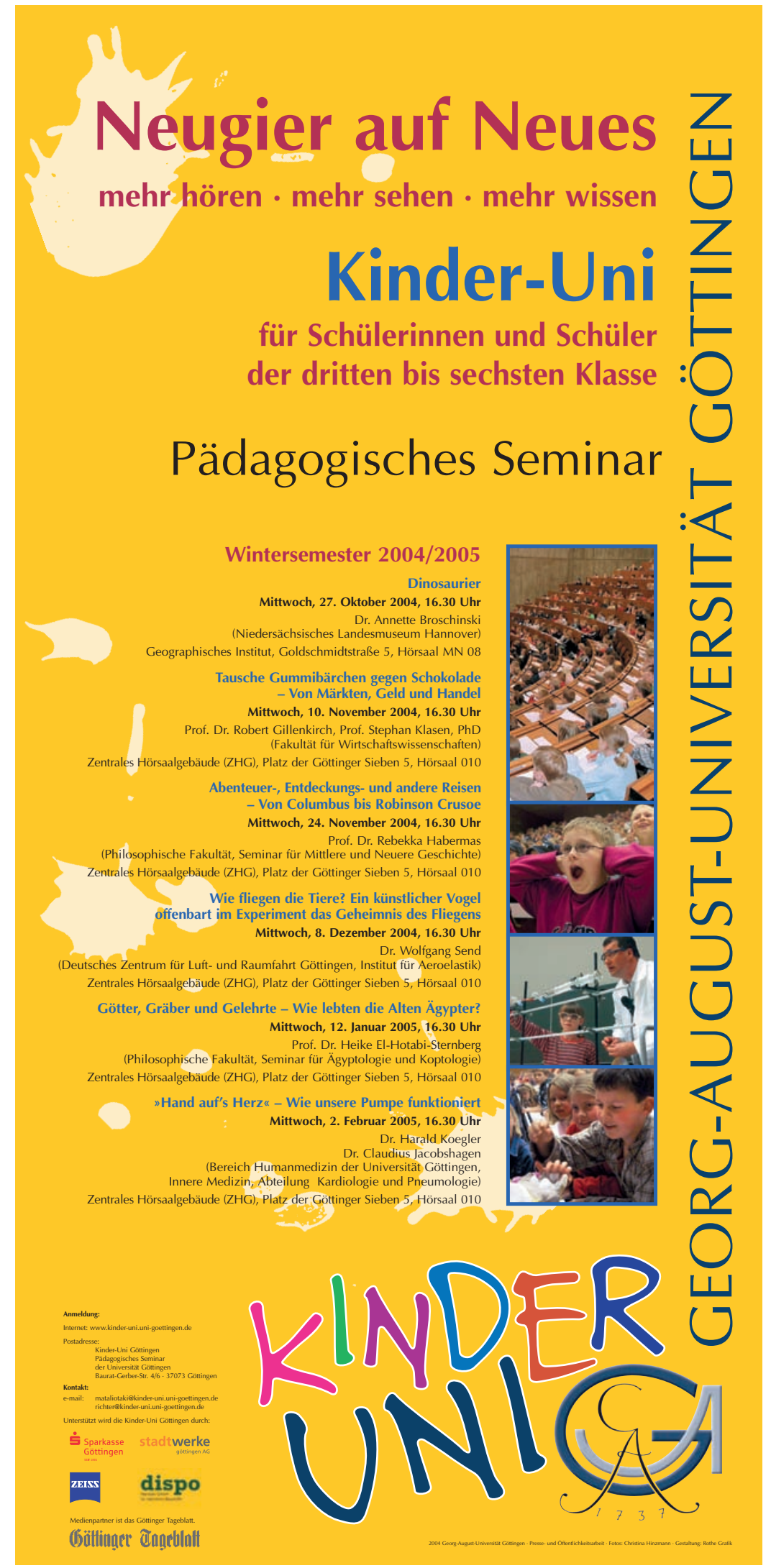




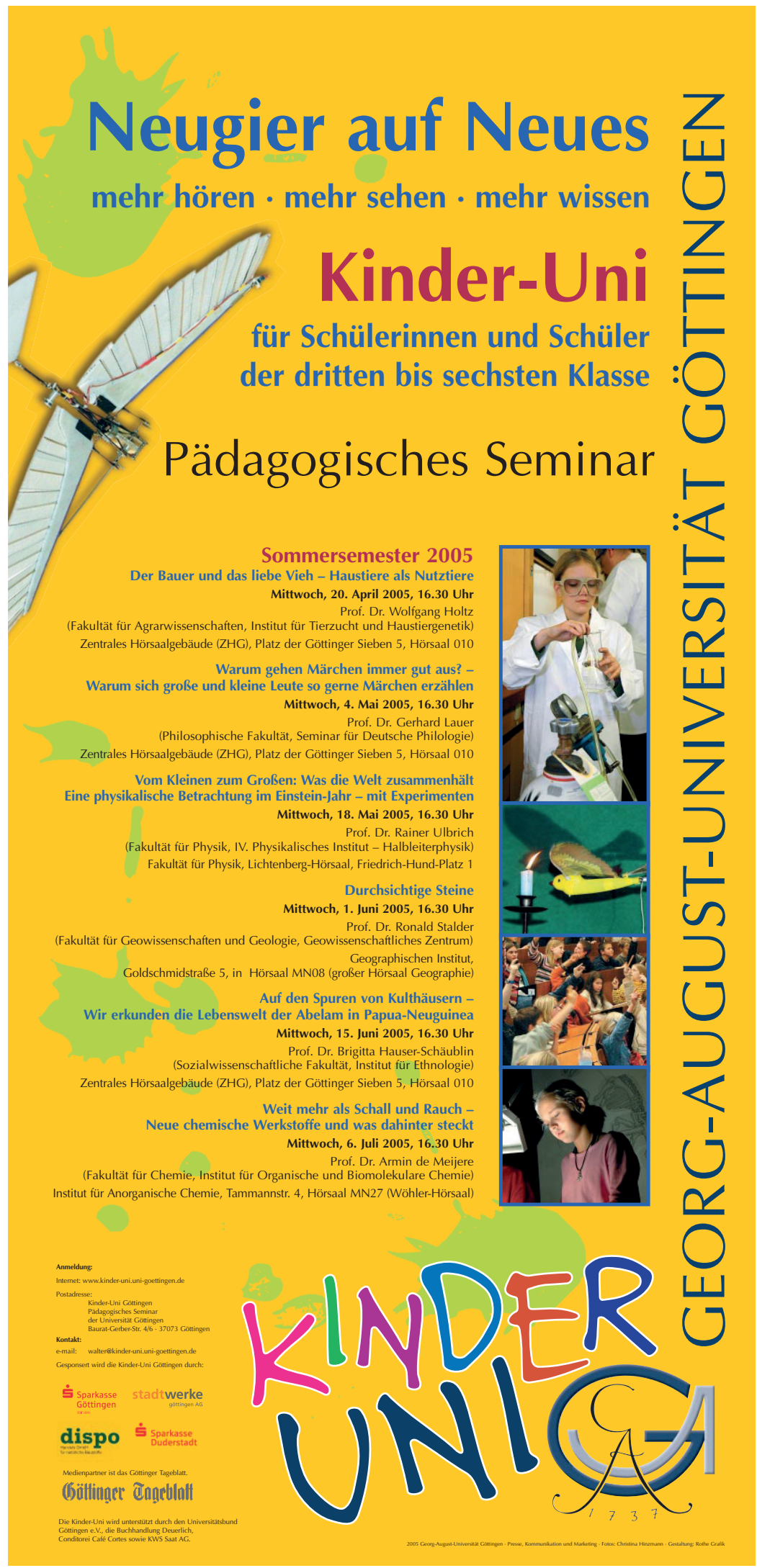




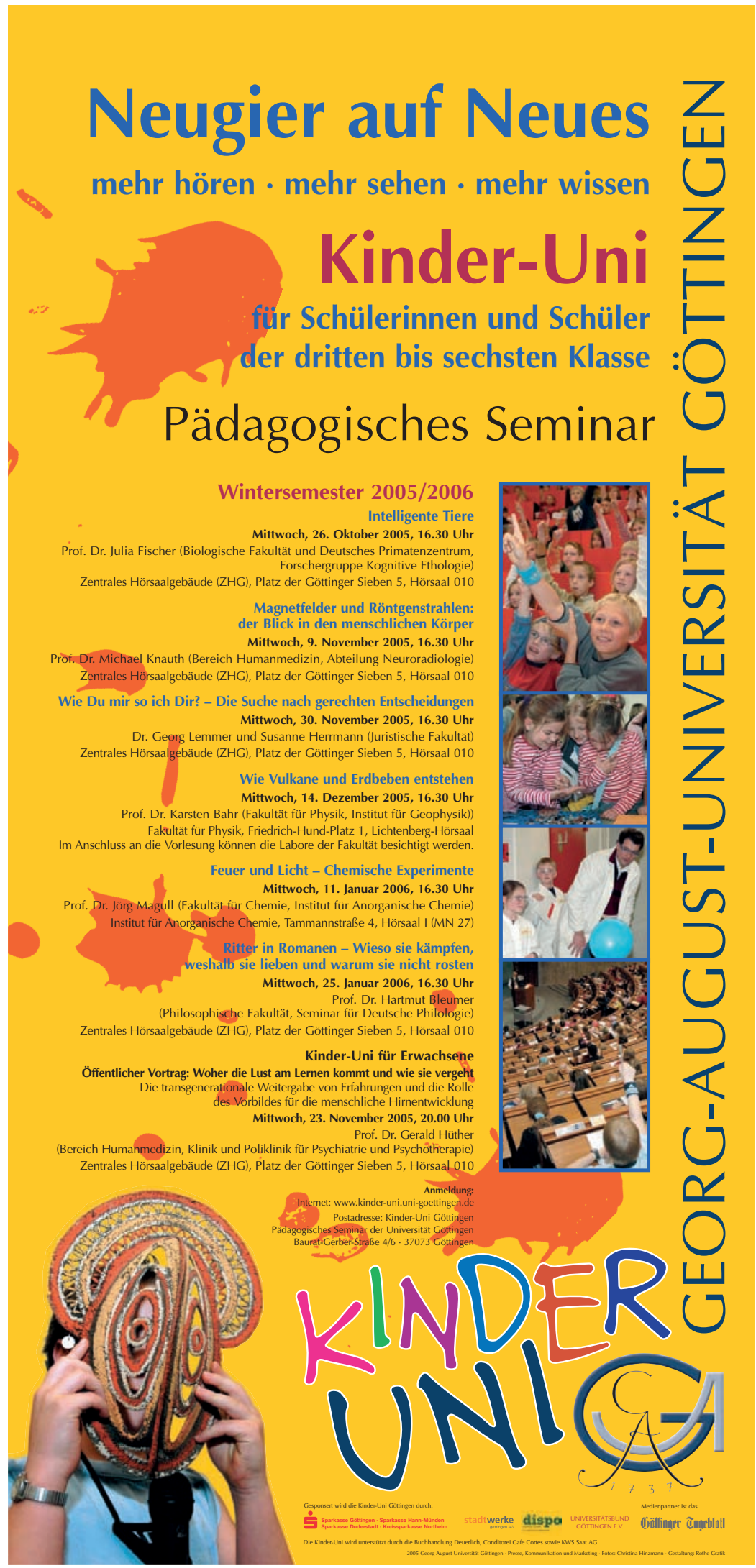




\section{Neugier auf Neues}

mehr hören · mehr sehen · mehr wissen

\section{Kinder-Uni}

Sommersemester 2006

für Schülerinnen und Schüler der dritten bis sechsten Klasse

Pädagogisches Seminar

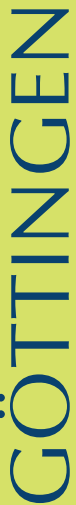

Neandertaler und Co - Stammt der Mensch vom Affen ab? Prof. Dr. Hartmut Rothe (Biologische Fakultät, Institut für Zoologie, Anthropologie

Zentrales Hörsaalgebäude (ZHG), Platz der Göttinger Sieben 5, Hörsaal 010 Prof. Dr. Herbert. W. Roesky (Fakultät für Chemie, Institut für Anorganische Chemie) Fakultät für Chemie, Tammannstraße 4, Wöhlerhörsaal (MN 27)

Wie Du mir so ich Dir? - Die Suche nach gerechten Entscheidungen Dr. Georg Lemmer und Susanne Herrmann (Juristische Fakultät)

Zentrales Hörsaalgebäude (ZHG), Platz der Göttinger Sieben 5, Hörsaal 010 Prof. Dr. Rudolf Kippenhahn
(Max-Planck-Institut für Astrophysik, Garching bei München Zentrales Hörsaalgebäude (ZHG), Platz der Göttinger Sieben 5, Hörsaal 010 Dr. Ysette Weiss-Pidstrygach, Annika Eickhoff-Schachtebeck, Robert Strich (Mathematische Fakultät, Mathematisches Institut)
Zentrales Hörsaalgebäude (ZHG), Platz der Göttinger Sieben 5, Hörsaal 010 Prof. Dr. Barbara Veit (Juristische Fakultät, Institut für Privat- und Prozessrecht) Zentrales Hörsaalgebäude (ZHG), Platz der Göttinger Sieben 5, Hörsaal 010 Akademischer Musikdirektor Ingolf Helm und das Universitätsorchester Zentrales Hörsaalgebäude (ZHG), Platz der Göttinger Sieben 5, Hörsaal 010

Sommersemester 2006

Mittwoch, 26. April 2006, 16.30 Uhr und Entwicklungsbiologie

Zauberstunde Chemische Experimente Mittwoch, 10. Mai 2006, 16.30 Uh Mittwoch, 30. November 2005, 16.30 Uh

Wie Sterne leben und sterben Mittwoch, 31. Mai 2006, $16.30 \mathrm{Uh}$

Zahlenzauber

Mittwoch, 14. Juni 2006, 16.30 Uhr

Haben Eltern immer Recht?

Mittwoch, 28. Juni 2006, 16.30 Uh

Jeder für sich und doch alle zusammen Das Universitätsorchester stellt sich vor Mittwoch, den 12. Juli 2006, 16,30 Uh

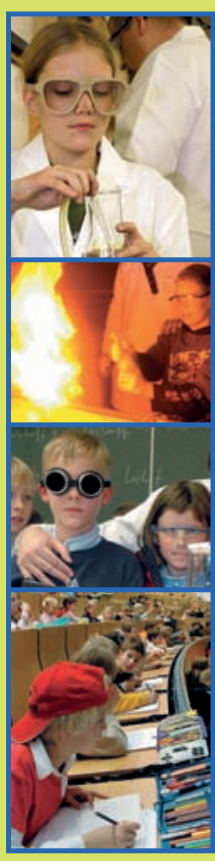

Anmeldung: Anettingen.de Internet: www.kind Postadresse: Kinder-Uni Goling Pädagogisches Seminar der Universităt Göttingen - Baura

Kinder-Uni für Erwachsene: Der Aufbau von Wissen im Kindesalter Neuere Ergebnisse aus der Psychologie und den Neurowissenschaften
Mittwoch, 21. Juni 2006, 20 Uhr Neuere Ergebnisse aus der Psychologie und den Neurowissenschaften
Mittwoch, 21. Juni 2006, 20 Uhr Prof. Dr. Elsbeth Stern (Max-Planck-Institut für Bildungsforschung, Berlin) Zentrales Hörsaalgebäude (ZHG), Platz der Göttinger Sieben 5, Hörsaal 010

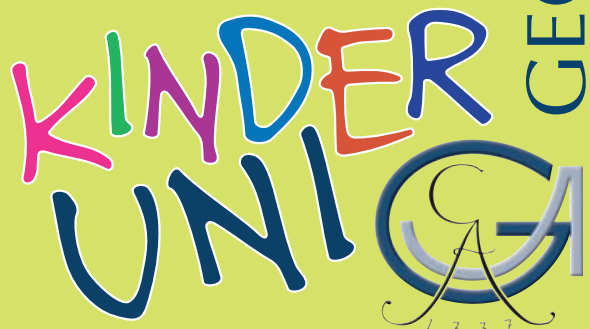




\section{Neugier auf Neues}

mehr hören · mehr sehen · mehr wissen

\section{Kinder-Uni}

für Schülerinnen und Schüler der dritten bis sechsten Klasse

Pädagogisches Seminar

Wintersemester 2006/2007
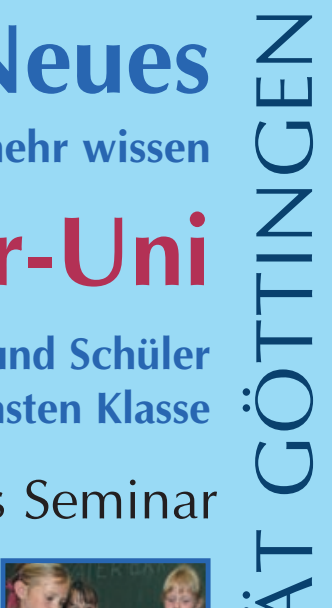

Vom Geben und Nehmen oder: Wer bezahlt die Eiswiese?

Mittwoch, 8. November 2006, 16.30 Uhr Prof. Dr. Robert Gillenkirch, Prof. Stephan Klasen, PhD

Fakultät für Wirtschaftswissenschaften

Zentrales Hörsaalgebäude (ZHG), Platz der Göttinger Sieben 5, Hörsaal 010

Wie kommt die Farbe in die Welt?

Mittwoch, 22. November 2006, 16.30 Uh Prof. Dr. Susanne Schneider, Fakultät für Physik - IV. Physikalisches Institut Fakultät für Physik, Friedrich-Hund-Platz 1, Lichtenberg-Hörsaal

Können wir unseren Augen trauen? Mittwoch, 6. Dezember 2006, 16.30 Uhr Prof. Dr. Stefan Treue · Deutsches Primatenzentrum,
Zentrales Hörsaalgebäude (ZHG), Platz der Göttinger Sieben 5, Hörsaal 010

Wir haben doch kein Stroh im Kopf ...

Eine Entdeckungsreise in die Wunderwelt unseres Gehirns

Mittwoch, 13. Dezember 2006, 16.30 Uhr

Prof. Dr. Gerald Hüther - Medizinische Fakultät

Zentrales Hörsaalgebäude (ZHG), Platz der Göttinger Sieben 5, Hörsaal 010

Feuer und Luft - Chemische Experimente Mittwoch, 17. Januar 2007, 16.30 Uhr

Prof. Dr. Jörg Magull, Fakultät für Chemie, Institut für Anorganische Chemie Institut für Anorganische Chemie, Tammannstr. 4, Hörsaal I (MN 27)

Haftstrafe für Eisbären - oder welche Rechte haben Tiere? Mittwoch, den 31. Januar 2007, 16.30 Uhr
Dr. Georg Lemmer und Susanne Herrmann, Juristische Fakultät

Zentrales Hörsaalgebäude (ZHG), Platz der Göttinger Sieben 5, Hörsaal 010

Kinder informieren Kinder · Jungstudenten der Kinder-Uni berichten in Kurzvorträgen über spannende Themen Mittwoch, 14. Februar 2007, 16.30 Uh Mutige melden sich unter: www.kinder-uni.uni-goettingen de mit ihrem Them

Zentrales Hörsaalgebäude (ZHG), Platz der Göttinger Sieben 5, Hörsaal 010

Anmeldung:

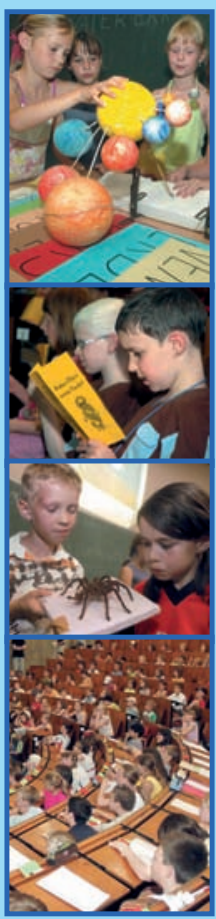

Pădagogisches Semnet: Wher Universit̆t Cötingen - Baurat-Gerber-Straße 4/6 -37073 Göttingen

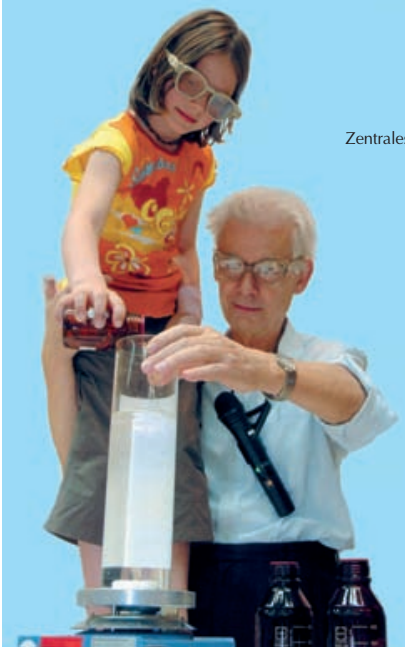

Kinder-Uni für Erwachsene: Lehirnen von Schülern?
Lim Kindesalte Lernen im Kindesalter

Donnerstag, 16. November 2006, 20 Uhr Prof. Dr. Annette Scheunpflug, Erziehungswissenschaftliche Fakultät Zentrales Hörsaalgebäude (ZHG), Platz der Göttinger Sieben 5, Hörsaal 011
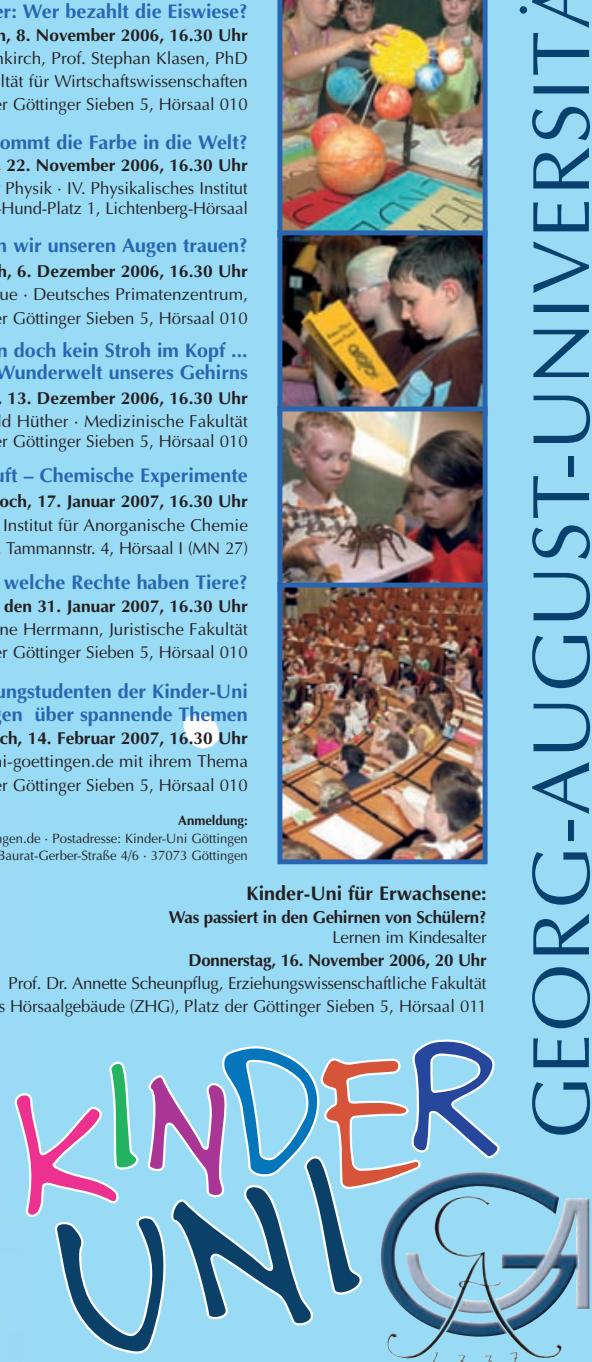

I

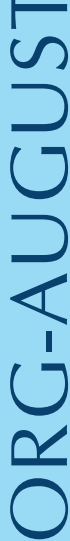

प

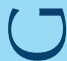

stadtwerke $\dot{5}=$

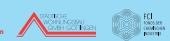

dispo

distillinger Tingrblat 


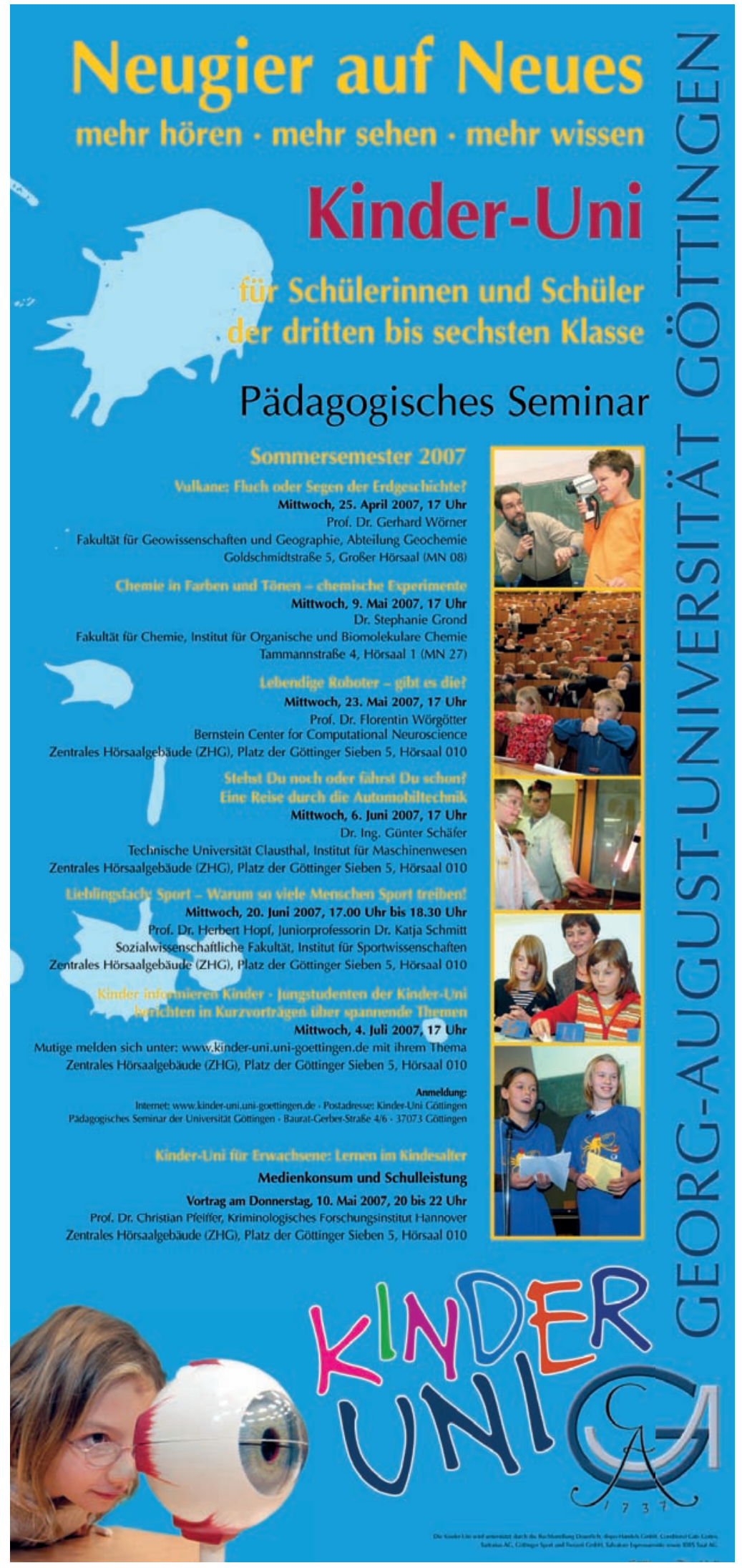




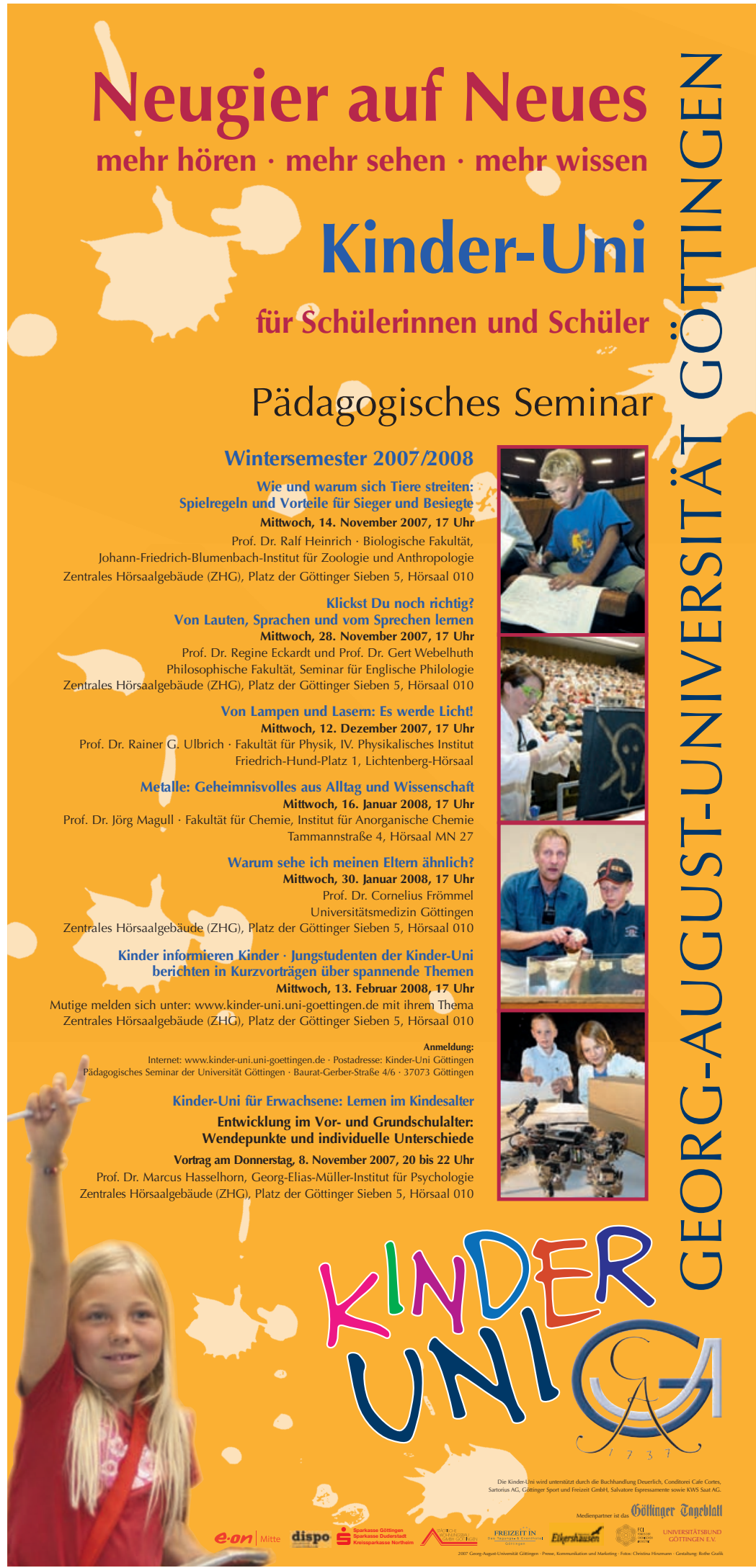




\section{Neugier auf Neues}

mehr hören · mehr sehen - mehr wissen

\section{Kinder-Uni}

für Schülerinnen und Schüler der dritten bis sechsten Klasse

Wintersemester 2008/2009

Reimen, dichten, fabulieren - Wie Gedichte entstehen

Mittwoch, 5. November 2008, 17 Ur

Prof. Dr. Heinnich Detering
Philosophische Fakultat, Seminar für Deutsche Philologie

Das grö́tte Săugetier der Welt - D

Biologische Fakultat - Johnann-Friedrich-Blumenbach-Institu

Wir machen Wind - Ein Experimentalvortn

uber die Grundlagen des Fliegens

Dr. Wolligang Send. Deeusches Zentrum für Luit und Raumfiaht IDLR, Götingen

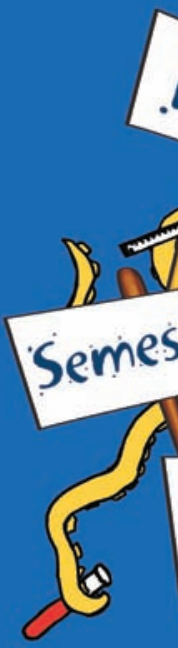<smiles></smiles><smiles>B</smiles>
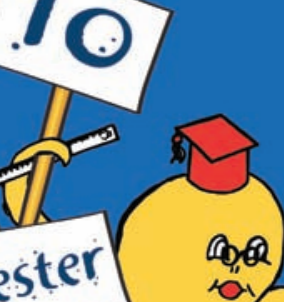

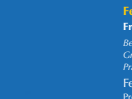

Kartofiéln im Magen - Wissenswertes über Köper, Kreisluf stuffwechsed Mittwoch, 14. lanuar 2009, 17 Uhr

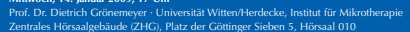
Erde, Feuer, Wasser, Luft und andere Elemente - Chemische Experimen Mittwoch, 28. lanuar 2009, 17 Uhr
Prot. Dr. Dietrar Stalke. Fakultat fur Chemie, Institut fir Anorganische Chemie Tammannstrale 4, Hörsal MN 27 Kinder informieren Kinder - KiK
Jungstudierende halten Kurvorträge zu spannenden Themenn

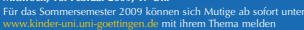

Kinder-Uni für Enwachsene

Wir wollen keine Couch-Potatoes
Gesundheitsunterricht mit dem kleinen Medicus

Vortag am Mittwoch, 14. Januar 2009, $20 \mathrm{Uhr}$

Prot. Dr. Dietrich Gronemeyer Universitat Witten/Herdecke, Institut für Mikrotherapie

Fistveranstaltung: Zehn Semester Kinder-Uni

ag, 6. Februar 2009, 17 bis 19 Uhr, Withelmsplatz 1, Aula

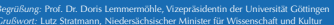
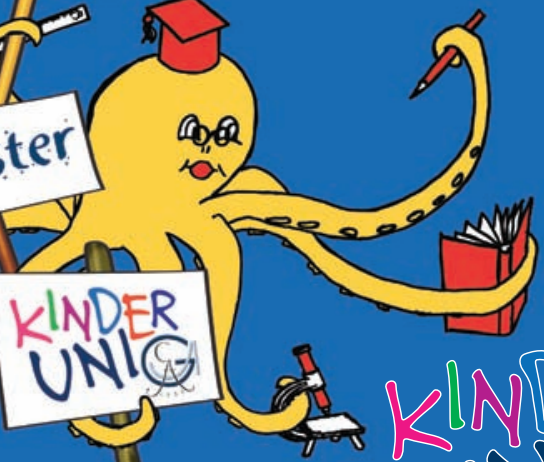

www.kinder-uni.uni-goettingen.de
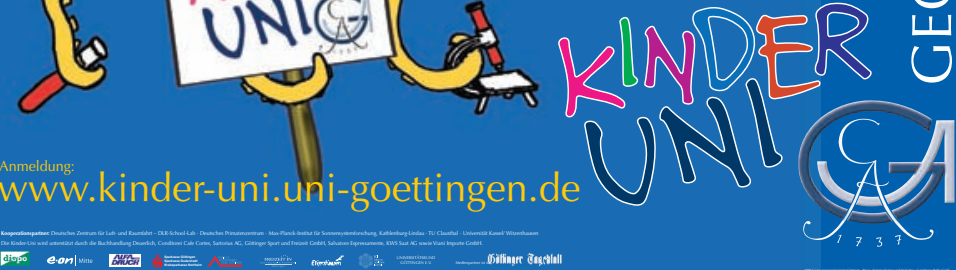


\section{Neugier auf Neues mehr hören · mehr sehen · mehr wissen

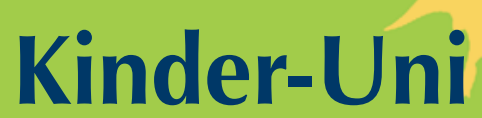

für Schülerinnen und Schüler der dritten bis sechsten Klasse

Pädagogisches Seminar

Sommersemester 2009

Wer die Wahl hat, hat die Qual Wie wird man Bundeskanzlerin oder Bundeskanzler? Mittwoch, 22. April 2009, 17 Uhr

Prof. Dr. Thomas Mann - Juristische Fakultät, Institut für Öffentliches Recht Zentrales Hörsaalgebäude (ZHG), Platz der Göttinger Sieben 5, Hörsaal 010

Gibt es schwarze Löcher im Universum? Mittwoch, 6. Mai 2009, 17 Uh

Prof. Dr. Wolfram Kollatschny · Fakultät für Physik, Institut für Astrophysik Zentrales Hörsaalgebäude (ZHG), Platz der Göttinger Sieben 5, Hörsaal 010

In der Werkstatt wilder Schimpansen. Primatenforschung in Afrika Mittwoch, 20. Mai 2009, 17.00 Uhr Prof. Dr. Volker Sommer - University College London, Institut für Anthropologie Zentrales Hörsaalgebäude (ZHG), Platz der Göttinger Sieben 5, Hörsaal 010 Römer, Germanen und die Varusschlacht vor 2000 Jahren Mittwoch, 3. Juni 2009, 17 Uhr Dr. Birgit Großkopf, Biologische Fakultät

Johann-Friedrich-Blumenbach-Institut für Zoologie und Anthropologie Dr. Klaus Grote, Kreisarchäologe, Untere Denkmalschutzbehörde, Göttingen Zentrales Hörsaalgebäude (ZHG), Platz der Göttinger Sieben 5, Hörsaal 010

Zauberhafte Physik - Von schwebenden Schiffen und rauchenden Ringen Mittwoch, 17. Juni 2009, 16.30 und 18 Uh
Prof. Dr. Arnulf Quadt . Fakultät für Physik, II. Physikalisches Institut Fakultät für Physik, Friedrich-Hund-Platz 1, Lichtenberg-Hörsaal

Kinder informieren Kinder · Jungstudenten der Kinder-Uni berichten in Kurzvorträgen über spannende Themen Mittwoch, 24. Juni 2009, $17 \mathrm{Uhr}$ Mutige melden sich unter: kik@kinder-uni.uni-goettingen.de mit ihrem Thema Zentrales Hörsaalgebäude (ZHG), Platz der Göttinger Sieben 5, Hörsaal 010 Anmeldun Anmeldun Pädagogisches Seminar der Universität Göttingen · Baurat-Gerber-Straße 4/6 · 37073 Göttingen Kinder-Uni für Erwachsene Lernen im Kindesalter - Eltern, Kita, Schule: Partner für erfolgreiche Bildung

Vortrag am Freitag 8. Mai 2009, 20 Uhr Prof. Dr. Karl Neumann. TU Braunschweig - Institut für Erziehungswissenschaft Zentrales Hörsaalgebäude (ZHG), Platz der Göttinger Sieben 5, Hörsaal 010 Der kultivierte Schimpanse. Wie Tiere Traditionen pflegen Vortrag am Mittwoch, 20. Mai 2009, 20 Uhr Prof. Dr. Volker Sommer · University College London, Institut für Anthropologie Wilhelmsplatz 1, Aula
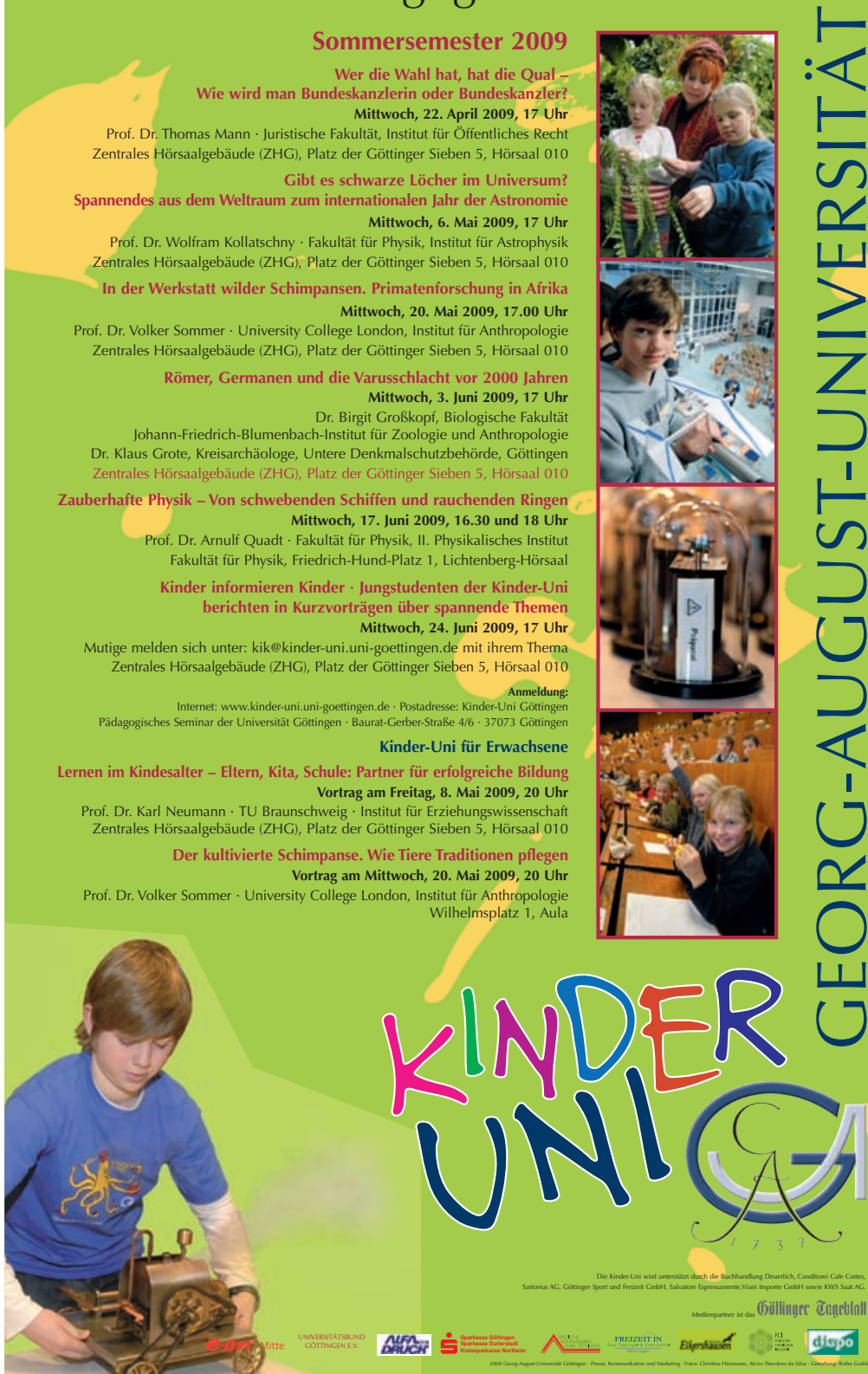


\section{Neugier auf Neues}

mehr hören · mehr sehen · mehr wissen

\section{Kinder-Uni}

für Schülerinnen und Schüler der dritten bis sechsten Klasse

\section{Pädagogisches Seminar}

Wintersemester 2009/2010

Urlaub bei den Dinos - Eine Zeitreise in das tropische Niedersachsen von vor 140 Millionen Jahren Mittwoch, 28. Oktober 2009, 17 Uh Dr. Annette Richter - Niedersächsisches Landesmuseum Hannove Zentrales Hörsaalgebäude (ZHG), Platz der Göttinger Sieben 5, Hörsaal 010

Verdienen und Verteilen - Geht es im Wirtschaftsleben fair zu? Mittwoch, 11. November 2009, 17 Uh Prof. Stephan Klasen, PhD . Prof. Dr. Claudia Keser Wirtschaftswissenschaftliche Fakultät Zentrales Hörsaalgebäude (ZHG), Platz der Göttinger Sieben 5, Hörsaal 010

Bei den Affen zu Hause - Geschichten aus dem Dschungel Mittwoch, 25. November 2009, $17 \mathrm{Uhr}$ Prof. Dr. Julia Ostner . Dr. Oliver Schülke Courant Forschungszentrum »Evolution des Sozialverhaltens Zentrales Hörsaalgebäude (ZHG), Platz der Göttinger Sieben 5, Hörsaal 010

Wie kaufe ich mir einen Fußballspieler? Moderne Menschenhandel und was unsere Rechtsordnung dazu sagt Mittwoch , 9. Dezember 2009, 17 Uh Dr. Georg Lemmer - Juristische Fakultät Dr. Klaus Grote, Kreisarchäologe, Untere Denkmalschutzbehörde, Göttingen Zentrales Hörsaalgebäude (ZHG), Platz der Göttinger Sieben 5, Hörsaal 010

Feuer, Luft, Wasser, Erde - Chemische Experimente Mittwoch, 13. Januar 2010, 17.00 Uhr Prof. Dr. Dietmar Stalke · Fakultät für Chemie Fakultät für Chemie, Tammannstraße 4, Hörsaal 1 (MN 27)

Kinder informieren Kinder · Jungstudenten der Kinder-Uni halten Kurzvorträge zu spannenden Themen Mittwoch, 27. Januar 2010, 17 Uh

Für das Sommersemester 2010 können sich Mutige sofort unter: kik@kinder-uni.uni-goettingen.de mit ihrem Thema melden. Zentrales Hörsaalgebäude (ZHG), Platz der Göttinger Sieben 5, Hörsaal 010

Anmeldung.

Internet: www.kinder--uni. uni-goettingen de - Postadresse: Kinder-Uni Göttinge Pädagogisches Seminar der Universität Göttingen · Baurat-Gerber-Straße 4/6 · 37073 Göttinge

Kinder-Uni für Erwachsene Hochbegabte Kinder - Phänomen, Mensche und Möglichkeiten für Förderung in Elternhaus und Schule Freitag, 6. November 2009, 20 Uh Prof. Dr. Franzis Preckel Universität Trier, Lehrstuhl für Hochbegabtenforschung und -förderun

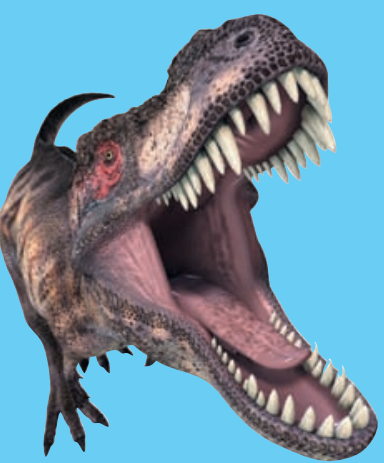
Wilhelmsplatz 1, Aula
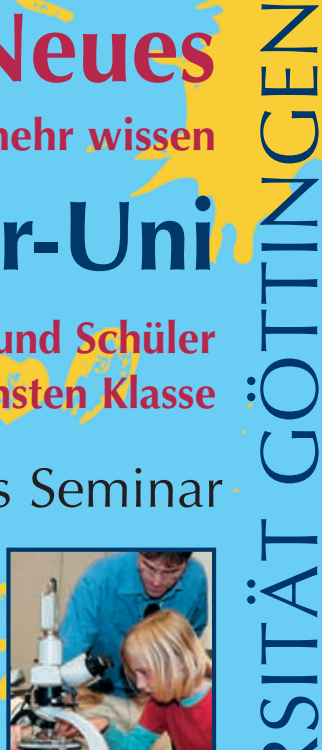

$\vdash$

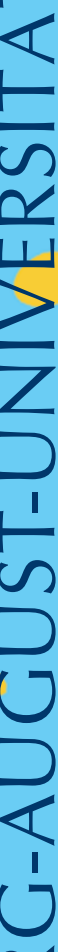

I
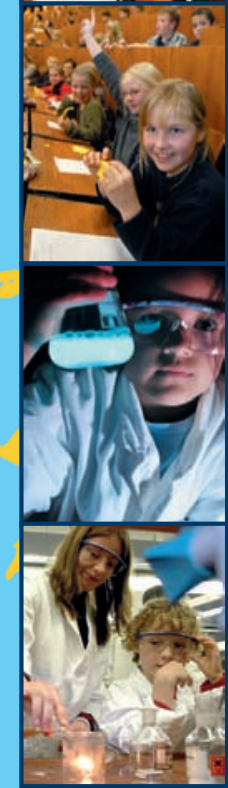

*

I-

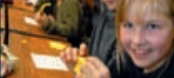

and

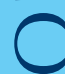

பு

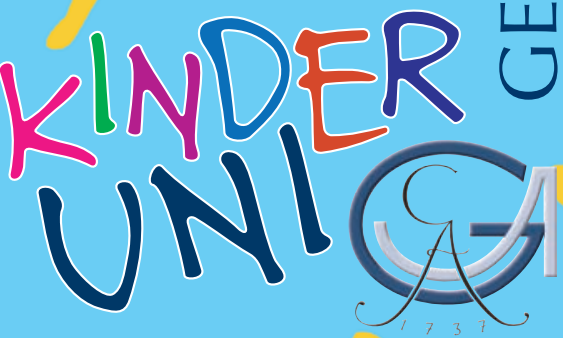




\section{Neugier auf Neues}

mehr hören · mehr sehen · mehr wissen

\section{Pädagogisches Seminar}

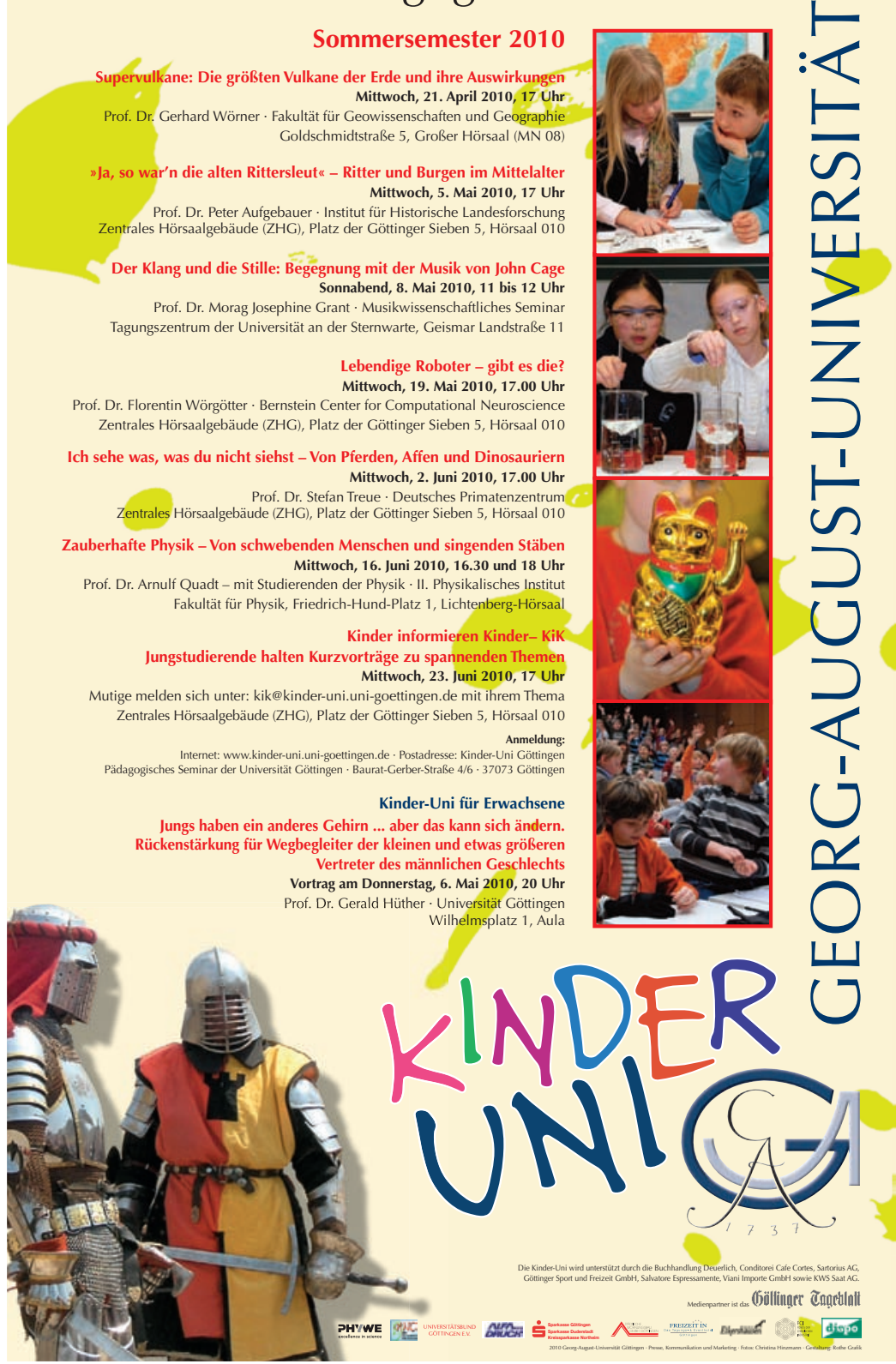




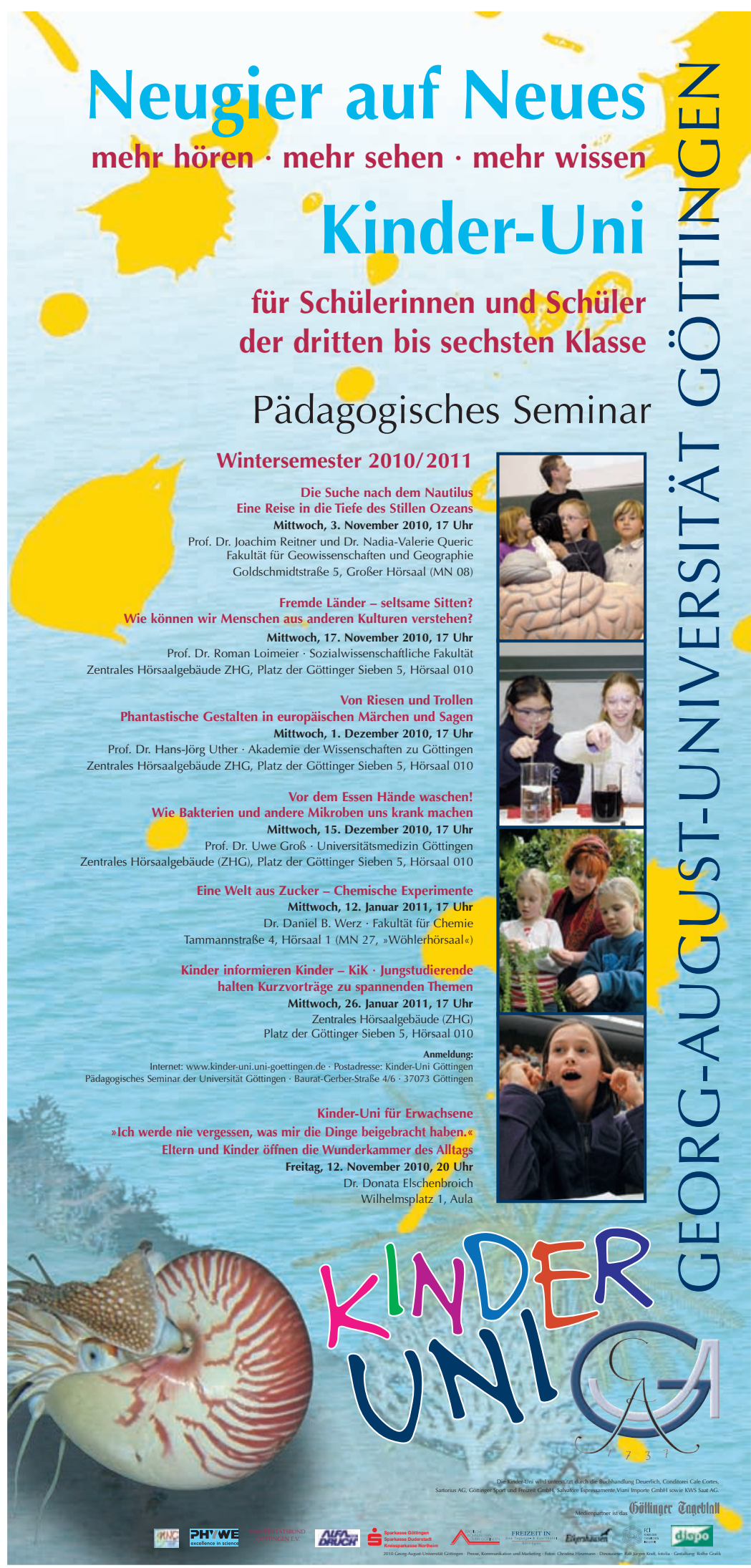




\section{Neugier auf Neues}

Z

mehr hören · mehr sehen - mehr wissen

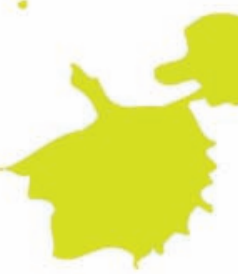

\section{Kinder-Uni}

für Schüllerinnen und Schüler der dritten bis sechsten Klasse

\section{Pädagogisches Seminar}

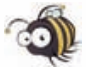

Sommersemester 2011

Schau mal genau hin: Die geheimnisvolle Welt der Insekten Mittwoch, 4. Mai 2011, 17 Uh Prof. Dr. André Fiala, Biologische Fakultät,

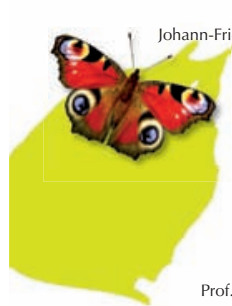

bach-Institut für Zoologie und Anthropologie

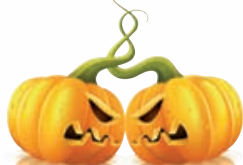
Mittwoch, 25. Mai 2011, 17 Uhr
auer mit den Schauspielern Christoph Huber

Der Kampf zwischen Horus und Seth ein ägyptischer Mythos für Kinder Mittwoch, 18. Mai 2011, $17 \mathrm{Uhr}$ Dr. Janne Arp, Dorothea Drischel · Philosophische Fakultät ZHG, Platz der Göttinger Sieben 5, Hörsaal 010

Warum wollen wir alles wissen? Geister, Teufel und Goethes Faust und Stefan Dehler ("stille hunde»), Philosophische Fakultät

ZHG, Platz der Göttinger Sieben 5, Hörsaal 010

Warum streiten Menschen sich .. ... und dies häufig auch in Israel und Palästina? Mittwoch, 8. Juni 2011, 17 Uhr Dr. Nicole Witte - Sozialwissenschaftliche Fakultät ZHG, Platz der Göttinger Sieben 5, Hörsaal 010

Physik-Schau »Zauberhafte Physik« - Physikalische Experimente Mittwoch, 22, Juni 2011, 17 Uhr Mittwoch, 22. Juni 2011, 17 Uhr Prof. Dr. Arnulf Quadt mit Studierenden der Physik
Fakultät für Physik, Friedrich-Hund-Platz 1, Lichtenberg-Hörsaal

Kinder informieren Kinder - KiK Jungstudierende halten Kurzvorträge zu spannenden Themen Mittwoch, 29. Juni 2011, $17 \mathrm{Uhr}$ ZHG, Platz der Göttinger Sieben 5, Hörsaal 010 Anmeldung: Internet: www.kinder-uni.uni-goettingen.de
dagogisches Seminar der Universität Göttingen Postadresse: Kinder-Uni Göttingen - Pädagogisches Seminar der Universitat Gottingen

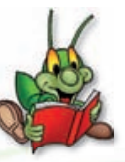

Kinder-Uni für Erwachsene ... Lernen im Kindesalter Wie unterscheiden sich Kinder in ihrem Lernvermögen? Phänomene, Ursachen und Diagnosemöglichkeiten Freitag, 20. Mai 2011, 20 Uh Freitag, 20. Mai 2011, 20 Uhr
Prof. Dr. Marcus Hasselhorn (Frankfurt/M.) Deutsches Institut für Internationale Pädagogische Forschung
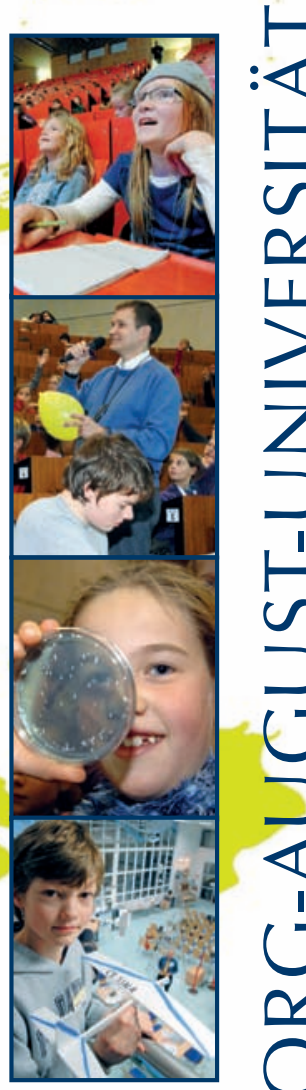
E 0

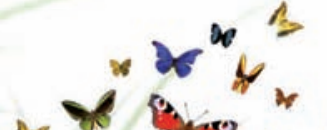

Wilhelmsplatz 1, Aula

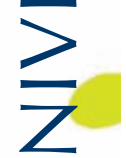

. 
Neugier auf Neues mehr hören · mehr sehen - mehr wissen

\section{Kinder-Uni}

für Schülerinnen und Schüler der dritten bis sechsten Klasse

\section{Pädagogisches Seminar}

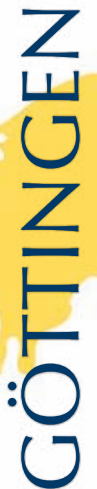

Wintersemester 2011/2012

Abenteuer Urwald - im Jahr der Wälder 2011

Mittwoch, 9. November 2011, $17 \mathrm{Uhr}$

Prof. Dr. Achim Dohrenbusch . Fakultät für

Forstwissenschaften und Waldökologie, Burckhardt-Institut

ZHG, Platz der Göttinger Sieben 5, Hörsaal 010

Bitte einsteigen - eine Reise mit dem Chemie-

Express um die Welt - Chemische Experimente Mittwoch, 23. November 2011, $17 \mathrm{Uhr}$ Prof. Dr. Thomas Waitz

Fakultät für Chemie, Institut für Anorganische Chemie

Tammannstraße 4, Hörsaal 1 (MN 27), "Wöhlerhörsaal ".

Bunte Götter - Griechische Statuen, farbig rekonstruiert

Mittwoch, 7. Dezember 2011, $17 \mathrm{Uhr}$

Prof. Dr. Johannes Bergemann

Philosophische Fakultät, Archäologisches Institut ZHG, Platz der Göttinger Sieben 5, Hörsaal 010

Sonnenenergie - vom Solarkocher über den Sonnenkollektor zum Wasserstoffauto Physikalische Experimente Mittwoch, 11, Januar 2012, $17 \mathrm{Uhr}$ Prof. Dr. Christian Jooß
Fakultät für Physik, Institut für Materialphysik Friedrich-Hund-Platz 1, Lichtenberg-Hörsaal

Eine Reise zu den Planeten Mittwoch, 25. Januar 2012, $17 \mathrm{Uhr}$ Prof. Dr. Ulrich Christensen - Max-Planck-Institut für

Sonnensystemforschung $\cdot$ Katlenburg-Lindau

ZHG, Platz der Göttinger Sieben 5, Hörsaal 010

Kinder informieren Kinder - KiK · Jungstudierende

halten Kurzvorträge zu spannenden Themen Mittwoch, 7. Februar 2012, $17 \mathrm{Uhr}$

ZHG, Platz der Göttinger Sieben 5, Hörsaal 010

Anmeldung:

ini-goettingen.de · Postadresse: Kinder-Uni Göttingen

Pädagogisches Seminar der Universitat Gottingen

Kinder-Uni für Erwachsene Pubertäres Durcheinander im Frontalhirn und wie es sich besser ertragen lässt...

Donnerstag, 16. Februar 2012, $20 \mathrm{Uhr}$ Prof, Dr. Gerald Hüther - Universitätsmedizin Göttingen

Neurobiologische Präventionsforschung

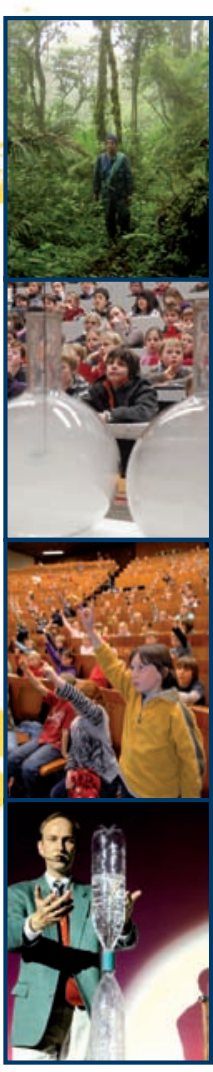

$\vdash$

$:<$

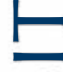

n

$\alpha$

山

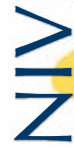

$\frac{1}{0}$

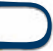

$\checkmark$

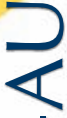

1

$\circlearrowleft$

$\alpha$

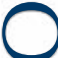
Aula am Wilhelmsplatz
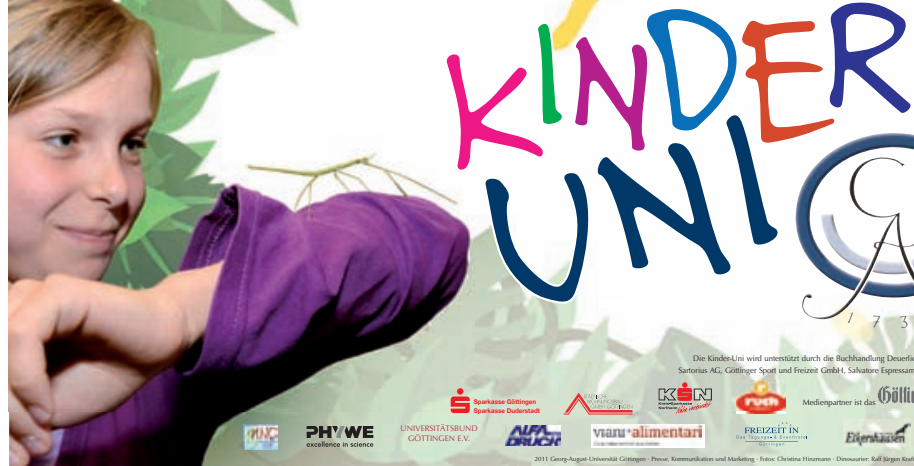


\section{Neugier auf Neues}

mehr hören . mehr sehen . mehr wissen

\section{Kinder-Uni}

fürr Schülerinnen und Schưller der drittien bis sechsten Klasse

Pädagogisches Seminar

Sommersemester 2012

Dinosaurier - Fakten und Fantasien Spannendes aus der Dinosaurierforschung Mittwoch, 25. April 2012, 17 Uhr Torsten van der Lubber $\cdot \mathrm{Ni}^{2}$ ZHG, Platz der Göttinger Sieben 5, Hörsaal 010

Die Universität, der Oberbürgermeister und das Ende der Jubiläumsfeierlichkeiten Mittwoch, 9. Mai 2012, 17 Uhr Mittwoch, 9. Mai 2012, 17 Uhr Dr. Georg Lemmer · Juristische Fakultät mit Schauspielern des Deutschen Theaters
atz der Göttinger Sieben 5, Hörsaal 010 ZHG, Platz der Göttinger Sieben 5, Hörsaal 010

Umarmung im Urwald: Von Freundschaft unter Tieren Mittwoch, 23. Mai 2012, $17 \mathrm{Uhr}$ Prof. Dr Julia Ostner und Dr. Oliver Schülke Prof. Dr. Julia Ostner und Dr. Oliver Schulke ZHG, Platz der Göttinger Sieben 5, Hörsaal 010

Die ganze Welt auf einer Bühne. 275 Wie ein Theater von innen funktioniert. Mittwoch, 6. Juni 2012, 17 Uhr Prof. Dr. Ge hard Lauer Philosophische Fakulb̈i, Mark Zurmühe Intendant, Joachim von Burchard junges schauspiel (DT) mit Schaspiele Deutsches Theater, Theaterpla 11, Groper Sal

Physik-Show - Zauberhafte Physik 275 Mit Experimenten von Georg-Christoph-Lichtenberg

Mittwoch, 20. Juni 2012, 15.30 Uhr und 17 Uhr Prof. Dr. Arnulf Quadt · Fakultät für Physik mit Studierenden des II. Physikalischen Instituts Fakultät für Physik, Friedrich-Hund-Platz 1, Lichtenberg-Hörsaal

Kinder informieren Kinder - KiK · Jungstudierende halten Kurzvorträge zu spannenden Themen Mittwoch, 11. Juli 2012, 17 Uh ZHG, Platz der Göttinger Sieben 5, Hörsaal 010 Anmeldung:

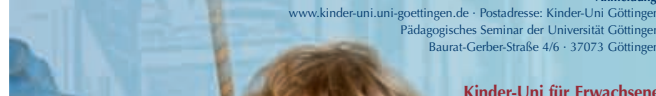
, Kinder-Uni für Erwachsen
Die Bedeutung der Emotione
für eine gelingende Entwicklun Donnerstag, 12. Juli 2012, 20 Uh Dr. Karl Gebauer - Göttingen Aula am Wilhelmsplatz

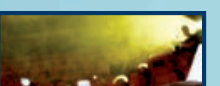

3

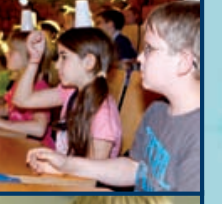

$:<$

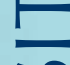

准

$\alpha$

님

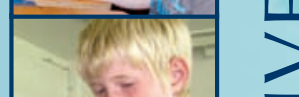

(1)
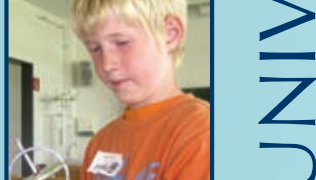

t. 2

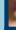

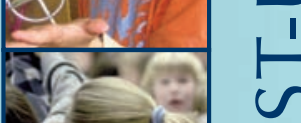

I

ก

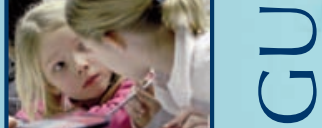

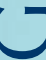

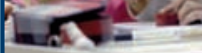

-

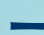

4

I

$(7$

$\alpha$

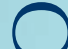

(4)

니
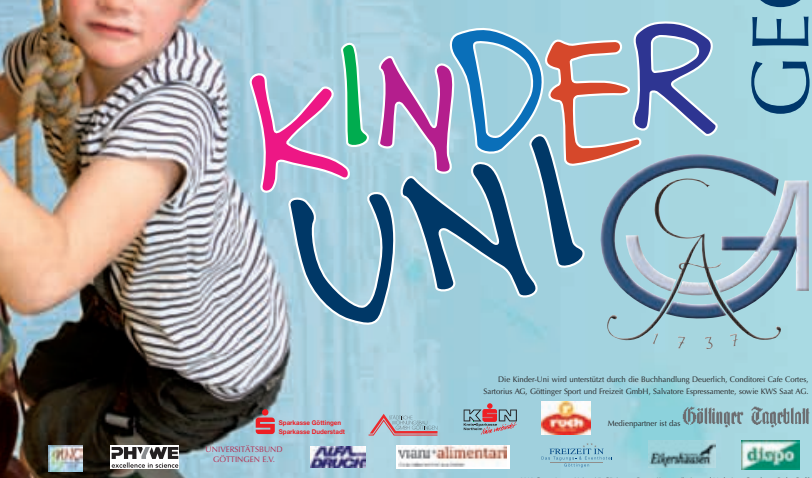

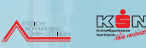

m

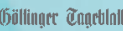
Eimantase diopo 


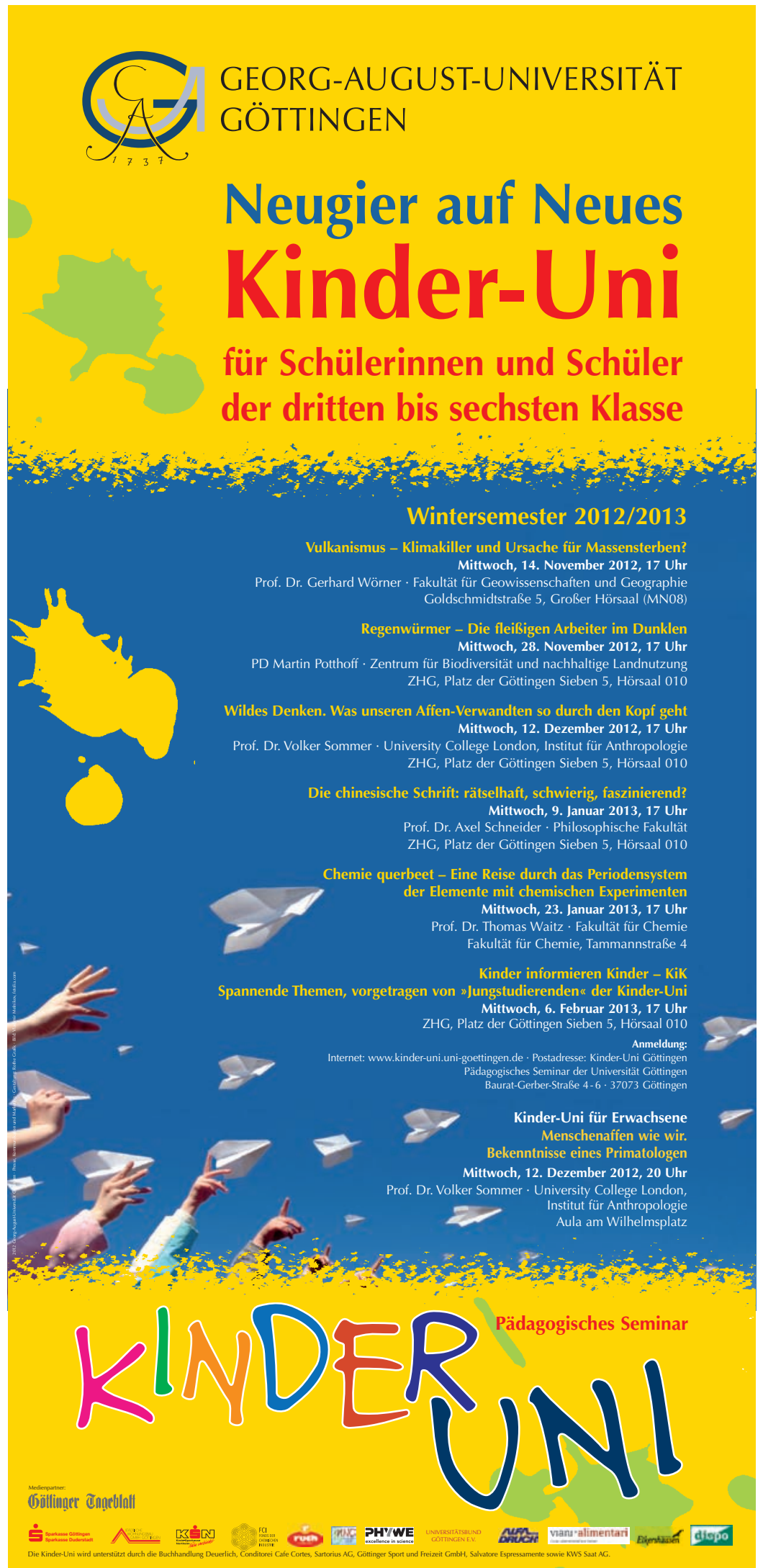




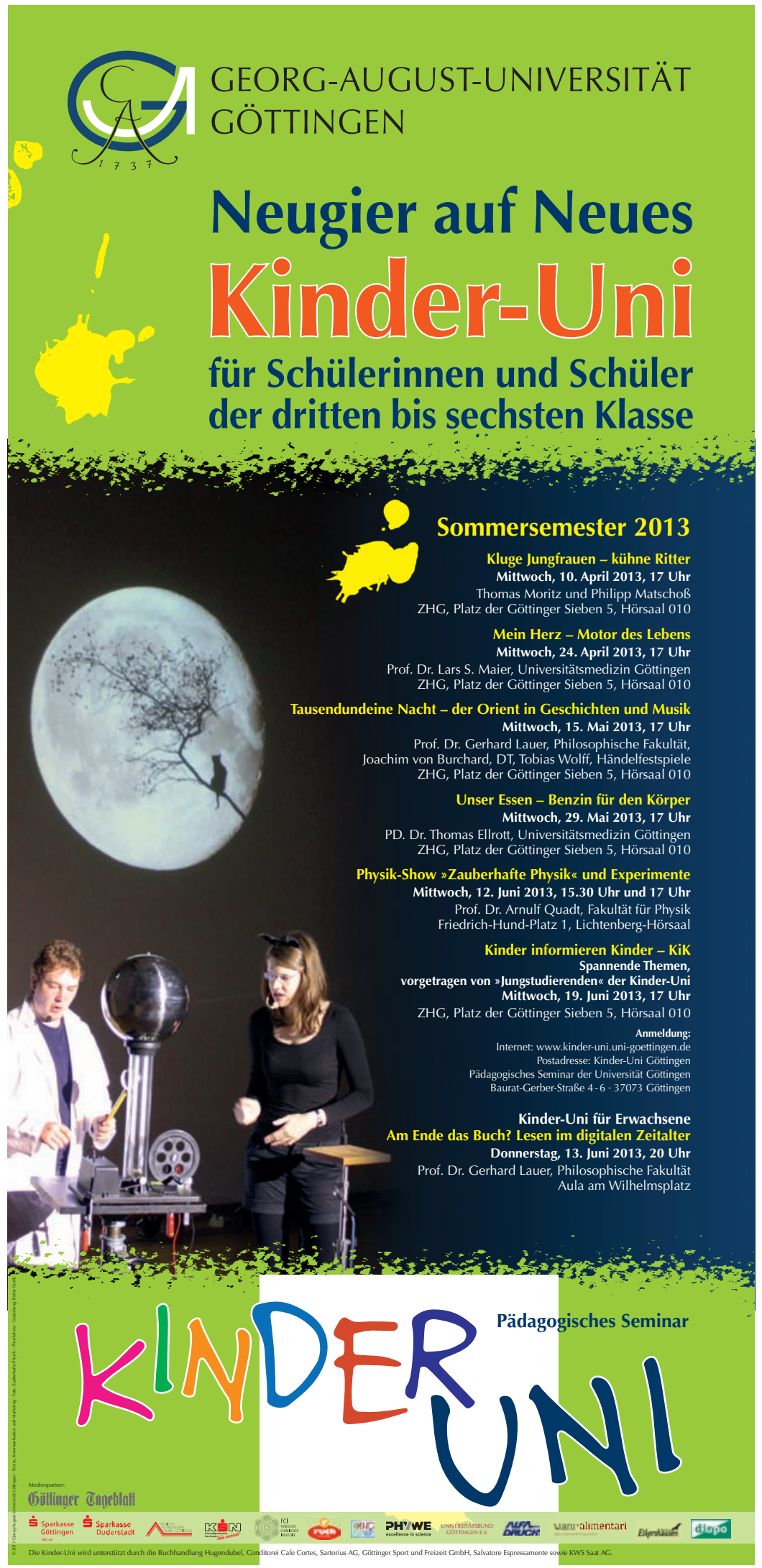




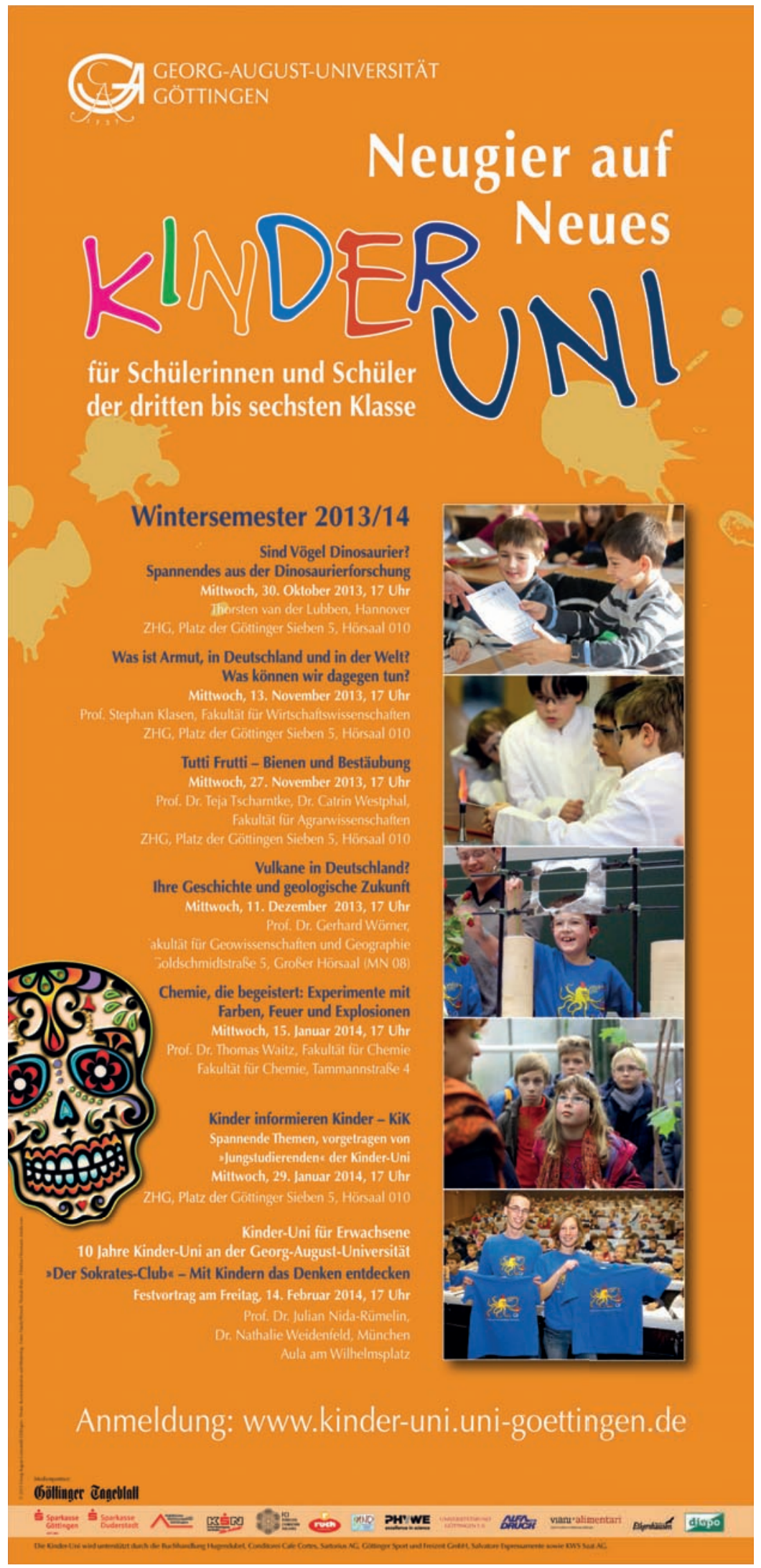




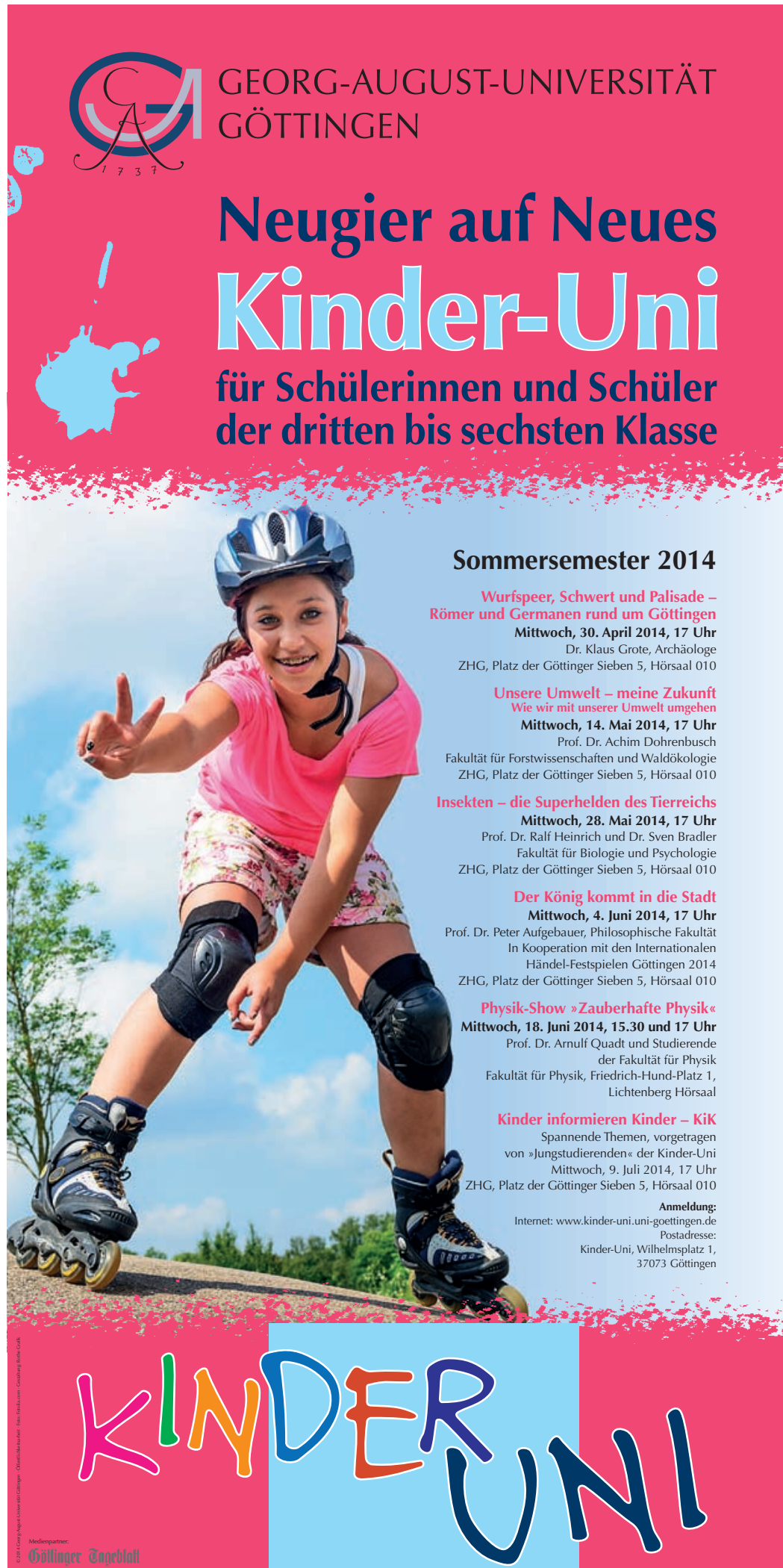

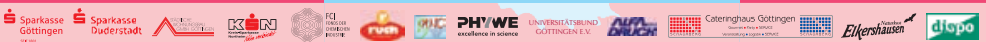



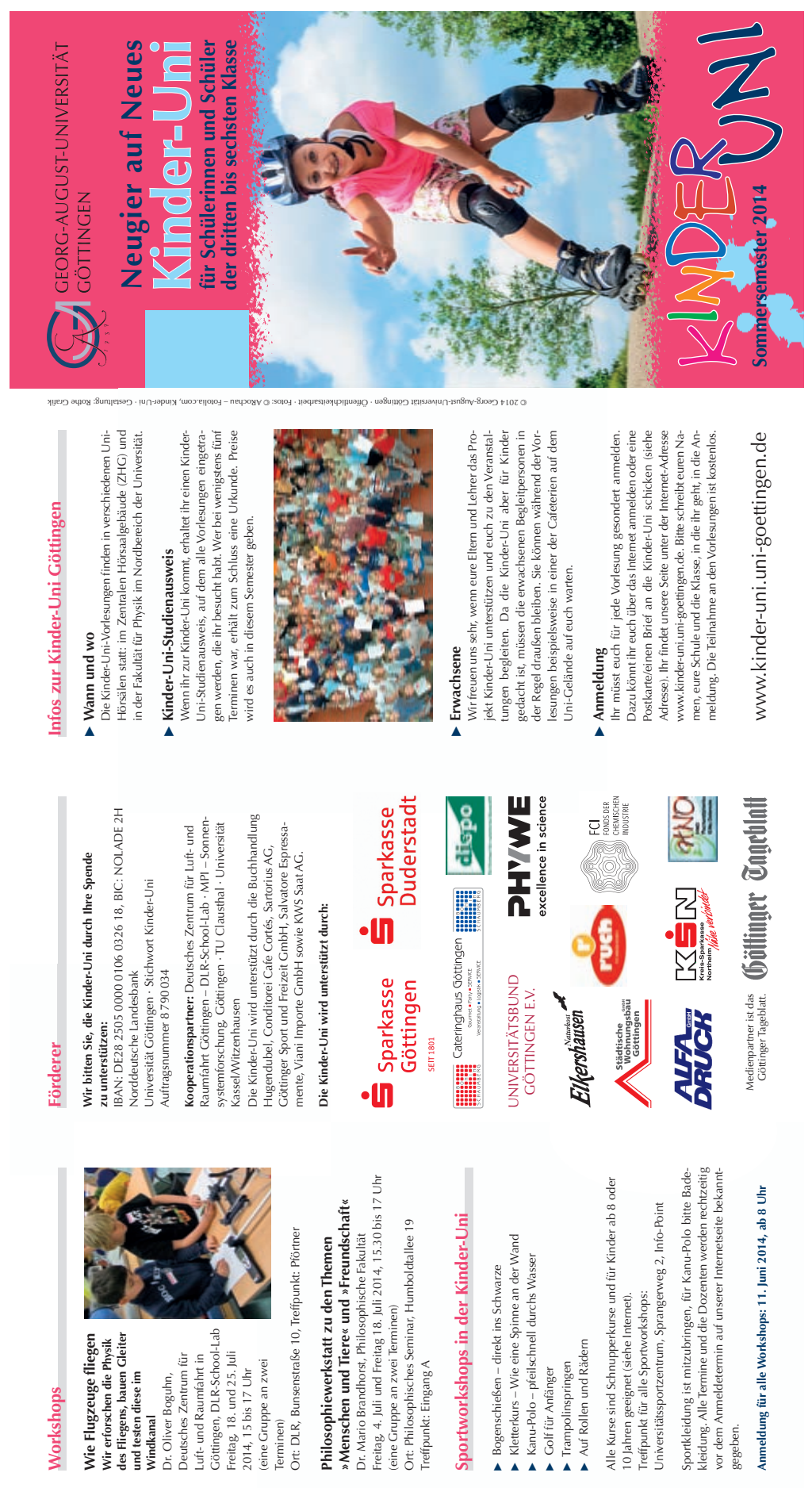

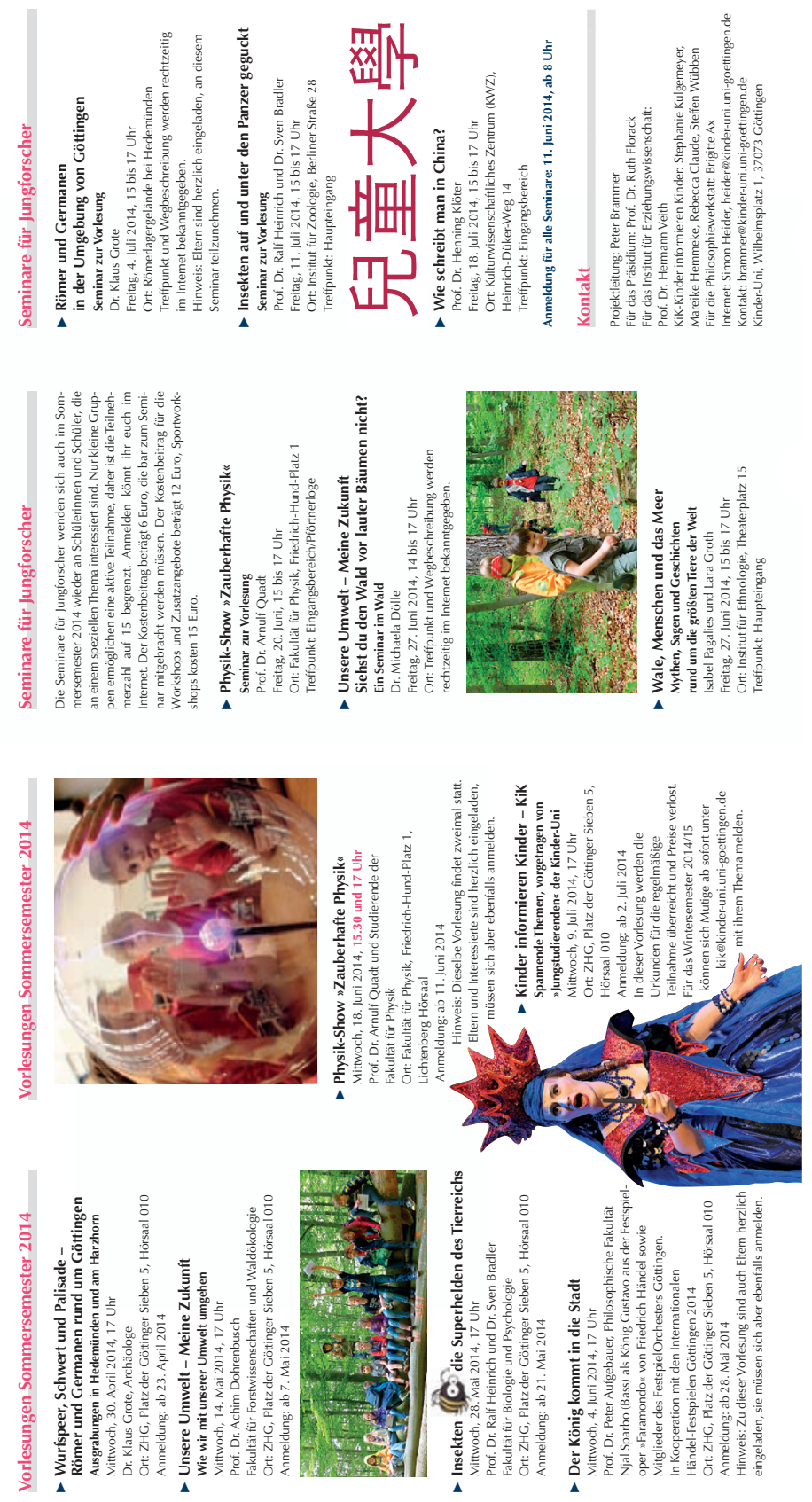
„Sehr geehrter Herr Professor Quadt,

Sehr geehrter Herr Brammer,

mein Sohn Robin hat am 20.06.[2014] an dem Physik-Seminar der Kinder-Uni teilgenommen. Da er gerne experimentiert, dachte ich mir schon, dass ihn das Seminar interessieren würde. Da er ein eher zurückhaltender Mensch ist, saß er mit einem flauen Gefühl im Bauch im Eingangsbereich. Als ich ihn nach zwei Stunden wieder abholte, war er wie ausgewechselt. Stolz, glücklich und mit einem Leuchten in den Augen kam er mir entgegen, als wenn ihn die Physik verzaubert hätte. Begeistert erzählte er mir, was sie alles gemacht haben.

Robin ist jetzt in der 4 . Klasse und die Wahl der weiterführenden Schule steht an. In der Grundschule lassen sich nur wenige Erfahrungen mit den naturwissenschaftlichen Fächern machen und trotzdem sollen die Kinder schon sagen können, in welche Richtung ihre Interessen gehen. Das ist sehr schwierig.

Dank solcher Veranstaltungen wie dem Physik-Vortrag und -Seminar der Kinder-Uni wurde uns bei der Entscheidung sehr geholfen.

Vielen, vielen Dank, dass die Kinder von Ihnen verzaubert wurden.

Zum Schluss sagte Robin dann zu uns: „Ich möchte später auch mal Kindern Experimente erklären."

Da wussten wir, dass Sie wirklich Robin mit Ihrer Arbeit erreicht haben.

Mit freundlichen Grüßen

..."

(Brief einer Mutter als Reaktion auf das Seminar zur Vorlesung "Zauberhafte Physik" am 20.6.2014)
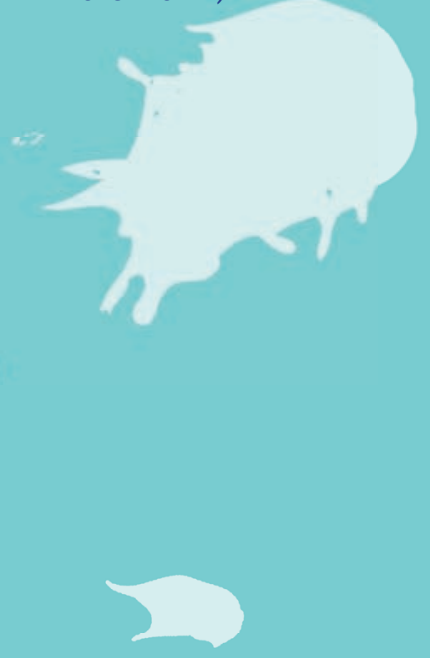

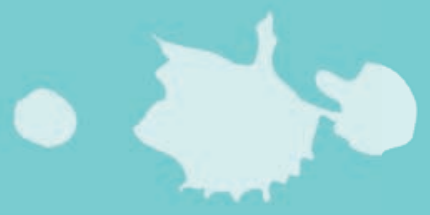

ISBN: $978-3-86395-171-9$

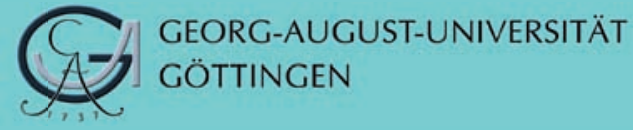

Universitätsverlag Göttingen 